\title{
Establishing credible reaction-kinetics distributions to fit and explain multi-heating rate S2 pyrolysis peaks of kerogens and shales
}

\author{
David A. Wood ${ }^{\circledR} *$ \\ DWA Energy Limited, Lincoln, United Kingdom
}

(Received July 18, 2018; revised August 23, 2018; accepted August 24, 2018; available online September 1, 2018)

\section{Citation:}

Wood, D.A. Establishing credible reaction-kinetics distributions to fit and explain multi-heating rate $\mathrm{S} 2$ pyrolysis peaks of kerogens and shales. Advances in Geo-Energy Research, 2019, 3(1): 1-28, doi: 10.26804/ager.2019.01.01.

Corresponding author:

*E-mail: dw@dwasolutions.com

Keywords:

Kerogen-kinetics distributions pyrolysis S2-peak shape analysis mixing kerogen kinetics

multi-versus single-heating rate kinetics case for varying A pre-exponential factor applying optimizers to derive kinetic distributions

\begin{abstract}
:
Extracting reaction-kinetic distributions, in terms of activation energies $(E)$ and preexponential factors $(A)$, from the S2 peak data generated by pyrolysis tests conducted at three or more distinct heating ramps, is a well-established technique. These reactionkinetics distributions are of paramount importance in establishing the timing and degree of petroleum generation from shales undergoing a range of burial and thermal histories. A commonly adopted approach is to determine and define reaction kinetics using a derivative of the Arrhenius equation configured in terms of a fixed/constant $A$ value. Although the fixed- $A$ approach can obtain good fits to multi-rate pyrolysis data, here it is shown that a formulation of the Arrhenius equation that involves reactions with a range of $E$ and $A$ values provides equally good fits to the multi-rate pyrolysis data. Moreover, the kinetic distributions with variable $E$ - $A$ provide more credible reaction kinetics consistent with those established for a range of kerogen types known for decades.

To establish accurate fits to multi-rate pyrolysis S2 peak data at $1{ }^{\circ} \mathrm{C}$ intervals from 250 to $700{ }^{\circ} \mathrm{C}$ an optimizer is applied to the preferred Arrhenius equation formulation to derive reaction increments and transformation fractions to a range of reaction kinetics $(E-A$ pairs). The methodology applied involves two steps: Step 1 finds the single $E-A$ pair that best matches the S2 peak temperatures (three or more for multi-rate pyrolysis data); step 2 uses the $E$ - $A$ pair from step 1 as its modal focus and fits the full S2 peak shape using a distribution of 11 distinct reaction. This approach can replicate the fixed- $A$ approach but is best applied using reactions with variable $E-A$ values. The results of applying this method to multi-rate pyrolysis data for ten published kerogens and shales show credible kinetic distributions spread along the established $E-A$ trend for kerogen/shales.
\end{abstract}

\section{Introduction}

The temperature and timing of transformation of the kerogen in source rocks (organic-rich sedimentary rocks, predominantly shales) into petroleum depending upon the formation's burial history are key unknowns to be modelled for petroleum exploration purposes (Hood et al., 1975; Tissot and Espitalie, 1975). Thermal maturity indices linked to Arrhenius equation first-order reactions (Arrhenius, 1889) effective across laboratory and geological-time scales, and responsive to different heating rates are essential for such modelling (Lerche et al., 1984; Lewan, 1985; Wood, 1988; Larter, 1989).

The type of kerogen (e.g., types I, II, III, IV), macerals involved and their reaction kinetics vary among organic-rich shales (e.g., Tissot and Welte, 1984; Lewan, 1985, Ungerer and Pellet, 1987). The reaction kinetics of kerogen can vary within individual shales on a local and regional basis (Peters et al., 2015) and many shales contain mixtures of kerogen types complicating their combined reaction kinetics. The level of thermal maturity measured using vitrinite reflectance can be adequately modelled with a limited set of reaction kinetics (Wood, 1988; Larter, 1989; Nielsen and Barth, 1991) that match the thermal maturity level reached by vitrinite. However, thermal transformation of kerogen into petroleum is typically modelled with a distribution of multiple, parallel Arrhenius reaction kinetics (Sweeney and Burnham, 1990; Peters and Cassa, 1994; Pepper and Corvi, 1995; Inan and Schenk, 2001; Dieckmann, 2005; Stainforth, 2009). Such reaction kinetics distributions reflect the heterogeneity of the kerogen(s) present in shales and the multiple reactions required to match kerogen/shale pyrolysis experiments at laboratory conditions, specifically the shapes and temperature ranges of their S2 peaks. It is therefore reasonable to associate petroleum 
generation under geological conditions with multiple kinetic reactions and potentially other processes.

In addition to time and temperature, other factors contribute to the pace of petroleum generation and expulsion (primary migration) from the kerogens within the source rocks. Cracking of bitumen and natural gas liquids (i.e., ethane to butane; $\mathrm{C} 1$ to $\mathrm{C} 4$ alkanes) to smaller hydrocarbon molecules is an ongoing process in maturing shales (Tissot and Welte, 1984). Reactions stimulated by sulfur, water, alumino-silicates, charcoal and potentially other materials present in source rocks have been shown to significantly influence and catalyse petroleum formation (e.g., yields and composition) and accelerate kerogen reaction rates in certain conditions (Larson and Walton, 1940; Espitalie et al., 1980; Lewan, 1985; Huang, 1996; Lewan, 1997; Lewan and Ruble, 2002). The growth of micro-porosity in kerogens as shale formations progressively pass through stages of thermal maturity (Chalmers et al., 2009, 2012; Passey et al., 2010; Clarkson et al., 2013; Wood and Hazra, 2017) is likely to effect the timing, temperature and efficiency of petroleum expulsion from kerogen. Some or all of these processes, together with first-order reaction kinetics, are likely to be reflected in the pyrolysis S2 peak characteristics of specific source rock and kerogen samples.

Modelling kerogen conversion to petroleum, by applying a parallel set of first-order Arrhenius reactions, therefore, provides only an approximation of the full petroleum generation processes that evolve in shales during their thermal maturation. Nevertheless, parallel sets of Arrhenius equation evaluations, exploiting their integrals, can be meaningfully applied to model and fit the shapes of S2 pyrolysis peaks measured for kerogens and shales in the laboratory. It is then straightforward to translate those reaction kinetics distributions to model and predict the most likely timing and degree of petroleum conversion over geological time scales and geothermal gradients.

This study proposes a new methodology for extracting reaction kinetics distributions from multi-heating rate pyrolysis data avoiding the oversimplified assumptions involved in the methods typically applied for that purpose. The implications of this approach are considered at laboratory and geological time scales and burial histories.

\section{Method}

Arrhenius (1889) proposed and justified Eq. (1) to model reaction rates across a significant range of time scales and its usefulness in modelling reaction kinetics is well established (Friedman, 1963; Coats and Redfern, 1964).

$$
k_{A R R}=A e^{-\frac{E}{R T}}
$$

where $k_{A R R}$ is the reaction rate constant. $A$ is the preexponential (frequency) factor. This a constant that can be varied to express reactions over different time scales (e.g., geological in millions of years $\left(\mathrm{my}^{-1} \mathrm{or} / \mathrm{my}\right)$; laboratory in minutes $\left(\mathrm{min}^{-1}\right.$ or $\left./ \mathrm{min}\right)$ or seconds $\left(\mathrm{s}^{-1}\right.$ or $\left./ \mathrm{sec}\right) . e$ is the mathematical exponent. $E$ is the activation energy for the reaction (typically expressed in $\mathrm{kJ} / \mathrm{mol}$; although, U.S. labora- tories use $\mathrm{kcal} / \mathrm{mol}) . R$ is the universal gas constant $(0.008314$ $\mathrm{kJ} / \mathrm{mol} /{ }^{\circ} \mathrm{K}$ ). $T$ is the absolute temperature (in degrees Kelvin, $\left.{ }^{\circ} \mathrm{K}\right)$.

Eq. (1) can be rearranged to express it in a linear form and expressed in terms of E (Eq. (2)):

$$
E=R T \log _{e}(A)-R T \log _{e}(k)
$$

where $\log _{e}$ refers to the natural logarithm (also expressed as $\ln )$.

The relationship of the reaction kinetics of different types of kerogen are meaningfully expressed in relation to Eq. (2) by an $E$ versus $\log _{e}(A)$ or $\ln A$ crossplot. Wood (1988, his Fig. 1 and Table 1) used Eq. (2) to display a broad linear correlation between $E$ and $\ln A$ from data published in the 1970s and 1980s for different types of kerogen and hydrocarbon reactions. Fig. 1, which incorporates more recently published kerogen kinetic data (Peters et al., 2015), confirms the relevance of that $E$ and $\ln A$ trend to kerogen reaction kinetics, as it was originally defined, particularly over the range $E=$ 175 to $E=275 \mathrm{~kJ} / \mathrm{mol}$. That trend identifies that activation energies varying from $E=100 \mathrm{~kJ} / \mathrm{mol}$ to $300 \mathrm{~kJ} / \mathrm{mol}$, covering a wider range of hydrocarbon reactions are characterized by a strong positive correlation between $\mathrm{E}$ and $\ln A$-the so-called compensation effect. Eq. (2) with a temperature value of 659 ${ }^{\circ} \mathrm{K}\left(\sim 386^{\circ} \mathrm{C}\right)$ defines that trend (along which the $E$ - $A$ pairs yield the same reaction rate constant at $659^{\circ} \mathrm{K}$ ).

Ungerer (1990) published a $\operatorname{linear} E-\log A$ relationship (with $A$ expressed in/sec) for reaction kinetics derived from kerogen, shale and coal pyrolysis analysis performed in the 1980s. That trend is also shown in Fig. 1, with $\ln A$ expressed on a/my scale. It is based on Eq. (2) evaluated with a temperature of $450{ }^{\circ} \mathrm{C}$. Across the range $E=175 \mathrm{~kJ} / \mathrm{mol}$ to $E$ $=265 \mathrm{~kJ} / \mathrm{mol}$, where the reaction kinetics of most Type I, Type II and Type III kerogens tend to lie, the $E-A$ trends defined by Wood (1988) and Ungerer (1990) intersect and are in close agreement. This is the $E-A$ range that the analysis presented in this study focuses upon.

Useful conversions and relationships relevant to reaction kinetics:

$\mathrm{kJ} / \mathrm{mol} \sim 4.184 \mathrm{kcal} / \mathrm{mol}$;

$A$ expressed as $/ \mathrm{my}=5.2596 \mathrm{E}+11^{*} A$ expressed as $/ \mathrm{min}$;

$A$ expressed as $/ \mathrm{min}=60 * A$ expressed as $/ \mathrm{sec}$;

1 million years $=60 * 24 * 365.25 * 10^{6}=5.2596 \mathrm{E}+11 \mathrm{~min}$ utes.

The Arrhenius time temperature index $\left(T T I_{A R R}\right)$, as defined by Wood (1988), multiplies the integral of Eq. (1) (shown as Eq. (3)) between specific temperature intervals by the time (expressed on a/my scale) spent in each of a series of specified time intervals. The time intervals are defined so that each experienced a constant heating rate, but that heating rate is crucially able to vary from time interval $n$ to the next time interval $n+1$ to reflect changing geological and heat flow conditions.

$$
T T I_{A R R}\left(t_{n} \text { to } t_{n+1}\right)=\frac{A}{q^{n}} \int_{T_{n}}^{T_{n+1}} e^{-\frac{E}{R T}} d T
$$




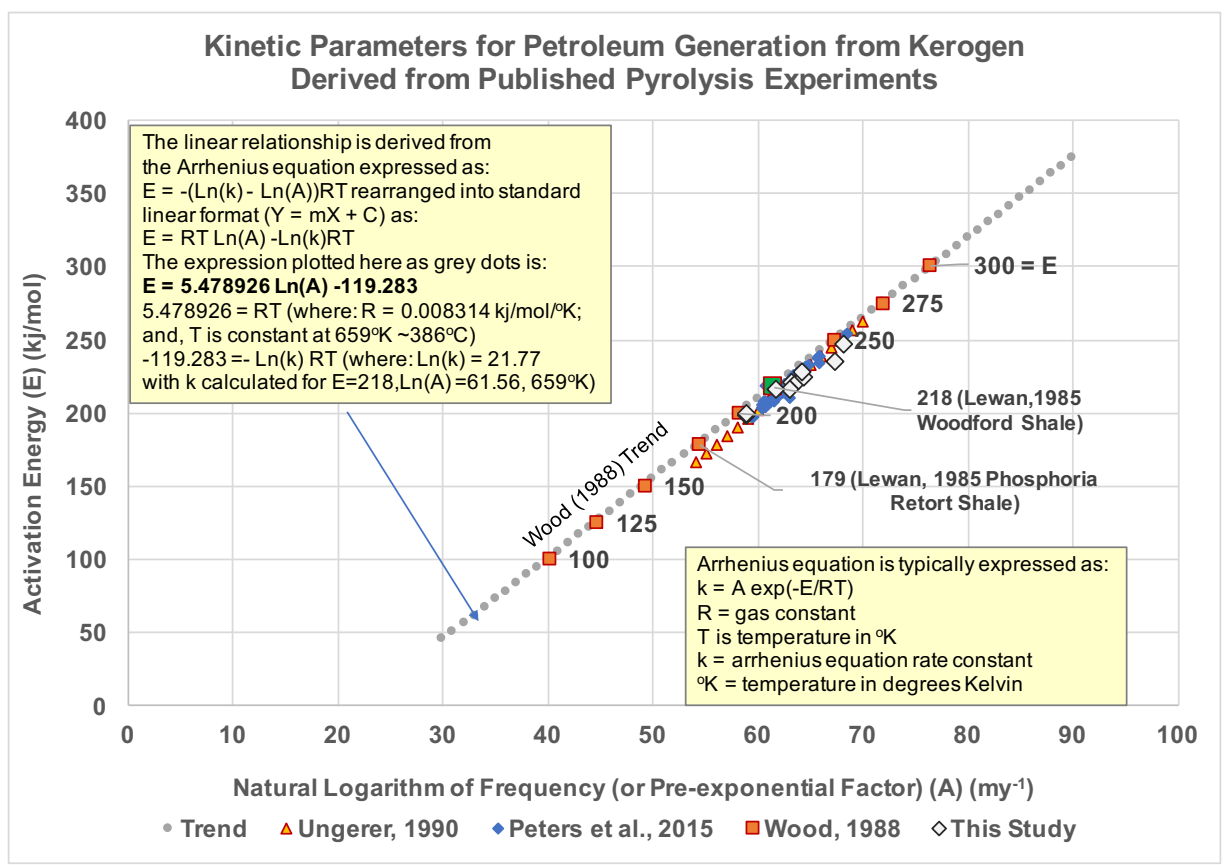

Fig. 1. Arrhenius equation reaction kinetics in terms of activation energies $(E)$ versus the natural logarithms of the pre-exponential (frequency) factors expressed on a/million years scale $(\ln A)$. This study refers to the calculated weighted averages for the ten samples $\mathrm{A}$ to $\mathrm{J}$ described in the text and using the proposed optimization method (Opt 3). The Wood (1988) trend was based on an approximate fit through kerogen and hydrocarbon reaction kinetics published in the 1970s and 1980s. It was drawn to originally focus the $\sum T T I_{A R R}$ thermal maturity modelling method. The Ungerer (1990) $450{ }^{\circ} \mathrm{C}$ trend is based on independent kerogen pyrolysis data performed in the 1980s. Other more-recent pyrolysis data for two well-studied shales (Kimmeridge and Monterey, Peters et al., 2015) are also shown. The $E-A$ values selected $(E=218 \mathrm{~kJ} / \mathrm{mol}$ and $\ln A=61.56 / \mathrm{my})$ by Wood (1988) for the $\sum T T I_{A R R}$ thermal maturity modelling method are situated close to the center of this trend and close to the reported reaction kinetics of vitrinite.

where $q^{n}$ is the heating rate expressed in ${ }^{\circ} \mathrm{C} /$ my determined by the geothermal gradient applied at the basin scale for the time interval $n$. Calculating the temperatures at times $t_{n}$ and $t_{n+1}$ from the burial history enables a unique value of $q^{n}$ to be applied for each time interval modelled at the geological scale.

$\frac{A}{q^{n}}$ represents the time adjustment factor for the index. For the same temperature difference between time point $n$ and $n$ +1 , the value of $q^{n}$ will become smaller as the length of that time interval between $n$ and $n+1$ increases so the value of $\frac{A}{q^{n}}$ increases. Hence, the $T T I_{A R R}$ as defined by Eq. (3) is not a double integral (i.e., an integral of time and an integral of temperature), but a temperature integral with a time adjustment factor applied to each time interval modelled.

The Eq. (3) integral is determined to sufficient accuracy by Eq. (4), which applies the approximate solution of Gorbachev (1975) for each specific temperature $\left(T_{n+1}\right.$ in $\left.{ }^{\circ} \mathrm{K}\right)$ interval experiencing a constant heating rate relative to $T_{n}=0{ }^{\circ} \mathrm{K}$.

$$
\operatorname{TTI}_{A R R}\left(t_{n} \text { to } t_{n+1}\right) \approx \frac{A}{q^{n}} \frac{R T_{n+1}^{2}}{E+2 R T_{n+1}} e^{-\frac{E}{R T_{n+1}}}
$$

The $T T I_{A R R}$ can be meaningfully applied at the geological scale with the capability of modelling the incremental reaction contributions from specific kerogen reaction kinetics (i.e., a single $E-A$ pair) subjected to complex burial histories (Wood, 1988, 2017a). It can also be easily manipulated to provide similar calculations at laboratory scales $(/ \mathrm{min}, / \mathrm{sec})$ relevant to pyrolysis tests.
There are several other effective integral solutions for the Arrhenius equation (Flynn, 1997). Eq. (5) is an example of an alternative expression of the Arrhenius equation to derive the incremental reaction contributions over small temperature intervals across a constant heating-rate ramp applied in recent modelling of pyrolysis S2 peak data at the laboratory scale (e.g., Chen et al., 2017).

$$
\frac{d x}{d T} \approx \frac{A R T^{2}}{q}\left[1-\frac{2 R T}{E}\right] e^{-\frac{E}{R T_{n+1}}}
$$

Most laboratory-based kerogen kinetic and S2-peak pyrolysis studies apply Arrhenius equation derivatives similar to Eq. (5), where it is appropriate to assume a constant heating rate between all temperatures recorded. This laboratory assumption does not, of course, reflect the realities of a multi-dimensional burial history of a shale formation, where geothermal gradients and burial (uplift) rates vary significantly over geological time.

At the geological scale it is a necessity to be able to calculate an Arrhenius equation integral for a series of time intervals experiencing different heating rates. Wood (1988) resolved this by expressing the $T T I_{A R R}$ (reaction increments) for a time interval between any two different temperatures as Eq. (6), and for time intervals with the same temperature (e.g., periods of non-deposition) as Eq. (7).

$$
\begin{aligned}
& \operatorname{TTI}_{A R R}\left(t_{n} \text { to } t_{n+1}\left[T_{n} \neq T_{n+1}\right]\right) \\
& =\frac{A}{q^{n}}\left[\frac{R T_{n+1}^{2}}{E+2 R T_{n+1}} e^{-\frac{E}{R T_{n+1}}}-\frac{R T_{n}^{2}}{E+2 R T_{n}} e^{-\frac{E}{R T_{n}}}\right]
\end{aligned}
$$




$$
T T I_{A R R}\left(t_{n} \text { to } t_{n+1}\left[T_{n}=T_{n+1}\right]\right)=\left(t_{n} \text { to } t_{n+1}\right) A e^{-\frac{E}{R T_{n}}}
$$

To derive the cumulative time-temperature index $\left(T T I_{A R R}\right)$ of a rock formation buried at varying rates over geological time, the values for Eq. (6) and Eq. (7) are summed for all $\mathrm{m}$ time intervals involved in the formations burial history, as formulated by $\mathrm{Eq}$. (8).

$$
\begin{aligned}
\Sigma T T I_{A R R} & =\sum_{n=1}^{n=m} E q . \text { (6) for } T_{n} \neq T_{n+1} \\
& +\sum_{n=1}^{n=m} E q . \text { (7) for } T_{n}=T_{n+1}
\end{aligned}
$$

Eq. (8) is equation 15 of Wood (1988) expressed in an abbreviated form and is correlated with vitrinite reflectance for $E=218 \mathrm{~kJ} / \mathrm{mol}$ and $\ln A=61.56 / \mathrm{my}$ (Wood, 2018a, 2018b).

The Arrhenius equation and the $T T I_{A R R}$ measure can also be manipulated to readily calculate the extent to which a reaction has been completed (i.e., the transformation fraction or factor, $T F$ ) and/or the amount of reactants remaining for a reaction to continue. Eq. (9) determines the quantity of a reactant yet to be transformed $\left(Y_{t}\right)$ by a reaction at time $t$.

$$
Y_{t}=Y_{0} e^{-k t}
$$

where $t$ is time, and $Y_{0}$ is the quantity of a reactant available before the reaction began. $Y_{t}$ is dependent upon the values of the $E-A$ applicable to the specific reaction, and $k$ is the Arrhenius equation constant reaction rate for that specific reaction.

The $k_{t}$ term in Eq. (9) realistically reflects the thermal maturation process. The $\sum T T I_{A R R}$ index (Eq. (8)) essentially does that for the burial history of the kerogen over a geological time scale. The $\sum T T I_{A R R}$ index can, therefore, be substituted for exponent $\left(k_{t}\right)$ in Eq. (9) and, the quantity of reactant, $Y_{t}$, can be normalised to a 1 to 0 scale (Wood, 1988). This simplifies the petroleum conversion reaction calculation to Eq. (10).

$$
X_{t}=e^{-\Sigma T T I_{A R R}}
$$

where $X_{t}$ represents the fraction of that kerogen reaction yet to be converted to petroleum, starting at a value of " 1 " and reaching a value of " 0 " when that kerogen reaction has generated the last of its petroleum. In petroleum exploration and in reaction kinetic studies it is usually more relevant to calculate $1-X_{t}$, the transformation fraction at time $t\left(T F_{t}\right)$ using Eq. (12). The scale for $T F_{t}$ is from " 0 " (that kerogen reaction has not yet generated any petroleum) to "1" (that kerogen reaction has generated the last of its petroleum).

$$
T F_{t}(\text { oil })=1-e^{-\sum T T I_{A R R}}
$$

Eq. (6) and Eq. (11) are easily adapted by expressing $A$ on $\mathrm{a} /$ min scale to model at the laboratory scale $\mathrm{S} 2$ peaks derived from pyrolysis tests at constant heating rates to provide the reaction increments (Eq. (6)) and the transformation fraction (Eq. (11)) at each $1{ }^{\circ} \mathrm{C}$ increment. This study focuses on a model applying Eq. (6) and Eq. (11) to derive meaningful values of $E$ and $A$.

Peak transformation temperature $T$ Peak $_{T F}$ is important at the geological scale for petroleum explorationists, because it identifies when a kerogen reaction is generating petroleum at the highest incremental rate. It is also of high importance in pyrolysis S2 peak characterization and modelling, because it identifies the $\mathrm{S} 2$ peak temperature. TPeak $k_{T F}$ is established at the temperature point $T$ for the conditions (Eq. (12)):

$$
\begin{gathered}
\text { TPeak }_{T F}=T \text { when }(T F)_{T}-(T F)_{T-1}>=0 \\
\text { and }(T F)_{T+1}-(T F) T<0
\end{gathered}
$$

where $T=T$ Peak $_{T F}$ in ${ }^{\circ} \mathrm{C} ; T-1=T$ Peak $_{T F}-1{ }^{\circ} \mathrm{C} ; T+1=$ TPeak $_{T F}+1{ }^{\circ} \mathrm{C}$.

For single kerogens or shales with a dominant kerogen type or a mixture of kerogens with quite similar kinetics the incremental reaction products produced calculated using Eq. (6) over an appropriate temperature ramp and the S2 pyrolysis peaks typically involves a single peak (unimodal) with a relatively symmetrical shape. However, for mixtures of significantly different kerogen types with distinct reaction kinetics the incremental reaction products produced can be bimodal or multimodal leading to various asymmetrical reaction peak shapes. In such circumstances more than one temperature may satisfy the TPeak ${ }_{T F}$ conditions expressed by Eq. (12).

Here, the ability to use Eq. (6) and Eq. (11) to model and accurately fit pyrolysis S2 peak shapes and $T F$ curves, respectively, for kerogens and shales is demonstrated using published multi-heating rate pyrolysis curves for shales from different geographic regions and with distinct kerogen types. The method used to do this involves the following steps:

(1) Digitize the pyrolysis S2 peak curves at each heating rate from their published images deriving between 25 and 50 points of "counts" (reaction products) versus temperature for an S2 peak temperature range lying between $250{ }^{\circ} \mathrm{C}$ and $650{ }^{\circ} \mathrm{C}$;

(2) Interpolate between the digitized data points to provide a data distribution on $\mathrm{a} /{ }^{\circ} \mathrm{C}$ basis;

(3) Normalize the interpolated data to provide an S2 peak where the normalized counts for the $/{ }^{\circ} \mathrm{C}$ temperature range sum to 1 to generate the reaction increment distribution;

(4) Calculate the cumulative normalized counts versus per $/{ }^{\circ} \mathrm{C}$ temperature distribution to generate the $T F$ distribution;

(5) Use Eq. (6) to model and fit the incremental distribution (from step 3) and/or Eq. (11) to model and fit the $T F$ distribution (from step 4) by varying $E$ and/or $A$ values across a series (11 in total) parallel reactions with the aid of an optimizer;

(6) The results presented here apply Excel's Solver (GRG option) as the optimizer in two sequential steps: (a) to match the S2 peak temperatures for three or more distinctive pyrolysis heating rates to derive the $E-A$ pair that best reproduce those peak temperatures; and, (b) use the $E-A$ pair established by step 6(a) as the central point of an $E-A$ distribution (of 11 parallel reactions) that is optimized to reproduce most accurately (minimum 
mismatch as measured by mean squared error) the shape of the full S2 pyrolysis peak;

(7) The objective function of the step 6(b) optimizer is set to minimize the mean squared error (MSE) between modelled and normalized data curves. This can be performed with the normalized counts bell-shaped curve using the reaction-increment distribution from step 3 (with Eq. (6)), or the sigmoidal $T F$ distribution from step (with Eq. (11)), or the combination of the two.

Good matches between model and normalized pyrolysis data are achieved for various kerogen reaction kinetic combinations. The data set that is optimized in step 6(b) involves intervals of $1{ }^{\circ} \mathrm{C}$ for a temperature range extending from $\sim 250$ to $\sim 750{ }^{\circ} \mathrm{C}$ for three $\mathrm{S} 2$ peaks measured at significantly different $\left({ }^{\circ} \mathrm{C} / \mathrm{min}\right)$ heating rates. Hence, about 1,500 individual data points are tested in each iteration by the optimizer as part of the curve-fitting optimization process. The differences between modelled and measured values for each $1{ }^{\circ} \mathrm{C}$ temperature interval contribute to the MSE value for the combination of the eleven $E-A$ pairs tested.

How the $E-A$ pairs of values are calculated using the parallel reactions is critical in establishing meaningful reaction kinetics distributions. In steps 6 and 7 of the proposed methodology each of the eleven parallel first-order reactions is evaluated separately (with different $E$ - $A$ pairs and contribution fractions $f_{i}(0$ to 1$)$ to the mixed kinetics peaks generated from the combination of those individual reactions). For example, the model $T F$ curve for each iteration of the optimizer is generated using Eq. (13).

$$
\begin{aligned}
T F_{t}(\text { mixed kinetics }) & =\sum_{i=1}^{p} f_{i} *\left(1-e^{-\Sigma T T I_{A R R}}\right)_{i} \\
i & =1 \cdots p
\end{aligned}
$$

where $p$ is the number of kinetic components contributing to the shale/kerogen sample with mixed kinetics (i.e., $p=11$ for the optimization methodology applied here); $f_{i}=$ the fraction of each kinetic component contributing to the shale/kerogen sample with mixed kinetics, where: $0 \leq f_{i} \leq 1$, and, $\sum_{i=1}^{n} f_{i}=1$; Each of the $p$ kinetic transformations, $\left(1-e^{-\sum T T I_{A R R}}\right)_{i}$, can be calculated with different $E-A$ pairs, or (not recommended) with a fixed $A$ value.

Most models applied in the past three decades to extract reaction kinetics distributions from multi-heating rate pyrolysis tests use a simpler formulation of the Arrhenius equation derivative to determine the $E$ and $A$ values for a series of multiple parallel reactions, as expressed in Eq. (14) (e.g., Abbassi et al., 2014; Han et al., 2014; Liao et al., 2018).

$$
\frac{d x_{i}}{d t}=-A x_{i} \exp \left(-\frac{E_{i}}{R T}\right), i=1 \cdots p
$$

where $x_{i}$ is the residual potential of petroleum formation associated with reaction $i ; p$ is the total number of parallel reactions considered; $t$ is time; $T$ is temperature; $R$ is molar gas constant; $A$ is a fixed frequency factor; $E_{i}$ is a distinct activation energy for each of the $i$ reactions.
Using Eq. (14) to locate the $A$ value that best fits the multirate pyrolysis peaks and then adjusting the $E$ values to refine the fit to the S2 peak shapes underpins the programmed micropyrolysis process (Burnham et al., 1987; Braun and Burnham, 1990; Braun et al., 1991; Sundararaman et al., 1992) that applies a mathematical routine to optimize the best fit between the calculated and measured curves. The method typically derives S2 pyrolysis peaks using three different heating rates applying specific furnace setups (Schaefer et al., 1990). Schenk and Dieckmann (2004) suggested that to obtain reasonable geological predictions from kerogen reaction kinetics, petroleum transformation factors are best measured using on low heating rates of $0.7^{\circ} \mathrm{C} / \mathrm{min}, 2{ }^{\circ} \mathrm{C} / \mathrm{min}$ and $5{ }^{\circ} \mathrm{C} / \mathrm{min}$. However, Peters (2014) suggested that only temperature ramps of $>30^{\circ} \mathrm{C} / \mathrm{min}$ appear to be too fast to obtain good reaction kinetic fits between modelled and measured curves because of delayed heat transfer between the thermocouple and the sample. Consequently, most multi-heating-rate pyrolysis conducted in recent years uses heating ramps that vary between 1 and $25^{\circ} \mathrm{C} / \mathrm{min}$.

A version of this simplified (discrete) methodology (Miura, 1995; Kinetics 2000 software developed by Lawrence Livermore National Laboratory (LLNL) and Humble Instruments and Services) continues to be widely applied (e.g., Abbassi et al., 2014, 2016; Han et al., 2014; Liao et al., 2018). It makes the dubious assumption that parallel first-order reactions with a single frequency factor and variable activation energies can accurately invert kerogen reaction kinetics from multi-heating rate pyrolysis peaks. The justification for applying a single frequency factor to all reactions in the distribution was valid in the 1980s due to limited computing capacity and the empirical need to reduce the number of unknown parameters involved in the multiple parallel calculations. However, this approach is clearly inconsistent with theoretical considerations associated with kerogen distribution and behavior in shales subjected to both laboratory or geological conditions (Ungerer and Pelet, 1987; Wood, 1988; Ungerer, 1990).

Rather than use the simplified Eq. (14) with its fixed- $A$ assumption and constant heating rate restriction (which works fine in the laboratory, but not for geological burial rates) Eqs. (6), (11) and (13) are used in this study to demonstrate a new method for extracting accurate reaction kinetics distributions from multi-heating rate pyrolysis data applying variables $E-A$ values to individual reactions in the best-fit distribution. This new method is compared with the fixed- $A$ methods and the distinct results obtained by the two methods have significant implications for the reaction kinetic modelling of petroleum generation under geological conditions.

\section{Pyrolysis data modelled}

Published multi-heating-rate pyrolysis S2-peaks for ten samples of pure kerogen (extracted from source rocks) and shales displayed as images of incremental hydrocarbon yields at specific temperatures (within the range 250 to $650{ }^{\circ} \mathrm{C}$ ) used in this study, and labelled A to J, are derived from the following published sources.

A Kerogen from Pingliang Formation (PL-M-O $\mathrm{O}_{2} \mathrm{p}$, marine shale, Middle Ordovician) an outcrop sample from the 
Erdos/Ordos Basin (China). Digitized for heating rates 5 $\mathrm{deg} / \mathrm{min} ; 15 \mathrm{deg} / \mathrm{min}$ and $25 \mathrm{deg} / \mathrm{min}$ (Liao et al., 2018).

B Kerogen from Yangchang Formation (YC-L, $\mathrm{T}_{3} \mathrm{y}$, lacustrine shale, Upper Triassic) from borehole Zheng-8 in the Erdos/Ordos Basin (China). Digitized for heating rates 5 $\mathrm{deg} / \mathrm{min} ; 15 \mathrm{deg} / \mathrm{min}$ and $25 \mathrm{deg} / \mathrm{min}$ (Liao et al., 2018).

C Kerogen from AP22 Green River Formation (Anvil Points Mine, Colorado) (Eocene). Digitized for heating rates 1 $\mathrm{deg} / \mathrm{min} ; 7 \mathrm{deg} / \mathrm{min}$ and $50 \mathrm{deg} / \mathrm{min}$ (Reynolds and Burnham, 1995).

D Kerogen from the Kimmeridge Clay (Draupne Formation, Late Jurassic) Northern North Sea (Norway) core sample. Digitized for heating rates $1 \mathrm{deg} / \mathrm{min} ; 7 \mathrm{deg} / \mathrm{min}$ and 50 deg/min (Reynolds and Burnham, 1995).

E Kerogen from the Phosphoria Shale (Early Permian) from the Retort Mountain Quarry in Beaverhead, Montana (USA). Digitized for heating rates $1 \mathrm{deg} / \mathrm{min} ; 7 \mathrm{deg} / \mathrm{min}$ and $50 \mathrm{deg} / \mathrm{min}$ (Reynolds and Burnham, 1995).

F South Elwood-composite Monterey Formation (Miocene) shale sample (13.58 wt\% S) from cores drilled in the South Elwood Field well, Santa Barbara-Ventura Basin, California (USA). Digitized for heating rates $1 \mathrm{deg} / \mathrm{min} ; 7 \mathrm{deg} / \mathrm{min}$ and $50 \mathrm{deg} / \mathrm{min}$ (Reynolds et al., 1995).

G Naples Beach Monterey Formation (Miocene) outcrop sample Santa Barbara County, from 921.5 feet above the base of the Monterey (8.88 wt\% S) formation. Digitized for heating rates $1 \mathrm{deg} / \mathrm{min} ; 7 \mathrm{deg} / \mathrm{min}$ and $50 \mathrm{deg} / \mathrm{min}$ (Reynolds et al., 1995).

H Onshore Los Angeles Basin Modelo Shale outcrop sample (Nodular Shale, Middle Miocene) Bel Air, California (USA); a bituminous-phosphatic high-S (6.16 wt\% S) formation. Digitized for heating rates $1 \mathrm{deg} / \mathrm{min} ; 7 \mathrm{deg} / \mathrm{min}$ and $50 \mathrm{deg} / \mathrm{min}$ (Reynolds et al., 1995).

I Montney Shale (Triassic) sample 172208 (immature, $\mathrm{R}_{\mathrm{o}}=$ $0.59 \mathrm{wt} \%$ ) Western Canada Sedimentary Basin (Alberta, Canada). Digitized for heating rates $5 \mathrm{deg} / \mathrm{min} ; 15 \mathrm{deg} / \mathrm{min}$ and $25 \mathrm{deg} / \mathrm{min}$ (Romero-Sarmiento et al., 2016).

J Doig Shale (Triassic) sample 173,182 (early mature, $\mathrm{R}_{\mathrm{o}}=$ $0.71 \mathrm{wt} \%$ ) Western Canada Sedimentary Basin (Alberta, Canada). Digitized for heating rates $5 \mathrm{deg} / \mathrm{min} ; 15 \mathrm{deg} / \mathrm{min}$ and $25 \mathrm{deg} / \mathrm{min}$ (Romero-Sarmiento et al., 2016).

The per degree $\mathrm{C}$ normalized incremental yield and cumulative transformation curves for each of these samples, at the three different pyrolysis heating ramps used for analysis, are listed in the supplementary file (see Appendix).

Another potential data source that was evaluated was the Upper Cretaceous lacustrine shale samples from the Songliao Basin (China), published by Wang et al. (2011) at five different heating rates varying from 10 to $50{ }^{\circ} \mathrm{C} / \mathrm{min}$. However, these pyrolysis results are published as very small images and as transformation ratios rather than incremental hydrocarbon yield S2 peaks. Once digitized these curves could not be used to identify the S2-peak temperatures with confidence, so were not used for this study. This suggests that in order to use digitized transformation curves for the method proposed here, the source images need to be published at a reasonably detailed scale.

\section{Results}

\subsection{Alternative approaches to mixing reaction kinet- ics to define kerogen kinetic distributions}

It is the mixing of individual reaction kinetics that is typically applied to match and fit pyrolysis S2-peak shapes. This combination of reactions reflects the fact that most shales and coals do not consist $100 \%$ of a single kerogen maceral, but rather their kerogen is made up of a mixture of different macerals with distinct reaction kinetics (i.e., $E-A$ values). Indeed, even in source rocks with a single kerogen type there are likely to be multiple reactions involved associated with the dissociation of various chemical bonds (e.g., C-C, C=C, C-H, $\mathrm{C}-\mathrm{S}$, etc.) associated with the various hydrocarbon molecules constituting that kerogen. Nevertheless, with a single kerogen component the set of reactions involved is likely to be simpler than for source rocks containing multiple kerogen types. There are several ways in which reactions kinetics can be combined in an optimum way to match S2 peak shapes. Here, three distinct peak-matching-optimization approaches are considered, compared and contrasted:

Opt 1-mix reactions along the $E-A$ kerogen trend defined in Fig. 1.

Opt 2-mix reactions of a constant $A$ value that match the $\mathrm{S} 2$ peaks of multi-rate pyrograms (produced by three distinct heat ramps). This is the approach that has been widely adopted since the 1990s in determining kerogen kinetic distributions.

Opt 3-mix reactions with variable $E$ - $A$ values centered on an $E$ - $A$ value that matches the S2-peak temperatures of multirate pyrograms produced by three distinct heat ramps (Steps $6 \mathrm{a}$ and $6 \mathrm{~b}$ of the preferred new methodology described here).

In attempting to match $\mathrm{S} 2$-peak shapes exactly with mixtures of reactions associated with distinct $E$ - $A$ kinetics, all three of these methods assume that the S2-peaks are made up only of the products and processes associated with first-order reactions. While this assumption is reasonable for thermally immature shales, it is less likely to be realistic for more thermally mature shales because second order reactions associated with the breakdown and release of bitumens, gases and other reaction products are likely also to be involved. Here, we focus upon thermally immature/early mature samples to avoid the complications of S2-peak matching of thermally mature shales, which are to be addressed as part of a future study.

A comparison of the reaction peak shapes for distinct kerogen kinetics using Opt 1 and Opt 2 for four different laboratory-scale heating ramps $\left(1{ }^{\circ} \mathrm{C} / \mathrm{min} ; 5{ }^{\circ} \mathrm{C} / \mathrm{min}\right.$; $15{ }^{\circ} \mathrm{C} / \mathrm{min}$; and, $25^{\circ} \mathrm{C} / \mathrm{min}$ ) highlights some of the peak characteristics and their relative temperature ranges.

Fig. 2 identifies three distinct reactions taken from the $E-A$ trend defined in Fig. 1. The two extremes lie beyond the range of typical kerogens, which mostly lie in a kinetic range that straddles the $E 150$ to- $E 300$ reaction rates close to the established $E-A$ trend. However, it is useful to consider the mixing implications of the peak relationships across this extreme range of possible reactions. Fig. 3 illustrates the peak characteristics (incremental curves on the left; transformation factors- $T F 0$ to 1 -on the right) for these three, reaction kinetics 


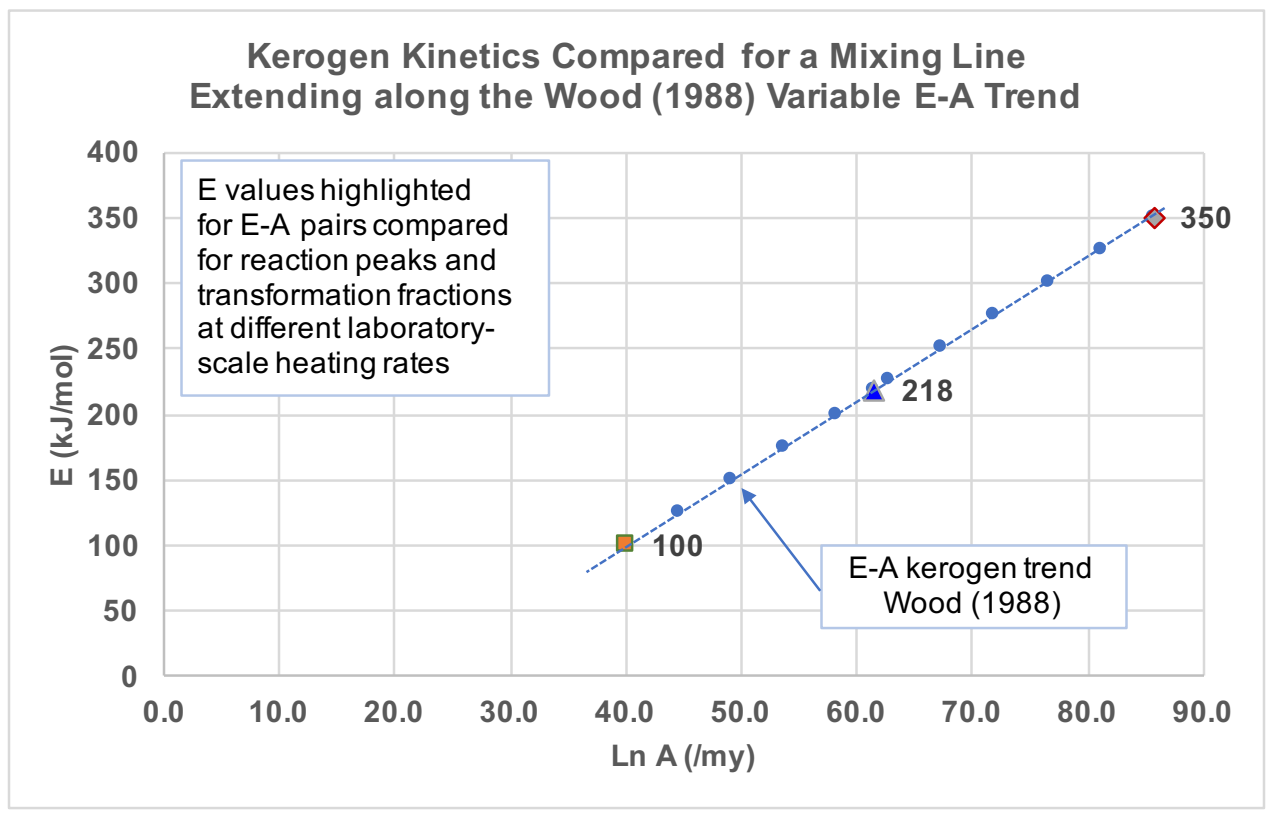

Fig. 2. Optimization method (Opt 1) S2 peak shape is adjusted by combining two or more reaction kinetics along the establish kerogen kinetic $E$ - $A$ trend. Three reaction kinetics are selected to illustrate the reaction peak characteristics (shape and temperature range), and to demonstrate that both activation energy $(E)$ and pre-exponential factor $(A)$ are important in determining these characteristics. These are: $E=100 ; \ln A=40.02 / \mathrm{my}$ or $13.03 / \mathrm{min} ; E=218 ; \ln A=$ $61.56 / \mathrm{my}$ or $34.57 / \mathrm{min}$; and, $E=350$; $\ln A=85.65 / \mathrm{my}$ or $58.66 / \mathrm{min}$.

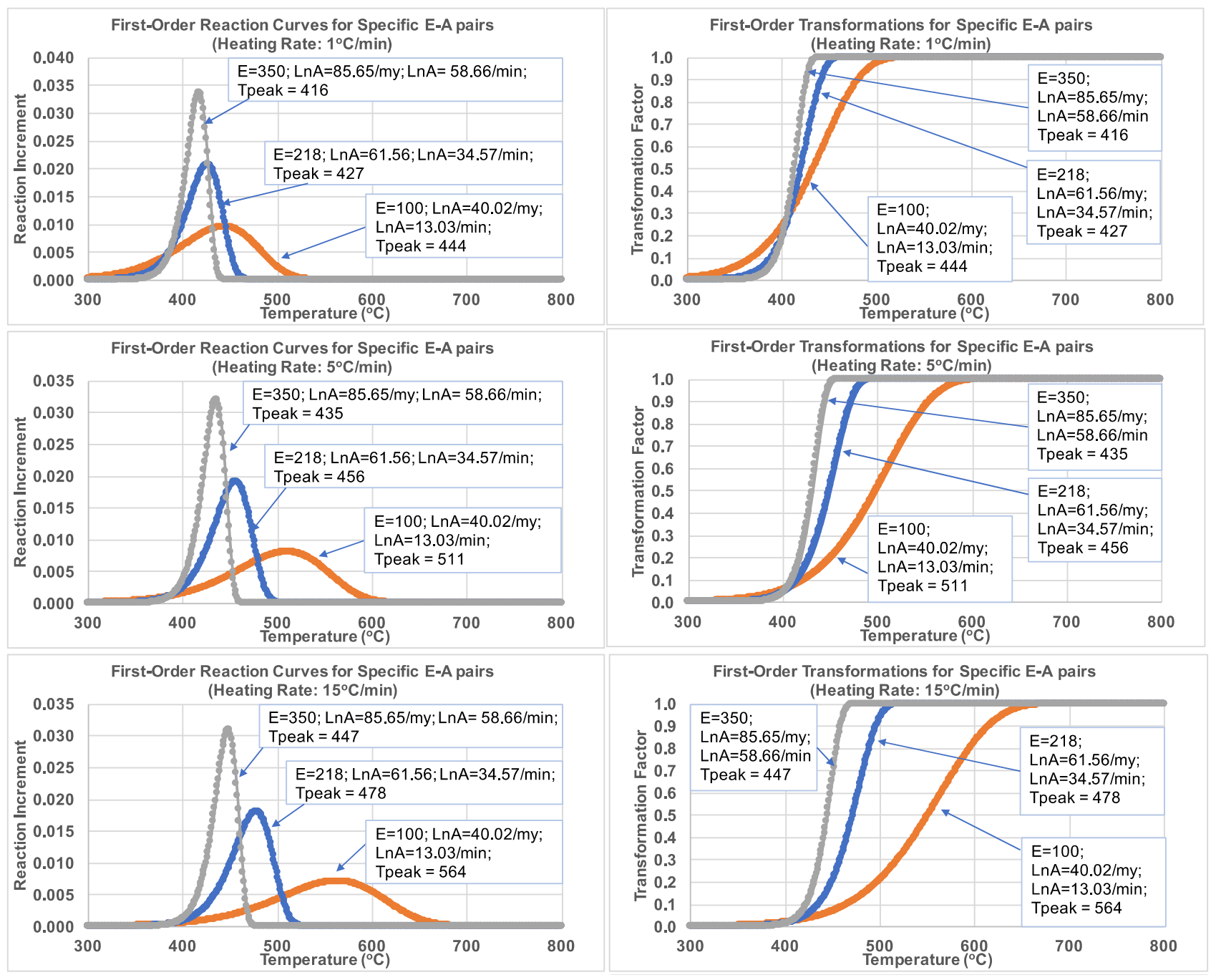




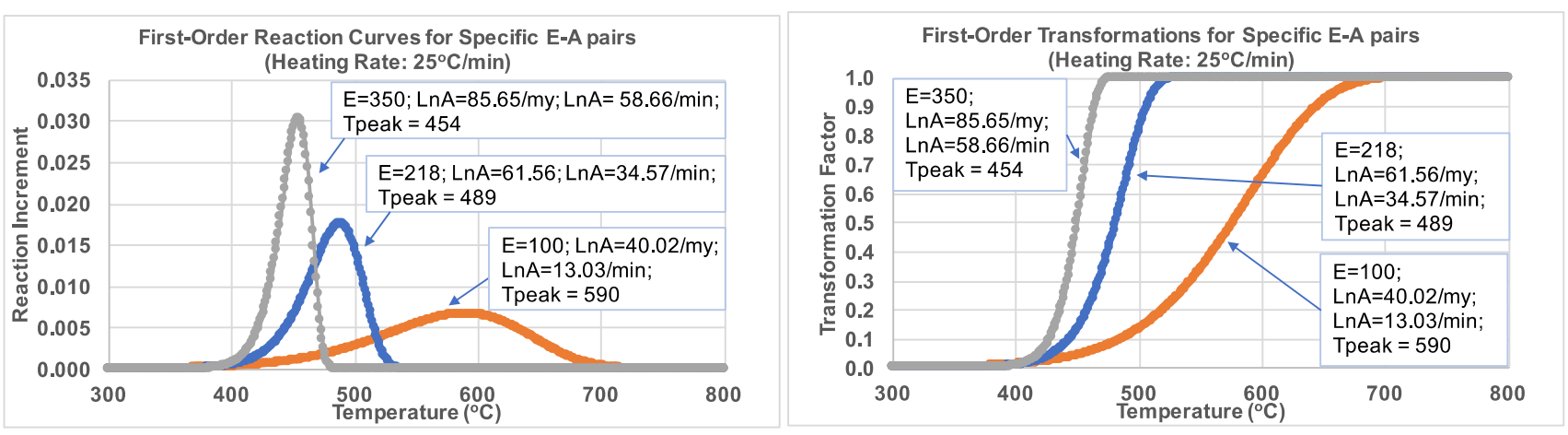

Fig. 3. Reaction increments (left) and transformation factors (right) for three distinct reaction kinetics identified in Fig. 2 ( $E=100$; 1 $A=40.02 / \mathrm{my}$ or $13.03 / \mathrm{min} ; E=218 ; \ln A=61.56 / \mathrm{my}$ or $34.57 / \mathrm{min}$; and, $E=350 ; \ln A=85.65 / \mathrm{my}$ or $58.66 / \mathrm{min}$ ) at four distinct pyrolysis-scale heating ramps. The peak temperature for reaction $E=350 ; \ln A=85.65 / \mathrm{my}$ is lower than the peak temperature for reaction $E=100 ; \ln A=40.02 / \mathrm{my}$ because of its much higher $A$ value (see Eq. (6)).

and the four different laboratory scale (i.e., pyrolysis) heating rates. What stands out in Fig. 3 are the relative positions of the three reaction peaks/curves at the different heating rates. Both activation energy $(E)$ and pre-exponential factor $(A)$ play a role in determining the characteristics of those peaks as demonstrated by Eq. (6).

At the lowest heating rate $\left(1{ }^{\circ} \mathrm{C} / \mathrm{min}\right)$ the three reaction curves overlap significantly with the $E 350-\ln A 86 /$ my reaction showing the lowest peak reaction temperature $E 100-\ln A 40 /$ my reaction showing the highest peak reaction temperature. As the heating rate increases the $E 100-\ln A 40 /$ my reaction progressively moves to the right and, at the two higher heating rates $\left(15{ }^{\circ} \mathrm{C} / \mathrm{min}\right.$; and, $\left.25^{\circ} \mathrm{C} / \mathrm{min}\right)$, occurs at significantly higher temperatures than the other two reactions. Reaction E350-ln A86/my displays the narrowest reaction peak (Fig. 3, left) and steepest $T F$ curve (Fig. 3, right) with a reaction peak that moves gradually to higher temperatures (from 416 to $454{ }^{\circ} \mathrm{C}$ ) as the heating rate increases. Reaction E218$\ln A 62 /$ my displays a somewhat broader peak than reaction $E 350-\ln A 86 /$ my with a reaction peak that moves to gradually to higher temperatures (from 427 to $489{ }^{\circ} \mathrm{C}$ ) as heating rate increases. Reaction $E 100-\ln A 40 /$ my shows the most significant variation of the reactions considered at different heating rates. It displays the broadest peak, which becomes broader as heating rate increases, and, in contrast to the other two reactions, its reaction peak moves to significantly higher temperatures (from 444 to $590{ }^{\circ} \mathrm{C}$ ) as heating rate increases.

The net effect of mixing these three reactions in equal proportions is that the peak of the mixed reactions would progressively move to a higher temperature as heating rate increases. These relationships suggest that the increase in the mixed peak reaction temperature as heating rate increases is most significantly influenced by reactions with lower $E$ $A$ values. they also suggest that the right flanks of mixedreaction curves are influenced more by the lower $E$ - $A$ reactions involved, whereas the left flanks of mixed-reaction curves are influenced more by the higher $E-A$ reactions involved. Fig. 3 highlights that mixing reactions with different $E-A$ kinetics can lead to quite complex outcomes at different heating rates depending upon the specific $E-A$ values involved.
Fig. 4 identifies three distinct reactions taken with identical $A$ values distributed along a vertical line that intersects the $E$ $A$ trend defined in Fig. 1 at $E=218 \mathrm{~kJ} / \mathrm{mol}$ (i.e., the reaction rate calibrated with vitrinite reflectance (Wood, 2017)). Mixing reactions along a fixed- $A$ trend is the approach used by many in defining reaction kinetic distributions. The two ends of the fixed- $A$ trend are $E=200 \mathrm{~kJ} / \mathrm{mol}$ and $E=245 \mathrm{~kJ} / \mathrm{mol}$. The narrow range of $E$ values along the fixed- $A$ trend compared to the variable $E-A$ trend approximating kerogen/hydrocarbon reactions highlights the sensitivity of varying $E$ at a specific $A$ value, compared to the compensation effect of increasing or decreasing $E$ and $A$ in conjunction with each other.

Fig. 5 illustrates the peak characteristics (incremental curves on the left; transformation factors- $T F 0$ to 1-on the right) for these three, reaction kinetics and the four different laboratory scale (i.e., pyrolysis) heating rates. What stands out in Fig. 5 is the similarity in the incremental peak shapes and widths and gradients of the $T F$ curves of the three reactions across all four heating rates considered. There is only a very slight overlap between the curves of the three reactions. The incremental peaks do increase slightly in width from the $E 200-\ln A 62 /$ my reaction to the $E 245-\ln A 62 /$ my reaction. Significantly, the peak temperatures are spread over a wide range (370 to $511{ }^{\circ} \mathrm{C}$ for the $1{ }^{\circ} \mathrm{C} / \mathrm{min}$ heating rate; 427 to $580{ }^{\circ} \mathrm{C}$ for the $25{ }^{\circ} \mathrm{C} / \mathrm{min}$ heating rate). These characteristics are quite distinct from the variations shown in Fig. 3.

The net effect of mixing the three reactions in equal proportions is that the peak of the mixed reactions would progressively move to a higher temperature as heating rate increases, but in a more regular manner than for mixing reactions with different $E$ and $A$ values. These relationships suggest that all $E$ values have similar relative impacts on the peak shape if present in similar fractions. It is also apparent that in fixed- $A$ reaction mixing the right flanks of mixedreaction curves are primarily influenced by the higher- $E$ reactions involved, whereas the left flanks of mixed-reaction curves are primarily influenced by the lower- $E$ reactions involved. In terms of $E$ values this is the opposite to their influence in Fig. 3. the consequence of these characteristics is that it is generally easier to fit reaction curve shapes by mixing 


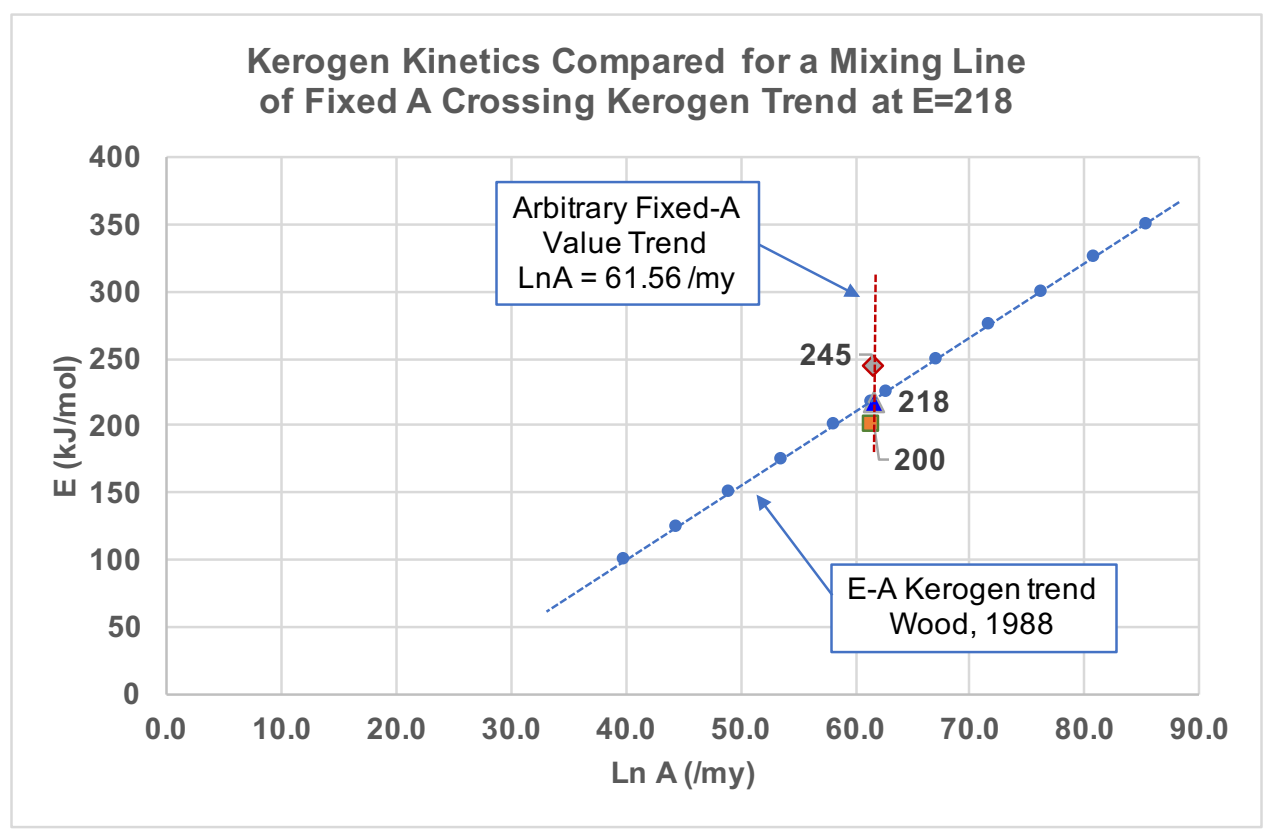

Fig. 4. Optimization method (Opt 2) S2 peak shape is adjusted by combining two or more reaction kinetics along the establish kerogen kinetic $E$ - $A$ trend. Three reaction kinetics are selected to illustrate the reaction peak characteristics (shape and temperature range). These are: $E=100 ; \ln A=40.02 / \mathrm{my}$ or $13.03 / \mathrm{min} ; E=218 ; \ln A=61.56 / \mathrm{my}$ or $34.57 / \mathrm{min}$; and, $E=350 ; \ln A=85.65 / \mathrm{my}$ or $58.66 / \mathrm{min}$.
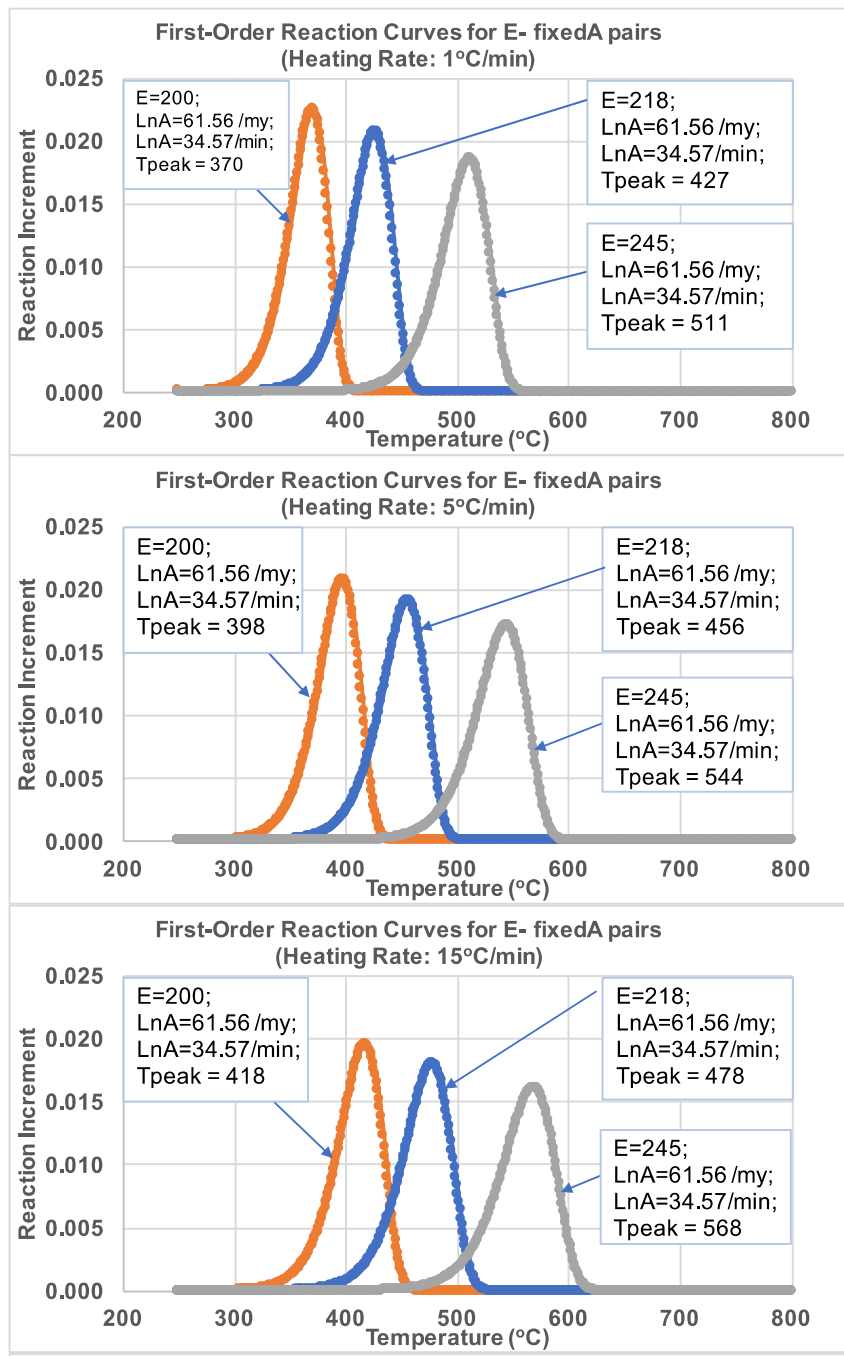
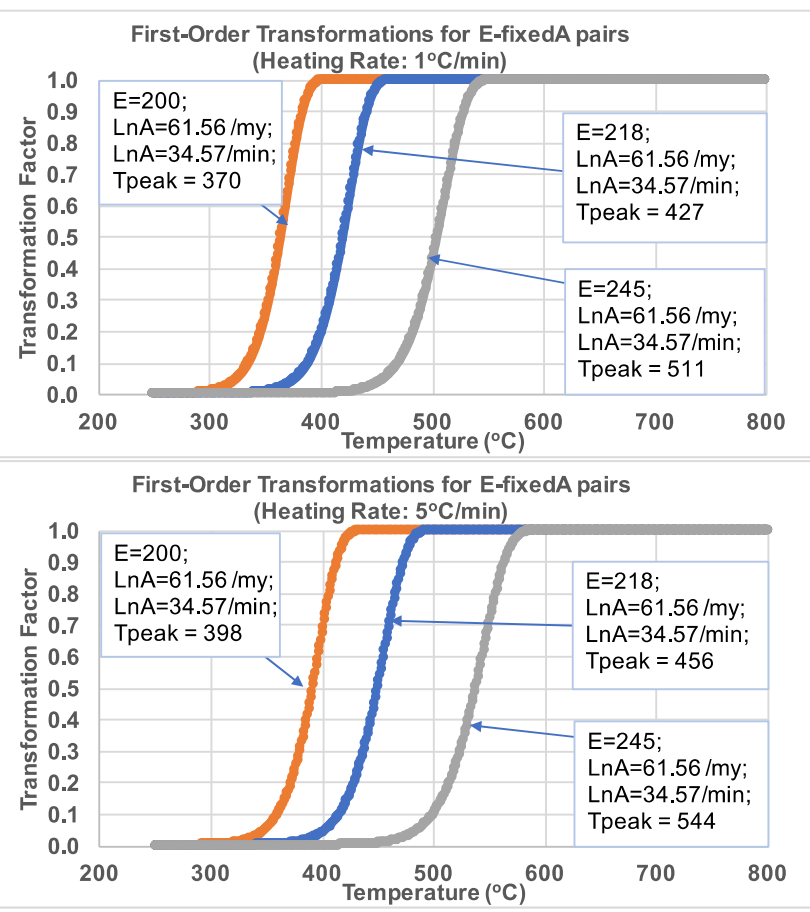

First-Order Transformations for E-fixedA pairs

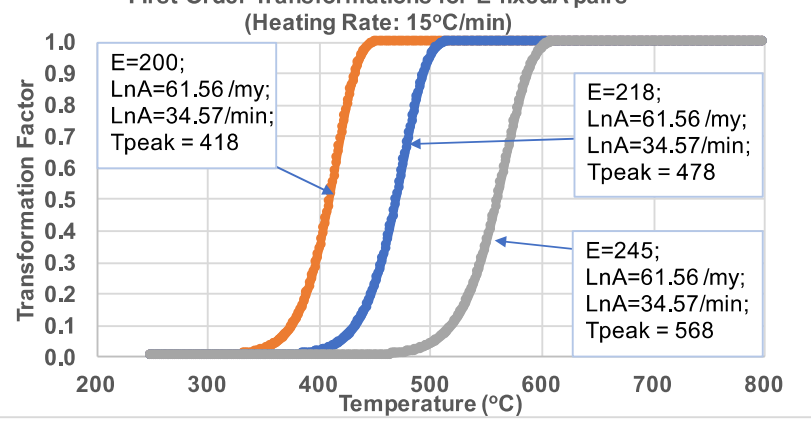



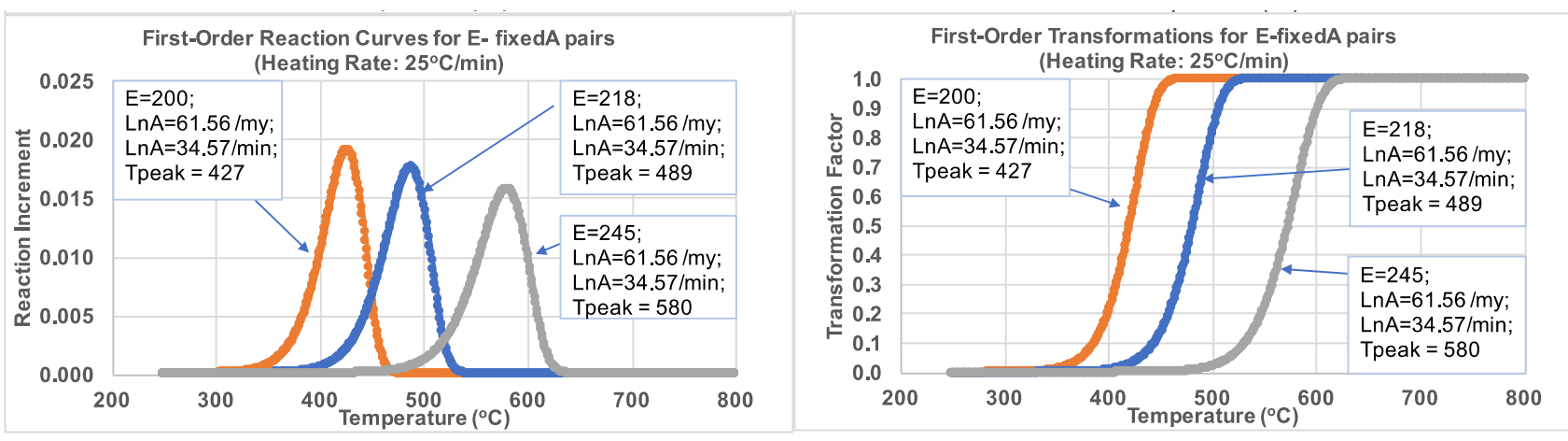

Fig. 5. Reaction increments (left) and transformation factors (right) for three distinct reaction kinetics along a constant $A$ trend identified in Fig. 4. These are: $E=200,218$ and 245 all with constant $A$ values: $\ln A=61.56 / \mathrm{my}$ (geological scale) or $34.57 / \mathrm{min}$ (laboratory/pyrolysis scale used for the four distinct $/ \mathrm{min}$ heating ramps modelled). Note that at a constant $A$ value it is the reactions with the lower $E$ values that have lower peak temperatures.

reactions in varying proportions along a single- $A$ trend, rather than applying variable $E-A$ kinetics. Just because it is easier to achieve peak fits using constant $A$ values does not though make it more appropriate to do so.

\subsection{The relationship between peak petroleum trans- formation temperatures and reaction kinetics}

To establish meaningful reaction kinetics in terms of a distribution of $E-A$ values from pyrolysis tests it is necessary to match the measured S2-peak data with modelled curves generated using theoretical reaction algorithms (e.g., Eqs. (6), (11) and (13)) evaluated at laboratory scale heating rates (i.e., /min scales). On the other hand, in order to apply the derived kinetics to evaluate petroleum generation in terms of kerogen transformation fractions into petroleum, it is necessary to apply the derived kinetics at geological-scale heating rates (i.e., /my scales). Evaluating pyrolysis data at multiple heating rates is essential to narrow down the possible $E-A$ ranges of the reactions that potentially match the S2 peaks. A first step in achieving appropriate kinetic matches to pyrolysis $\mathrm{S} 2$ peaks is to establish the $E-A$ values that best match the range of S2 peak temperatures across a range of at least three heating ramps. Tables 1 and 2 list the reaction peak temperatures, at laboratory and geological scales respectively, of single first-order reactions calculated using Eq. (6) and Eq. (12) for a range of $E-A$ values distributed along the established kerogen/hydrocarbon reaction trend (Fig. 1) at 5 $\mathrm{kJ} / \mathrm{mol}$ intervals.

Table 1 is a useful guide with which to access pyrolysis S2 peak temperatures across a range of heating rates. On the other hand, Table 2 complements Table 1 by expressing the reaction kinetics in terms of peak petroleum transformation temperatures. Switching between laboratory scale (/min) and geological scale (/my) $A$ values is essential for petroleum exploration and understanding the generation potential of specific shales over a range of sub-surface temperatures and thermal evolutions.

For generic thermal maturity modelling the reaction temperatures of the single reaction $E=218 \mathrm{~kJ} / \mathrm{mol} \ln A 61.56 / \mathrm{my}$ are calibrated in detail to the wide range of vitrinite reflectance
$\left(\mathrm{R}_{\mathrm{o}}\right)$ percentages to provide indicative measures of thermal maturity for a wide range of burial and thermal histories using Eq. (8) (Wood, 2018a, 2018b). Of course, it is possible to use other $E$ and $A$ values for that purpose (or indeed distributions of $E-A$ values) to establish alternative correlations between reaction kinetics and $\mathrm{R}_{\mathrm{o}} \%$. However, if the kerogen present in a specific shale has significantly different reaction kinetics to the reaction kinetics (whatever ones are used) for the vitrinite reflectance scale, they will not reflect when peak petroleum generation occurs in that specific shale. For example, at a $5{ }^{\circ} \mathrm{C} / \mathrm{my}$ heating rate, from Table 2 , for kerogen reaction kinetics $E=175 \ln A=53.7 / \mathrm{my}$, the peak petroleum transformation temperature is $117{ }^{\circ} \mathrm{C}$. On the other hand, for kerogen reaction kinetics $E=275 \ln A=72.0 / \mathrm{my}$, the peak petroleum transformation temperature at that heating rate is $185^{\circ} \mathrm{C}$. Both of these peak transformation temperatures differ significantly from the peak petroleum transformation temperature for kerogen reaction kinetics $E=218 \ln A=61.6 / \mathrm{my}$, close to vitrinite, of $152{ }^{\circ} \mathrm{C}$. This range of peak transformation temperatures emphasizes the importance of establishing and applying appropriate reaction kinetics to specific shales.

\subsection{Matching measured pyrolysis S2 peak tempera- tures for actual shales/kerogens with reaction kinetic E-A distributions}

With the context set in terms of the characteristics of reaction kinetic incremental contribution peaks and transformation fraction curves (Figs. 2 to 5), and the range of peak transformation temperatures for kerogen/hydrocarbon-type reactions, the reaction kinetics of the ten samples (A to J) with published multiple heating rate pyrolysis curves are now considered. The first step in achieving this is to match, with the aid of an optimizer, the measured S2 peak temperatures, for three or more distinct pyrolysis heating rates, to the $E-A$ pair that that best fits those temperatures (i.e., step 6(a) in the methodology described). Table 3 lists the results for the best matches to S2 peak temperatures achieved by the optimizer. Table 3 and Fig. 6 compare the reaction kinetics identified (modelled) by the optimizer with those published for each sample evaluated. The agreement between the modelled/optimized values and 
Table 1. Peak reaction temperatures at a laboratory scale for reaction kinetics spread along the $E-A$ trend highlighted in Fig. 1 and calculated with Eq. (6) and Eq. (12). These temperatures are useful for matching with S2 peak temperatures from pyrolysis tests.

\begin{tabular}{|c|c|c|c|c|c|c|c|c|c|c|c|c|c|}
\hline \multicolumn{14}{|c|}{ Indicative peak reaction temperatures $\left({ }^{\circ} \mathrm{C}\right)$ for potential kerogen reactions at laboratory scale heating rates } \\
\hline \multicolumn{2}{|c|}{ Reaction rate } & \multicolumn{2}{|c|}{ Laboratory scale } & \multicolumn{2}{|c|}{ Geological scale } & \multicolumn{8}{|c|}{ Heating rates ${ }^{\circ} \mathrm{C} / \mathrm{min}$ : Applying $A / \mathrm{min}$} \\
\hline \multirow{2}{*}{$E(\mathrm{~kJ} / \mathrm{mol})$} & \multirow{2}{*}{$E(\mathrm{kcal} / \mathrm{mol})$} & \multirow{2}{*}{$A(/ \min )$} & \multirow{2}{*}{$\ln A(/ \min )$} & \multirow{2}{*}{$A(/ \mathrm{my})$} & \multirow{2}{*}{$\ln A$ (/my) } & 50 & 25 & 15 & 10 & 7 & 5 & 2 & 1 \\
\hline & & & & & & \multicolumn{8}{|c|}{ Peak temperatures $\left({ }^{\circ} \mathrm{C}\right)$ for reactions at laboratory scale heating } \\
\hline 150 & 35.9 & $4.21 \mathrm{E}+09$ & 22.16 & $2.21 \mathrm{E}+21$ & 49.15 & 552 & 529 & 512 & 500 & 489 & 479 & 454 & 435 \\
\hline 155 & 37.0 & $1.05 \mathrm{E}+10$ & 23.07 & $5.51 \mathrm{E}+21$ & 50.06 & 547 & 525 & 509 & 497 & 487 & 477 & 452 & 435 \\
\hline 160 & 38.2 & $2.61 \mathrm{E}+10$ & 23.99 & $1.37 \mathrm{E}+22$ & 50.97 & 542 & 521 & 506 & 494 & 484 & 475 & 451 & 434 \\
\hline 165 & 39.4 & $6.50 \mathrm{E}+10$ & 24.90 & $3.42 \mathrm{E}+22$ & 51.89 & 538 & 517 & 503 & 491 & 482 & 473 & 450 & 433 \\
\hline 170 & 40.6 & $1.62 \mathrm{E}+11$ & 25.81 & $8.52 \mathrm{E}+22$ & 52.80 & 534 & 514 & 500 & 489 & 480 & 471 & 449 & 432 \\
\hline 175 & 41.8 & $4.03 \mathrm{E}+11$ & 26.72 & $2.12 \mathrm{E}+23$ & 53.71 & 530 & 511 & 497 & 486 & 477 & 469 & 447 & 432 \\
\hline 180 & 43.0 & $1.00 \mathrm{E}+12$ & 27.64 & $5.29 \mathrm{E}+23$ & 54.62 & 526 & 508 & 494 & 484 & 475 & 467 & 446 & 431 \\
\hline 185 & 44.2 & $2.50 \mathrm{E}+12$ & 28.55 & $1.32 \mathrm{E}+24$ & 55.54 & 523 & 505 & 492 & 482 & 474 & 466 & 445 & 430 \\
\hline 190 & 45.4 & $6.23 \mathrm{E}+12$ & 29.46 & $3.28 \mathrm{E}+24$ & 56.45 & 519 & 502 & 489 & 480 & 472 & 464 & 444 & 430 \\
\hline 195 & 46.6 & $1.55 \mathrm{E}+13$ & 30.37 & $8.17 \mathrm{E}+24$ & 57.36 & 516 & 499 & 487 & 478 & 470 & 463 & 443 & 429 \\
\hline 200 & 47.8 & $3.87 \mathrm{E}+13$ & 31.29 & $2.03 E+25$ & 58.27 & 513 & 497 & 485 & 476 & 468 & 461 & 442 & 429 \\
\hline 205 & 49.0 & $9.63 \mathrm{E}+13$ & 32.20 & $5.07 \mathrm{E}+25$ & 59.19 & 510 & 494 & 483 & 474 & 467 & 460 & 441 & 428 \\
\hline 210 & 50.2 & $2.40 \mathrm{E}+14$ & 33.11 & $1.26 \mathrm{E}+26$ & 60.10 & 507 & 492 & 481 & 472 & 465 & 458 & 440 & 427 \\
\hline 215 & 51.4 & $5.98 \mathrm{E}+14$ & 34.02 & $3.14 \mathrm{E}+26$ & 61.01 & 505 & 490 & 479 & 471 & 464 & 457 & 440 & 427 \\
\hline 220 & 52.6 & $1.49 \mathrm{E}+15$ & 34.94 & $7.83 \mathrm{E}+26$ & 61.93 & 502 & 488 & 477 & 469 & 462 & 456 & 439 & 426 \\
\hline 225 & 53.8 & $3.71 \mathrm{E}+15$ & 35.85 & $1.95 \mathrm{E}+27$ & 62.84 & 500 & 486 & 476 & 468 & 461 & 455 & 438 & 426 \\
\hline 230 & 55.0 & $9.23 \mathrm{E}+15$ & 36.76 & $4.86 \mathrm{E}+27$ & 63.75 & 498 & 484 & 474 & 466 & 460 & 453 & 437 & 425 \\
\hline 235 & 56.2 & $2.30 \mathrm{E}+16$ & 37.67 & $1.21 \mathrm{E}+28$ & 64.66 & 495 & 482 & 472 & 465 & 458 & 452 & 436 & 425 \\
\hline 240 & 57.4 & $5.73 \mathrm{E}+16$ & 38.59 & $3.01 \mathrm{E}+28$ & 65.58 & 493 & 480 & 471 & 463 & 457 & 451 & 436 & 424 \\
\hline 245 & 58.6 & $1.43 \mathrm{E}+17$ & 39.50 & $7.51 \mathrm{E}+28$ & 66.49 & 491 & 478 & 469 & 462 & 456 & 450 & 435 & 424 \\
\hline 250 & 59.8 & $3.55 \mathrm{E}+17$ & 40.41 & $1.87 \mathrm{E}+29$ & 67.40 & 489 & 477 & 468 & 461 & 455 & 449 & 434 & 424 \\
\hline 255 & 60.9 & $8.85 \mathrm{E}+17$ & 41.32 & $4.66 \mathrm{E}+29$ & 68.31 & 488 & 475 & 466 & 460 & 454 & 448 & 434 & 423 \\
\hline 260 & 62.1 & $2.21 \mathrm{E}+18$ & 42.24 & $1.16 \mathrm{E}+30$ & 69.23 & 486 & 474 & 465 & 458 & 453 & 447 & 433 & 423 \\
\hline 265 & 63.3 & $5.49 \mathrm{E}+18$ & 43.15 & $2.89 \mathrm{E}+30$ & 70.14 & 484 & 472 & 464 & 457 & 452 & 446 & 432 & 422 \\
\hline 270 & 64.5 & $1.37 \mathrm{E}+19$ & 44.06 & $7.20 \mathrm{E}+30$ & 71.05 & 482 & 471 & 463 & 456 & 451 & 446 & 432 & 422 \\
\hline 275 & 65.7 & $3.41 \mathrm{E}+19$ & 44.98 & $1.79 \mathrm{E}+31$ & 71.96 & 481 & 470 & 461 & 455 & 450 & 445 & 431 & 421 \\
\hline 280 & 66.9 & $8.49 \mathrm{E}+19$ & 45.89 & $4.46 \mathrm{E}+31$ & 72.88 & 479 & 468 & 460 & 454 & 449 & 444 & 431 & 421 \\
\hline 285 & 68.1 & $2.11 \mathrm{E}+20$ & 46.80 & $1.11 \mathrm{E}+32$ & 73.79 & 478 & 467 & 459 & 453 & 448 & 443 & 430 & 421 \\
\hline 290 & 69.3 & $5.27 \mathrm{E}+20$ & 47.71 & $2.77 \mathrm{E}+32$ & 74.70 & 476 & 466 & 458 & 452 & 447 & 442 & 430 & 420 \\
\hline 295 & 70.5 & $1.31 \mathrm{E}+21$ & 48.63 & $6.90 \mathrm{E}+32$ & 75.61 & 475 & 464 & 457 & 451 & 446 & 442 & 429 & 420 \\
\hline 300 & 71.7 & $3.27 \mathrm{E}+21$ & 49.54 & $1.72 \mathrm{E}+33$ & 76.53 & 473 & 463 & 456 & 450 & 445 & 441 & 429 & 420 \\
\hline 305 & 72.9 & $8.14 \mathrm{E}+21$ & 50.45 & $4.28 \mathrm{E}+33$ & 77.44 & 472 & 462 & 455 & 449 & 445 & 440 & 428 & 419 \\
\hline 310 & 74.1 & $2.03 \mathrm{E}+22$ & 51.36 & $1.07 \mathrm{E}+34$ & 78.35 & 471 & 461 & 454 & 449 & 444 & 439 & 428 & 419 \\
\hline 315 & 75.3 & $5.05 \mathrm{E}+22$ & 52.28 & $2.65 \mathrm{E}+34$ & 79.26 & 470 & 460 & 453 & 448 & 443 & 439 & 427 & 419 \\
\hline 320 & 76.5 & $1.26 \mathrm{E}+23$ & 53.19 & $6.61 \mathrm{E}+34$ & 80.18 & 468 & 459 & 452 & 447 & 442 & 438 & 427 & 418 \\
\hline 325 & 77.7 & $3.13 E+23$ & 54.10 & $1.65 \mathrm{E}+35$ & 81.09 & 467 & 458 & 451 & 446 & 442 & 437 & 426 & 418 \\
\hline 330 & 78.9 & $7.80 \mathrm{E}+23$ & 55.01 & $4.10 \mathrm{E}+35$ & 82.00 & 466 & 457 & 451 & 445 & 441 & 437 & 426 & 418 \\
\hline 335 & 80.1 & $1.94 \mathrm{E}+24$ & 55.93 & $1.02 \mathrm{E}+36$ & 82.91 & 465 & 456 & 450 & 445 & 440 & 436 & 425 & 417 \\
\hline 340 & 81.3 & $4.84 \mathrm{E}+24$ & 56.84 & $2.55 \mathrm{E}+36$ & 83.83 & 464 & 455 & 449 & 444 & 440 & 436 & 425 & 417 \\
\hline 345 & 82.5 & $1.21 \mathrm{E}+25$ & 57.75 & $6.34 \mathrm{E}+36$ & 84.74 & 463 & 454 & 448 & 443 & 439 & 435 & 425 & 417 \\
\hline 350 & 83.7 & $3.00 \mathrm{E}+25$ & 58.66 & $1.58 \mathrm{E}+37$ & 85.65 & 462 & 454 & 447 & 443 & 438 & 435 & 424 & 416 \\
\hline
\end{tabular}


Table 2. Peak reaction temperatures at a geological scale for reaction kinetics spread along the $E-A$ trend highlighted in Fig. 1 and calculated with Eq. (6) and Eq. (12). These temperatures are useful for identifying peak petroleum transformation temperatures in actual shales subjected to specific burial and thermal histories.

\begin{tabular}{|c|c|c|c|c|c|c|c|c|c|c|c|c|c|}
\hline \multicolumn{14}{|c|}{ Indicative peak reaction temperatures $\left({ }^{\circ} \mathrm{C}\right)$ for potential kerogen reactions at geological scale heating rates } \\
\hline \multicolumn{2}{|c|}{ Reaction rate } & \multicolumn{2}{|c|}{ Laboratory scale } & \multicolumn{2}{|c|}{ Geological scale } & \multicolumn{8}{|c|}{ Heating rates ${ }^{\circ} \mathrm{C} / \mathrm{my}$ : Applying $A /$ million years (my) } \\
\hline \multirow{2}{*}{$E(\mathrm{~kJ} / \mathrm{mol})$} & \multirow{2}{*}{$E(\mathrm{kcal} / \mathrm{mol})$} & \multirow{2}{*}{$A(/ \min )$} & \multirow{2}{*}{$\ln A(/ \min )$} & \multirow{2}{*}{$A(/ \mathrm{my})$} & \multirow[b]{2}{*}{$\ln A(/ \mathrm{my})$} & 10 & 9 & 7 & 5 & 4 & 3 & 2 & 1 \\
\hline & & & & & & \multicolumn{8}{|c|}{ Peak temperatures $\left({ }^{\circ} \mathrm{C}\right)$ for reactions at geological scale heating } \\
\hline 150 & 35.9 & $4.21 \mathrm{E}+09$ & 22.16 & $2.21 \mathrm{E}+21$ & 49.15 & 97 & 96 & 94 & 92 & 90 & 88 & 85 & 81 \\
\hline 155 & 37.0 & $1.05 \mathrm{E}+10$ & 23.07 & $5.51 \mathrm{E}+21$ & 50.06 & 102 & 101 & 99 & 97 & 95 & 93 & 91 & 86 \\
\hline 160 & 38.2 & $2.61 \mathrm{E}+10$ & 23.99 & $1.37 \mathrm{E}+22$ & 50.97 & 107 & 106 & 104 & 102 & 101 & 99 & 96 & 91 \\
\hline 165 & 39.4 & $6.50 \mathrm{E}+10$ & 24.90 & $3.42 \mathrm{E}+22$ & 51.89 & 112 & 111 & 109 & 107 & 106 & 104 & 101 & 96 \\
\hline 170 & 40.6 & $1.62 \mathrm{E}+11$ & 25.81 & $8.52 \mathrm{E}+22$ & 52.80 & 117 & 116 & 114 & 112 & 110 & 108 & 106 & 101 \\
\hline 175 & 41.8 & $4.03 \mathrm{E}+11$ & 26.72 & $2.12 \mathrm{E}+23$ & 53.71 & 121 & 121 & 119 & 117 & 115 & 113 & 110 & 106 \\
\hline 180 & 43.0 & $1.00 \mathrm{E}+12$ & 27.64 & $5.29 \mathrm{E}+23$ & 54.62 & 126 & 125 & 123 & 121 & 120 & 118 & 115 & 110 \\
\hline 185 & 44.2 & $2.50 \mathrm{E}+12$ & 28.55 & $1.32 \mathrm{E}+24$ & 55.54 & 130 & 130 & 128 & 125 & 124 & 122 & 119 & 115 \\
\hline 190 & 45.4 & $6.23 \mathrm{E}+12$ & 29.46 & $3.28 \mathrm{E}+24$ & 56.45 & 134 & 134 & 132 & 130 & 128 & 126 & 124 & 119 \\
\hline 195 & 46.6 & $1.55 \mathrm{E}+13$ & 30.37 & $8.17 \mathrm{E}+24$ & 57.36 & 139 & 138 & 136 & 134 & 132 & 130 & 128 & 123 \\
\hline 200 & 47.8 & $3.87 \mathrm{E}+13$ & 31.29 & $2.03 \mathrm{E}+25$ & 58.27 & 143 & 142 & 140 & 138 & 136 & 134 & 132 & 127 \\
\hline 205 & 49.0 & $9.63 \mathrm{E}+13$ & 32.20 & $5.07 \mathrm{E}+25$ & 59.19 & 146 & 146 & 144 & 142 & 140 & 138 & 136 & 131 \\
\hline 210 & 50.2 & $2.40 \mathrm{E}+14$ & 33.11 & $1.26 \mathrm{E}+26$ & 60.10 & 150 & 149 & 148 & 145 & 144 & 142 & 139 & 135 \\
\hline 215 & 51.4 & $5.98 \mathrm{E}+14$ & 34.02 & $3.14 \mathrm{E}+26$ & 61.01 & 154 & 153 & 151 & 149 & 148 & 146 & 143 & 139 \\
\hline 220 & 52.6 & $1.49 \mathrm{E}+15$ & 34.94 & $7.83 \mathrm{E}+26$ & 61.93 & 157 & 156 & 155 & 153 & 151 & 149 & 147 & 142 \\
\hline 225 & 53.8 & $3.71 \mathrm{E}+15$ & 35.85 & $1.95 \mathrm{E}+27$ & 62.84 & 161 & 160 & 158 & 156 & 154 & 153 & 150 & 146 \\
\hline 230 & 55.0 & $9.23 \mathrm{E}+15$ & 36.76 & $4.86 \mathrm{E}+27$ & 63.75 & 164 & 163 & 161 & 159 & 158 & 156 & 153 & 149 \\
\hline 235 & 56.2 & $2.30 \mathrm{E}+16$ & 37.67 & $1.21 \mathrm{E}+28$ & 64.66 & 167 & 166 & 165 & 162 & 161 & 159 & 157 & 152 \\
\hline 240 & 57.4 & $5.73 \mathrm{E}+16$ & 38.59 & $3.01 \mathrm{E}+28$ & 65.58 & 170 & 169 & 168 & 166 & 164 & 162 & 160 & 155 \\
\hline 245 & 58.6 & $1.43 \mathrm{E}+17$ & 39.50 & $7.51 \mathrm{E}+28$ & 66.49 & 173 & 173 & 171 & 169 & 167 & 165 & 163 & 159 \\
\hline 250 & 59.8 & $3.55 \mathrm{E}+17$ & 40.41 & $1.87 \mathrm{E}+29$ & 67.40 & 176 & 175 & 174 & 172 & 170 & 168 & 166 & 162 \\
\hline 255 & 60.9 & $8.85 \mathrm{E}+17$ & 41.32 & $4.66 \mathrm{E}+29$ & 68.31 & 179 & 178 & 177 & 175 & 173 & 171 & 169 & 165 \\
\hline 260 & 62.1 & $2.21 \mathrm{E}+18$ & 42.24 & $1.16 \mathrm{E}+30$ & 69.23 & 182 & 181 & 180 & 177 & 176 & 174 & 172 & 167 \\
\hline 265 & 63.3 & $5.49 \mathrm{E}+18$ & 43.15 & $2.89 \mathrm{E}+30$ & 70.14 & 185 & 184 & 182 & 180 & 179 & 177 & 174 & 170 \\
\hline 270 & 64.5 & $1.37 \mathrm{E}+19$ & 44.06 & $7.20 \mathrm{E}+30$ & 71.05 & 187 & 187 & 185 & 183 & 181 & 180 & 177 & 173 \\
\hline 275 & 65.7 & $3.41 \mathrm{E}+19$ & 44.98 & $1.79 \mathrm{E}+31$ & 71.96 & 190 & 189 & 188 & 185 & 184 & 182 & 180 & 176 \\
\hline 280 & 66.9 & $8.49 \mathrm{E}+19$ & 45.89 & $4.46 \mathrm{E}+31$ & 72.88 & 192 & 192 & 190 & 188 & 187 & 185 & 182 & 178 \\
\hline 285 & 68.1 & $2.11 \mathrm{E}+20$ & 46.80 & $1.11 \mathrm{E}+32$ & 73.79 & 195 & 194 & 193 & 190 & 189 & 187 & 185 & 181 \\
\hline 290 & 69.3 & $5.27 \mathrm{E}+20$ & 47.71 & $2.77 \mathrm{E}+32$ & 74.70 & 197 & 197 & 195 & 193 & 192 & 190 & 187 & 183 \\
\hline 295 & 70.5 & $1.31 \mathrm{E}+21$ & 48.63 & $6.90 \mathrm{E}+32$ & 75.61 & 199 & 199 & 197 & 195 & 194 & 192 & 190 & 186 \\
\hline 300 & 71.7 & $3.27 \mathrm{E}+21$ & 49.54 & $1.72 \mathrm{E}+33$ & 76.53 & 202 & 201 & 200 & 198 & 196 & 195 & 192 & 188 \\
\hline 305 & 72.9 & $8.14 \mathrm{E}+21$ & 50.45 & $4.28 \mathrm{E}+33$ & 77.44 & 204 & 203 & 202 & 200 & 199 & 197 & 194 & 191 \\
\hline 310 & 74.1 & $2.03 E+22$ & 51.36 & $1.07 \mathrm{E}+34$ & 78.35 & 206 & 206 & 204 & 202 & 201 & 199 & 197 & 193 \\
\hline 315 & 75.3 & $5.05 \mathrm{E}+22$ & 52.28 & $2.65 \mathrm{E}+34$ & 79.26 & 208 & 208 & 206 & 204 & 203 & 201 & 199 & 195 \\
\hline 320 & 76.5 & $1.26 \mathrm{E}+23$ & 53.19 & $6.61 \mathrm{E}+34$ & 80.18 & 210 & 210 & 208 & 206 & 205 & 203 & 201 & 197 \\
\hline 325 & 77.7 & $3.13 E+23$ & 54.10 & $1.65 \mathrm{E}+35$ & 81.09 & 212 & 212 & 210 & 208 & 207 & 205 & 203 & 199 \\
\hline 330 & 78.9 & $7.80 \mathrm{E}+23$ & 55.01 & $4.10 \mathrm{E}+35$ & 82.00 & 214 & 214 & 212 & 210 & 209 & 208 & 205 & 201 \\
\hline 335 & 80.1 & $1.94 \mathrm{E}+24$ & 55.93 & $1.02 \mathrm{E}+36$ & 82.91 & 216 & 216 & 214 & 212 & 211 & 209 & 207 & 203 \\
\hline 340 & 81.3 & $4.84 \mathrm{E}+24$ & 56.84 & $2.55 \mathrm{E}+36$ & 83.83 & 218 & 218 & 216 & 214 & 213 & 211 & 209 & 205 \\
\hline 345 & 82.5 & $1.21 \mathrm{E}+25$ & 57.75 & $6.34 \mathrm{E}+36$ & 84.74 & 220 & 220 & 218 & 216 & 215 & 213 & 211 & 207 \\
\hline 350 & 83.7 & $3.00 \mathrm{E}+25$ & 58.66 & $1.58 \mathrm{E}+37$ & 85.65 & 222 & 221 & 220 & 218 & 217 & 215 & 213 & 209 \\
\hline
\end{tabular}


Table 3. Optimizer best $E$-A reaction kinetic fits to S2-peak temperatures for ten kerogen/shale samples compared to published reaction kinetics for those samples. E-A comparisons are illustrated in Fig. 6.

\begin{tabular}{|c|c|c|c|c|c|c|c|c|c|c|c|c|c|c|c|}
\hline \multirow{3}{*}{ Sample } & \multicolumn{6}{|c|}{ Pyrolysis heating rates ${ }^{\circ} \mathrm{C} / \mathrm{min}$} & \multirow{3}{*}{$\begin{array}{l}\text { Sum } \\
\text { squared } \\
\text { error } \\
\text { fit }\end{array}$} & \multicolumn{6}{|c|}{ Best fit kinetics (this study) } & \multicolumn{2}{|c|}{ Published kinetics } \\
\hline & 50 & 25 & 15 & 7 & 5 & 1 & & $\begin{array}{l}E \\
(\mathrm{~kJ} / \mathrm{mol})\end{array}$ & $\begin{array}{l}E \\
(\mathrm{kcal} / \mathrm{mo}\end{array}$ & $\begin{array}{l}A \\
(/ \mathrm{my})\end{array}$ & $\begin{array}{l}\ln A \\
(/ \mathrm{my})\end{array}$ & $\begin{array}{l}A \\
(/ \min )\end{array}$ & $\begin{array}{l}\ln A \\
(/ \min )\end{array}$ & $\begin{array}{l}E \\
(\mathrm{~kJ} / \mathrm{mol})\end{array}$ & $\begin{array}{l}\ln A \\
(/ \mathrm{my})\end{array}$ \\
\hline & \multicolumn{6}{|c|}{$\mathrm{S} 2$ peak temperature ${ }^{\circ} \mathrm{C}$} & & & & & & & & & \\
\hline A measured & - & 470 & 462 & - & 438 & - & - & & & & & & & 193 & 57.83 \\
\hline A modelled & - & 471 & 461 & - & 438 & - & 2 & 204.17 & 48.80 & $1.27 \mathrm{E}+26$ & 60.11 & $2.41 \mathrm{E}+14$ & 33.12 & & \\
\hline B measured & - & 478 & 465 & - & 442 & - & - & & & & & & & 200 & 59.40 \\
\hline B modelled & - & 477 & 465 & - & 442 & - & 1 & 196.82 & 47.04 & $2.93 \mathrm{E}+25$ & 58.64 & $5.57 \mathrm{E}+13$ & 31.65 & & \\
\hline $\mathrm{C}$ measured & 496 & - & - & 459 & - & 423 & - & & & & & & & 226 & 63.03 \\
\hline $\mathrm{C}$ modelled & 496 & - & - & 458 & - & 423 & 1 & 225.24 & 53.83 & $2.41 \mathrm{E}+27$ & 63.05 & $4.58 \mathrm{E}+15$ & 36.06 & & \\
\hline D measured & 474 & - & - & 439 & - & 405 & - & & & & & & & 220 & 63.00 \\
\hline D modelled & 474 & - & - & 439 & - & 406 & 1 & 230.41 & 55.07 & $1.68 \mathrm{E}+28$ & 64.99 & $3.2 \mathrm{E}+16$ & 38.00 & & \\
\hline E measured & 472 & - & - & 436 & - & 402 & - & & & & & & & 233 & 65.24 \\
\hline E modelled & 472 & - & - & 436 & - & 402 & 0 & 222.75 & 53.24 & $5.30 \mathrm{E}+27$ & 63.84 & $1.01 \mathrm{E}+16$ & 36.85 & & \\
\hline$F$ measured & 463 & - & - & 426 & - & 396 & - & & & & & & & 226 & 62.27 \\
\hline F modelled & 463 & - & - & 427 & - & 396 & 1 & 227.71 & 54.42 & $2.01 \mathrm{E}+28$ & 65.17 & $3.83 \mathrm{E}+16$ & 38.18 & & \\
\hline $\mathrm{G}$ measured & 448 & - & - & 417 & - & 388 & - & & & & & & & 272 & 68.82 \\
\hline G modelled & 448 & - & - & 417 & - & 388 & 0 & 247.10 & 59.06 & $1.23 \mathrm{E}+30$ & 69.29 & $2.34 \mathrm{E}+18$ & 42.30 & & \\
\hline $\mathrm{H}$ measured & 461 & - & - & 428 & - & 397 & - & & & & & & & 226 & 64.46 \\
\hline $\mathrm{H}$ modelled & 461 & - & - & 428 & - & 397 & 0 & 237.57 & 56.78 & $1.14 \mathrm{E}+29$ & 66.90 & $2.16 \mathrm{E}+17$ & 39.91 & & \\
\hline I measured & - & 467 & 456 & - & 437 & - & - & & & & & & & 226 & 64.00 \\
\hline I modelled & - & 466 & 456 & - & 437 & - & 1 & 221.70 & 52.99 & $2.90 \mathrm{E}+27$ & 63.24 & $5.52 \mathrm{E}+15$ & 36.25 & & \\
\hline $\mathrm{J}$ measured & - & 479 & 467 & - & 446 & - & - & & & & & & & 226 & 63.48 \\
\hline $\mathrm{J}$ modelled & - & 478 & 467 & - & 446 & - & 1 & 215.01 & 51.39 & $5.57 \mathrm{E}+26$ & 61.59 & $1.06 \mathrm{E}+15$ & 34.60 & & \\
\hline
\end{tabular}

those published are generally good but not perfect. However, two factors standout: 1) the relative spread of $E$ - $A$ values among the samples is consistent fitted and published data sets; and, 2) both published and modelled values lie close to, but predominantly just to the right of, the established $E-A$ trend for kerogen/hydrocarbon reactions.

There are at least three contributing factors on why the published and modelled values do not coincide exactly: 1) the S2-peak temperature values used are digitized from published images and the S2 peak temperatures are likely to vary within 2 or $3{ }^{\circ} \mathrm{C}$ of the actual recorded values; 2) the published kinetics are representative modal or mean values from a distribution; 3 ) in some cases there is more than one possible $E-A$ solution with low sum of the squared error (SSE) that the optimizer could select to provide a good match for the multi-rate peak reaction temperatures. It is therefore more meaningful to compare the $E-A$ distributions of the full S2peak-shape fits (step 2 of the optimization methodology) to establish the most realistic reaction kinetic fit.

\subsection{Finding the best reaction kinetics to fits to the full S2 peak shapes with an optimizer}

The second step in the methodology to find the best distribution of $E-A$ values to reproduce the S2 peak shapes of the shale/kerogen samples (i.e., step 6(a) in the methodology described) can be performed using the three optimization approaches described above (i.e., Opt 1, Opt 2 and Opt 3). Although Opt 1 (i.e., constraining $E$ - $A$ values to the $E$ - $A$ trend displayed in Fig. 1) can provide approximate fits to the S2 peak shapes it is unable to provide exact fits to the full S2 peaks. On the other hand, Opt 2 and Opt 3 can provide exact fits to the full S2 peaks and it is those approaches that are compared and contrasted here. Both commence with the $E-A$ values established in Table 3 (i.e., the best S2 peak temperature matches) as their starting points (initial modal focus for the reaction kinetics distributions to be constructed) and match the exactly the same normalized $/{ }^{\circ} \mathrm{C}$ data sets for each $\mathrm{S} 2$ peak for each sample.

The results for the Opt 2 approach (i.e., mixing kerogens along a fixed $A$ trend) applied to the ten kerogen/shale samples (using Eq. (6), Eq. (11) and Eq. (13)) are displayed in Table 


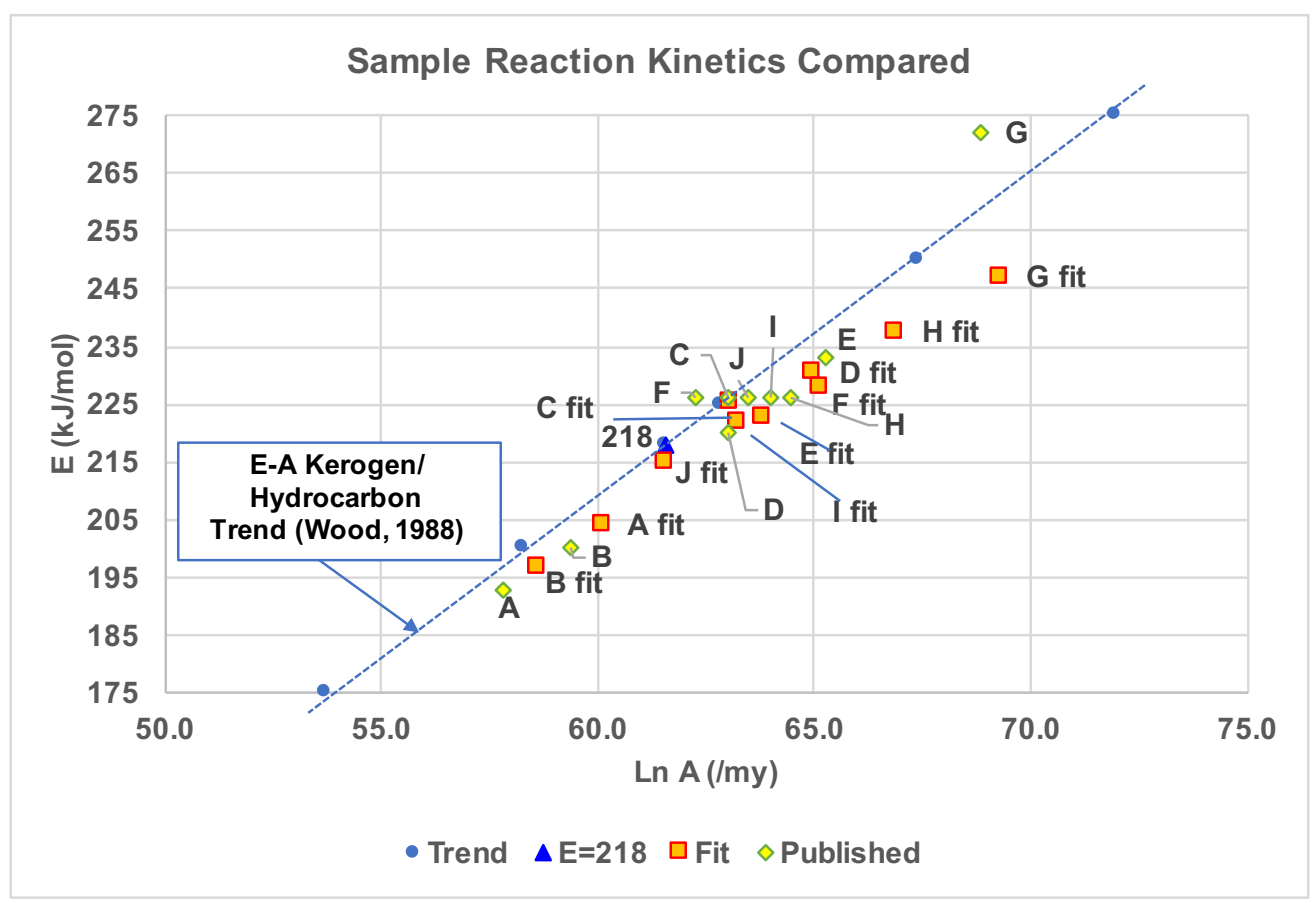

Fig. 6. Published (digitized samples) versus best-fit model results for reaction kinetic $E$ and $A$ values for ten kerogen and shale samples studied with multi-rate pyrolysis data. Details are listed in Table 3.

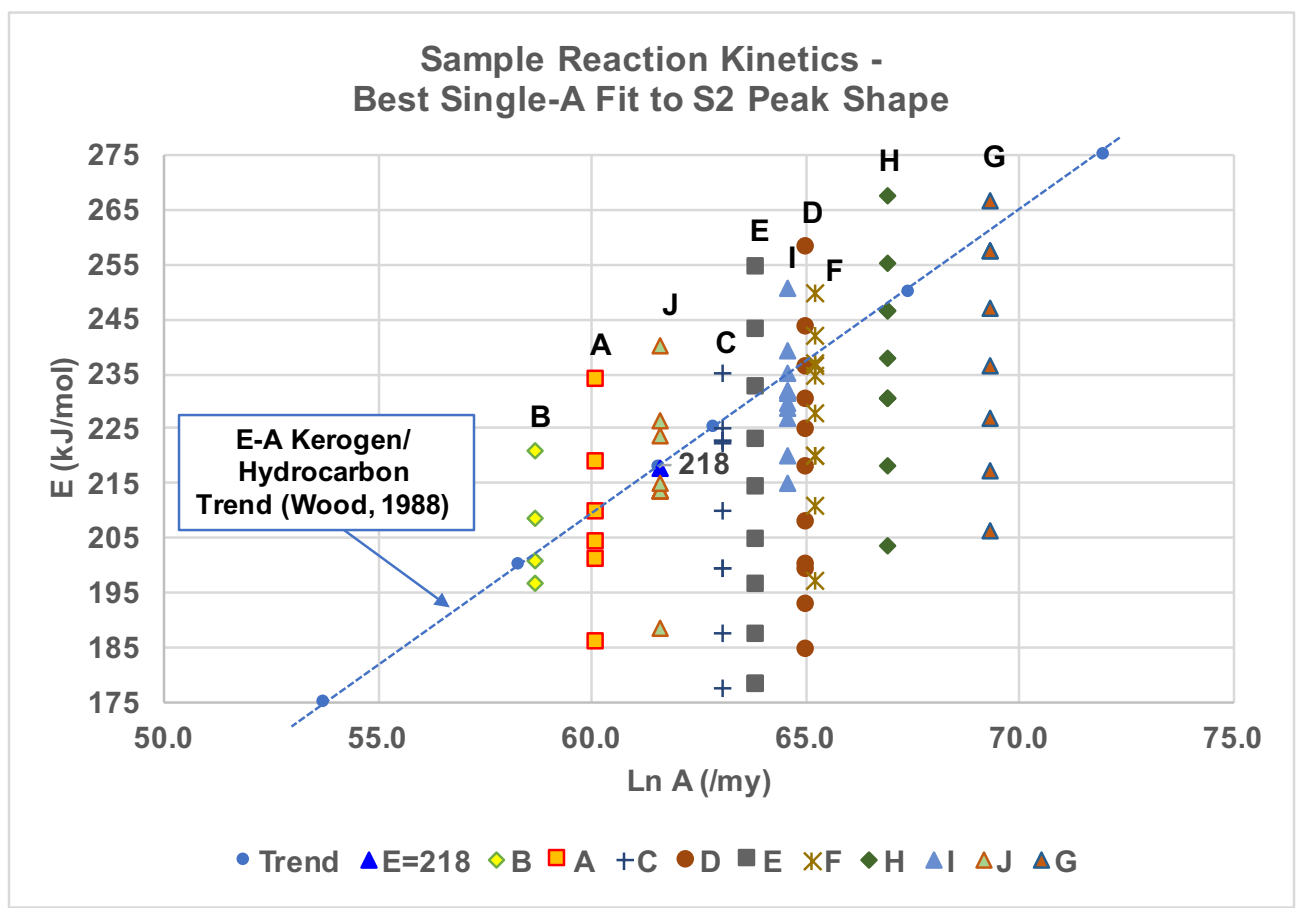

Fig. 7. Optimized best-fit reaction kinetic distributions using the fixed $A$ approach (Opt 2) results for the ten kerogen/shale samples studied. Note those distributions extend over wide ranges of $E$ values and all straddle the identified $E$ - $A$ kerogen/hydrocarbon trend. Details of the kinetic distributions are listed in Table 4. 
Table 4. Optimizer Opt 2 best $E$-A reaction kinetic fits to full S2-peak shapes for ten kerogen/shale samples using a distribution $E$ and a fixed $A$ values for up to 11 individual first-order kinetic reactions for each sample. $E-A$ distributions are illustrated in Fig. 7. Note the fractional contributions sum to 1 and the shaded values identify modal kinetics.

\begin{tabular}{|c|c|c|c|c|c|c|c|c|c|c|c|c|c|c|c|}
\hline & & & \multicolumn{11}{|c|}{2 peak shape fits applying a single $A$ (pre-exponential factor) value to each kinetic component (KC) } & \multirow{3}{*}{$\begin{array}{l}\text { Modal } \\
\text { kinetics }\end{array}$} & \multirow{3}{*}{$\begin{array}{l}\text { Weighted } \\
\text { average }\end{array}$} \\
\hline \multirow{2}{*}{ Sample } & \multirow{2}{*}{ Elements } & \multicolumn{11}{|c|}{ Up to 11 kinetic components involved in generating accurate shape fit to digitized S2 peak } & \multirow{2}{*}{$\begin{array}{l}\text { Fit Error } \\
\text { MSE }\end{array}$} & & \\
\hline & & KC\#1 & $\mathrm{KC \# 2}$ & KC\#3 & $\mathrm{KC \# 4}$ & $\mathrm{KC \# 5}$ & KC\#6 & KC\#7 & KC\#8 & $\mathrm{KC \# 9}$ & KC\#10 & KC\#11 & & & \\
\hline \multirow{3}{*}{ A } & $\mathrm{E}(\mathrm{kJ} / \mathrm{mol})$ & 185.80 & 200.95 & 204.00 & 209.62 & 218.63 & 234.09 & 304.33 & 334.24 & 341.90 & 350.00 & - & & 204.00 & 206.20 \\
\hline & LN A (/my) & 60.11 & 60.11 & 60.11 & 60.11 & 60.11 & 60.11 & 60.11 & 60.11 & 60.11 & 60.11 & - & 3.67E-01 & 60.11 & 60.11 \\
\hline & Fraction (f) & 0.0271 & 0.2336 & 0.4000 & 0.2352 & 0.0788 & 0.0236 & 0.0004 & 0.0003 & 0.0006 & 0.0004 & - & & & \\
\hline \multirow{3}{*}{ B } & $\mathrm{E}(\mathrm{kJ} / \mathrm{mol})$ & 197.00 & 201.08 & 208.53 & 221.06 & 336.19 & 338.18 & 350.00 & - & - & - & - & & 201.08 & 205.48 \\
\hline & LN A (/my) & 58.64 & 58.64 & 58.64 & 58.64 & 58.64 & 58.64 & 58.64 & - & - & - & - & $1.43 \mathrm{E}+00$ & 58.64 & 58.64 \\
\hline & Fraction (f) & 0.4000 & 0.4023 & 0.1289 & 0.0377 & 0.0046 & 0.0207 & 0.0058 & - & - & - & - & & & \\
\hline \multirow{3}{*}{$\mathrm{C}$} & $\mathrm{E}(\mathrm{kJ} / \mathrm{mol})$ & 177.50 & 187.57 & 199.39 & 199.43 & 209.98 & 222.66 & 222.76 & 222.77 & 225.00 & 235.11 & 289.44 & & 225.00 & 220.96 \\
\hline & LN A (/my) & 63.05 & 63.05 & 63.05 & 63.05 & 63.05 & 63.05 & 63.05 & 63.05 & 63.05 & 63.05 & 63.05 & $5.28 \mathrm{E}-01$ & 63.05 & 63.05 \\
\hline & Fraction (f) & 0.0150 & 0.0200 & 0.0010 & 0.0378 & 0.0890 & 0.0099 & 0.0271 & 0.3500 & 0.4000 & 0.0484 & 0.0019 & & & \\
\hline \multirow{3}{*}{ D } & $\mathrm{E}(\mathrm{kJ} / \mathrm{mol})$ & 184.73 & 192.72 & 198.94 & 200.24 & 207.73 & 218.06 & 224.92 & 230.00 & 236.07 & 243.47 & 258.27 & & 230.00 & 229.88 \\
\hline & LN A (/my) & 64.99 & 64.99 & 64.99 & 64.99 & 64.99 & 64.99 & 64.99 & 64.99 & 64.99 & 64.99 & 64.99 & $3.44 \mathrm{E}-01$ & 64.99 & 64.99 \\
\hline & Fraction (f) & 0.0076 & 0.0090 & 0.0099 & 0.0010 & 0.0270 & 0.0784 & 0.1416 & 0.4000 & 0.2083 & 0.0956 & 0.0214 & & & \\
\hline \multirow{3}{*}{ E } & $\mathrm{E}(\mathrm{kJ} / \mathrm{mol})$ & 178.31 & 178.33 & 187.46 & 196.33 & 204.54 & 214.15 & 223.00 & 232.68 & 243.20 & 254.33 & 350.00 & & 223.00 & 221.08 \\
\hline & LN A (/my) & 63.84 & 63.84 & 63.84 & 63.84 & 63.84 & 63.84 & 63.84 & 63.84 & 63.84 & 63.84 & 63.84 & 4.46E-01 & 63.84 & 63.84 \\
\hline & Fraction (f) & 0.0113 & 0.0116 & 0.0334 & 0.0360 & 0.0618 & 0.1694 & 0.4000 & 0.1970 & 0.0530 & 0.0257 & 0.0008 & & & \\
\hline \multirow{3}{*}{$\mathrm{F}$} & $\mathrm{E}(\mathrm{kJ} / \mathrm{mol})$ & 197.54 & 210.99 & 220.06 & 220.18 & 228.00 & 234.97 & 236.76 & 236.93 & 241.88 & 249.97 & 350.00 & & 228.00 & 229.38 \\
\hline & LN A (/my) & 65.17 & 65.17 & 65.17 & 65.17 & 65.17 & 65.17 & 65.17 & 65.17 & 65.17 & 65.17 & 65.17 & $5.73 \mathrm{E}-01$ & 65.17 & 65.17 \\
\hline & Fraction (f) & 0.0123 & 0.0284 & 0.1137 & 0.1004 & 0.4000 & 0.1519 & 0.0380 & 0.0455 & 0.0676 & 0.0396 & 0.0026 & & & \\
\hline \multirow{3}{*}{ G } & $\mathrm{E}(\mathrm{kJ} / \mathrm{mol})$ & 206.38 & 217.33 & 227.11 & 236.38 & 247.00 & 257.48 & 257.71 & 266.94 & 278.76 & 293.35 & - & & 247.00 & 246.14 \\
\hline & LN A (/my) & 69.29 & 69.29 & 69.29 & 69.29 & 69.29 & 69.29 & 69.29 & 69.29 & 69.29 & 69.29 & - & $4.20 \mathrm{E}-01$ & 69.29 & 69.29 \\
\hline & Fraction (f) & 0.0269 & 0.0558 & 0.1043 & 0.1710 & 0.2800 & 0.0878 & 0.1385 & 0.0932 & 0.0305 & 0.0120 & - & & & \\
\hline \multirow{3}{*}{$\mathrm{H}$} & $\mathrm{E}(\mathrm{kJ} / \mathrm{mol})$ & 203.71 & 218.14 & 230.49 & 230.49 & 230.49 & 238.00 & 246.67 & 246.67 & 255.42 & 267.47 & 287.87 & & 238.00 & 240.23 \\
\hline & LN A (/my) & 66.90 & 66.90 & 66.90 & 66.90 & 66.90 & 66.90 & 66.90 & 66.90 & 66.90 & 66.90 & 66.90 & 3.19E-01 & 66.90 & 66.90 \\
\hline & Fraction (f) & 0.0127 & 0.0308 & 0.1108 & 0.0601 & 0.0273 & 0.4000 & 0.1313 & 0.1101 & 0.0788 & 0.0296 & 0.0086 & & & \\
\hline \multirow{3}{*}{ I } & $\mathrm{E}(\mathrm{kJ} / \mathrm{mol})$ & 214.97 & 220.17 & 226.91 & 229.00 & 229.81 & 231.72 & 232.02 & 232.26 & 235.17 & 239.22 & 250.65 & & 229.00 & 229.09 \\
\hline & LN A (/my) & 64.54 & 64.54 & 64.54 & 64.54 & 64.54 & 64.54 & 64.54 & 64.54 & 64.54 & 64.54 & 64.54 & $6.58 \mathrm{E}-01$ & 64.54 & 64.54 \\
\hline & Fraction (f) & 0.0659 & 0.0012 & 0.3312 & 0.3500 & 0.0061 & 0.0013 & 0.0005 & 0.0982 & 0.0672 & 0.0633 & 0.0150 & & & \\
\hline \multirow{3}{*}{$\mathrm{J}$} & $\mathrm{E}(\mathrm{kJ} / \mathrm{mol})$ & 188.52 & 213.66 & 213.67 & 213.82 & 213.85 & 213.96 & 215.00 & 223.69 & 226.65 & 240.34 & 279.94 & & 215.00 & 215.06 \\
\hline & LN A (/my) & 61.59 & 61.59 & 61.59 & 61.59 & 61.59 & 61.59 & 61.59 & 61.59 & 61.59 & 61.59 & 61.59 & $8.66 \mathrm{E}-01$ & 61.59 & 61.59 \\
\hline & Fraction (f) & 0.0228 & 0.3151 & 0.0005 & 0.0707 & 0.0733 & 0.0741 & 0.3500 & 0.0013 & 0.0786 & 0.0121 & 0.0015 & & & \\
\hline
\end{tabular}

4 and illustrated in Fig. 7. These best fit kinetic distributions involve a significant range of $E$-values that all straddle the established $E-A$ kerogen/hydrocarbon trend. Note the MSE values for these fits are low. MSE values below about 1.0E00 demonstrate almost perfect fits to the S2 incremental peak shape and $T F$ curve for each sample. The weighted average $E$ value of the best-fit reaction kinetics distribution is close to the modal value in all cases. If the distribution is to be described by a single $E-A$ pair either the modal or weighted average values could be considered as representative.
The results for the Opt 3 approach (i.e., mixing kerogens with $E$ and $A$ unconstrained; the optimizer is free to select reactions with any $E-A$ combination in order to achieve the best S2 peak-shape fit) applied to the ten kerogen/shale samples are displayed in Table 5 and illustrated in Fig. 8. These best-fit kinetic distributions involve a significant range of $E-A$ values for each sample that also straddle the established $E-A$ kerogen/hydrocarbon trend, but tend to be distributed closer to that trend, mostly in a semi-parallel manner. Note the MSE values for these fits are also very low $(<1.0 \mathrm{E} 00$ in all 
Table 5. Optimizer Opt 3 best $E$-A reaction kinetic fits to full S2-peak shapes for ten kerogen/ shale samples using a distribution $E$ - $A$ values for up to 11 individual first-order kinetic reactions for each sample. $E-A$ distributions are illustrated in Fig. 8. Note the fractional contributions sum to 1 and the shaded values identify modal kinetics.

\begin{tabular}{|c|c|c|c|c|c|c|c|c|c|c|c|c|c|c|c|}
\hline \multicolumn{16}{|c|}{ S2 peak shape fits applying a variable $A$ (pre-exponential factor) value to each kinetic component $(\mathrm{KC})$} \\
\hline \multirow{2}{*}{ Sample } & \multirow{2}{*}{ Elements } & \multicolumn{11}{|c|}{ Up to 11 kinetic components involved in generating accurate shape fit to digitized S2 peak } & \multirow{2}{*}{$\begin{array}{l}\text { Fit Error } \\
\text { MSE }\end{array}$} & \multirow{2}{*}{$\begin{array}{l}\text { Modal } \\
\text { kinetics }\end{array}$} & \multirow{2}{*}{$\begin{array}{l}\text { Weighted } \\
\text { average }\end{array}$} \\
\hline & & KC\#1 & $\mathrm{KC \# 2}$ & KC\#3 & KC\#4 & KC\#5 & KC\#6 & KC\#7 & KC\#8 & KC\#9 & KC\#10 & KC\#11 & & & \\
\hline \multirow{3}{*}{ A } & $\mathrm{E}(\mathrm{kJ} / \mathrm{mol})$ & 150.86 & 155.76 & 175.84 & 195.82 & 196.13 & 196.17 & 196.18 & 196.19 & 196.34 & 196.53 & 204.00 & & 204.00 & 198.72 \\
\hline & LN A (/my) & 56.43 & 57.44 & 58.80 & 59.03 & 59.91 & 53.81 & 57.70 & 56.03 & 59.76 & 65.51 & 60.11 & $6.12 \mathrm{E}-01$ & 60.11 & 58.88 \\
\hline & Fraction (f) & 0.0005 & 0.0006 & 0.0227 & 0.2379 & 0.0279 & 0.0248 & 0.2272 & 0.0575 & 0.0003 & 0.0006 & 0.4000 & & & \\
\hline \multirow{3}{*}{ B } & $\mathrm{E}(\mathrm{kJ} / \mathrm{mol})$ & 168.68 & 176.09 & 197.00 & 198.01 & 198.68 & 198.84 & 198.93 & 204.36 & 208.57 & 223.519 & 4226.9708 & & 197.00 & 199.51 \\
\hline & LN A (/my) & 58.02 & 61.68 & 58.64 & 58.95 & 57.44 & 59.15 & 59.18 & 56.72 & 60.82 & 57.67 & 58.98 & $3.58 \mathrm{E}-01$ & 58.64 & 58.83 \\
\hline & Fraction (f) & 0.02006 & 0.0085 & 0.4000 & 0.0001 & 0.1392 & 0.0513 & 0.1979 & 0.0195 & 0.1293 & 0.0340 & 0.00005 & & & \\
\hline \multirow{3}{*}{$\mathrm{C}$} & $\mathrm{E}(\mathrm{kJ} / \mathrm{mol})$ & 183.98 & 197.86 & 201.00 & 210.46 & 223.74 & 223.77 & 225.00 & 233.74 & 237.08 & 248.84 & 249.08 & & 225.00 & 221.61 \\
\hline & LN A (/my) & 60.86 & 57.43 & 59.99 & 63.07 & 64.06 & 62.98 & 63.05 & 73.37 & 63.29 & 64.84 & 60.32 & $4.25 \mathrm{E}-01$ & 63.05 & 63.11 \\
\hline & Fraction (f) & 0.0271 & 0.0254 & 0.0172 & 0.0934 & 0.0285 & 0.3494 & 0.4000 & 0.0299 & 0.0260 & 0.0012 & 0.0018 & & & \\
\hline \multirow{3}{*}{ D } & $\mathrm{E}(\mathrm{kJ} / \mathrm{mol})$ & 177.66 & 188.41 & 199.53 & 210.73 & 220.63 & 220.88 & 220.93 & 220.96 & 220.97 & 221.07 & 230.00 & & 230.00 & 222.44 \\
\hline & LN A (/my) & 60.04 & 61.91 & 67.41 & 63.85 & 67.61 & 60.21 & 62.23 & 64.31 & 63.02 & 69.57 & 64.99 & $6.77 \mathrm{E}-01$ & 64.99 & 63.85 \\
\hline & Fraction (f) & 0.0020 & 0.0252 & 0.0188 & 0.0798 & 0.0070 & 0.0527 & 0.2254 & 0.1258 & 0.0546 & 0.0086 & 0.4000 & & & \\
\hline \multirow{3}{*}{$\mathrm{E}$} & $\mathrm{E}(\mathrm{kJ} / \mathrm{mol})$ & 176.06 & 183.78 & 192.39 & 200.92 & 211.50 & 213.88 & 214.09 & 223.00 & 234.83 & 235.56 & 247.45 & & 223.00 & 215.85 \\
\hline & LN A (/my) & 63.56 & 53.54 & 63.94 & 62.90 & 63.87 & 60.80 & 60.30 & 63.84 & 76.42 & 66.65 & 66.24 & 7.54E-01 & 63.84 & 63.03 \\
\hline & Fraction (f) & 0.0257 & 0.0361 & 0.0464 & 0.0804 & 0.0996 & 0.0669 & 0.1344 & 0.4000 & 0.0012 & 0.0897 & 0.0197 & & & \\
\hline \multirow{3}{*}{$\mathrm{F}$} & $\mathrm{E}(\mathrm{kJ} / \mathrm{mol})$ & 198.37 & 208.82 & 213.87 & 215.92 & 216.19 & 218.36 & 219.20 & 221.49 & 223.35 & 228.00 & 238.81 & & 228.00 & 224.63 \\
\hline & LN A (/my) & 64.49 & 64.57 & 64.48 & 64.95 & 62.24 & 62.47 & 63.98 & 62.89 & 65.74 & 65.17 & 64.54 & $5.61 \mathrm{E}-01$ & 65.17 & 64.35 \\
\hline & Fraction (f) & 0.0200 & 0.0188 & 0.0479 & 0.0025 & 0.1024 & 0.0917 & 0.0115 & 0.0765 & 0.0964 & 0.4000 & 0.1322 & & & \\
\hline \multirow{3}{*}{ G } & $\mathrm{E}(\mathrm{kJ} / \mathrm{mol})$ & 197.76 & 207.84 & 217.23 & 222.84 & 228.39 & 236.70 & 236.83 & 236.93 & 247.00 & 256.90 & 261.67 & & 247.00 & 235.23 \\
\hline & LN A (/my) & 58.87 & 60.56 & 68.59 & 66.69 & 68.41 & 65.81 & 75.18 & 65.28 & 69.29 & 64.30 & 67.46 & $5.17 \mathrm{E}-01$ & 69.29 & 67.23 \\
\hline & Fraction (f) & 0.0271 & 0.0539 & 0.0954 & 0.0585 & 0.1535 & 0.2043 & 0.0174 & 0.0151 & 0.2800 & 0.0349 & 0.0597 & & & \\
\hline \multirow{3}{*}{$\mathrm{H}$} & $\mathrm{E}(\mathrm{kJ} / \mathrm{mol})$ & 238.00 & 246.72 & 247.03 & 247.56 & 247.85 & 247.90 & 248.28 & 250.55 & 256.27 & 261.12 & 276.70 & & 238.00 & 247.07 \\
\hline & LN A (/my) & 66.90 & 68.48 & 71.90 & 67.06 & 70.08 & 66.97 & 67.37 & 67.03 & 71.12 & 67.88 & 68.94 & $8.27 \mathrm{E}-01$ & 66.90 & 68.05 \\
\hline & Fraction (f) & 0.4000 & 0.0123 & 0.0470 & 0.2220 & 0.0500 & 0.0104 & 0.0117 & 0.0120 & 0.1271 & 0.0597 & 0.0477 & & & \\
\hline \multirow{3}{*}{ I } & $\mathrm{E}(\mathrm{kJ} / \mathrm{mol})$ & 208.39 & 222.00 & 227.43 & 228.01 & 228.13 & 234.61 & 237.28 & 241.73 & 267.50 & 281.42 & 312.59 & & 228.01 & 227.76 \\
\hline & LN A (/my) & 58.99 & 63.24 & 64.11 & 64.44 & 62.74 & 69.02 & 66.41 & 61.04 & 65.45 & 67.56 & 75.57 & $6.39 \mathrm{E}-01$ & 64.44 & 64.23 \\
\hline & Fraction (f) & 0.0008 & 0.3500 & 0.1286 & 0.3542 & 0.0570 & 0.0214 & 0.0710 & 0.0008 & 0.0029 & 0.0035 & 0.0098 & & & \\
\hline \multirow{3}{*}{$\mathrm{J}$} & $\mathrm{E}(\mathrm{kJ} / \mathrm{mol})$ & 191.90 & 199.19 & 215.00 & 215.62 & 215.96 & 216.00 & 216.06 & 225.79 & 225.79 & 229.13 & 240.71 & & 215.00 & 216.44 \\
\hline & LN A (/my) & 55.26 & 53.12 & 61.59 & 67.77 & 61.82 & 61.83 & 61.83 & 57.15 & 63.46 & 61.92 & 65.93 & $6.86 \mathrm{E}-01$ & 61.59 & 61.73 \\
\hline & Fraction (f) & 0.0292 & 0.0020 & 0.3500 & 0.0017 & 0.1055 & 0.2074 & 0.1853 & 0.0005 & 0.0702 & 0.0320 & 0.0163 & & & \\
\hline
\end{tabular}

cases) indicating almost perfect fits to the $\mathrm{S} 2$ incremental peak shape and $T F$ curve for each sample. The weighted average $E-A$ value of the best-fit reaction kinetics distribution is close to the modal value in some cases (e.g., for samples B, C, F, I and $\mathrm{J}$ the $E$ values are within $5 \mathrm{~kJ} / \mathrm{mol}$ and $A$ values are very similar). On the other hand, the modal and weighted average values of the reaction kinetic distributions for samples $\mathrm{A}, \mathrm{D}$, $\mathrm{E}, \mathrm{G}$ and $\mathrm{H}$ differ by greater than $5 \mathrm{~kJ} / \mathrm{mol}$ and $A$ values are also distinct. If the distribution is to be described by a single $E-A$ pair for samples A, D, E, G and $\mathrm{H}$ the weighted average values are more representative of that distribution than the modal values of the distribution.

Note that the modal values of the best-fit distributions are the same for Opt 2 and Opt 3 approaches, as both optimization routines are seeded with those values (i.e., the best fit S2 peak temperature kinetics for Table 1). However, it should be recognized that in shales with significant proportions of more than one kerogen type that modal value is reflecting the combined effects of multiple reaction kinetics and may not itself represent the reaction kinetics of a single kerogen 


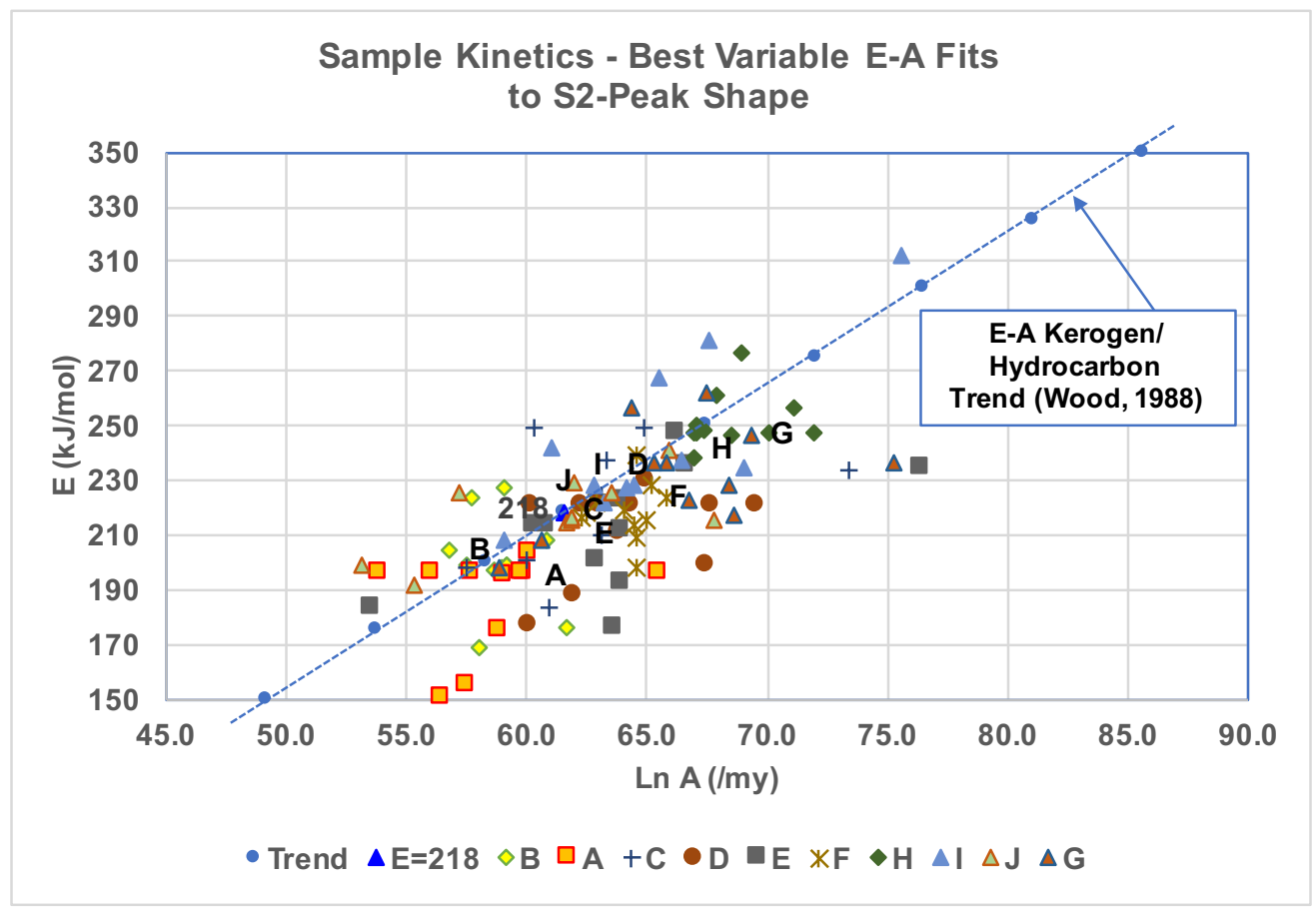

Fig. 8. Optimized best-fit reaction kinetic distributions using the variable $E-A$ approach (Opt 3 ) results for the ten kerogen/shale samples studied. Note those distributions extend over wide ranges of $E$ values and all straddle the identified $E-A$ kerogen/hydrocarbon trend. Details of the kinetic distributions are listed in Table 5.

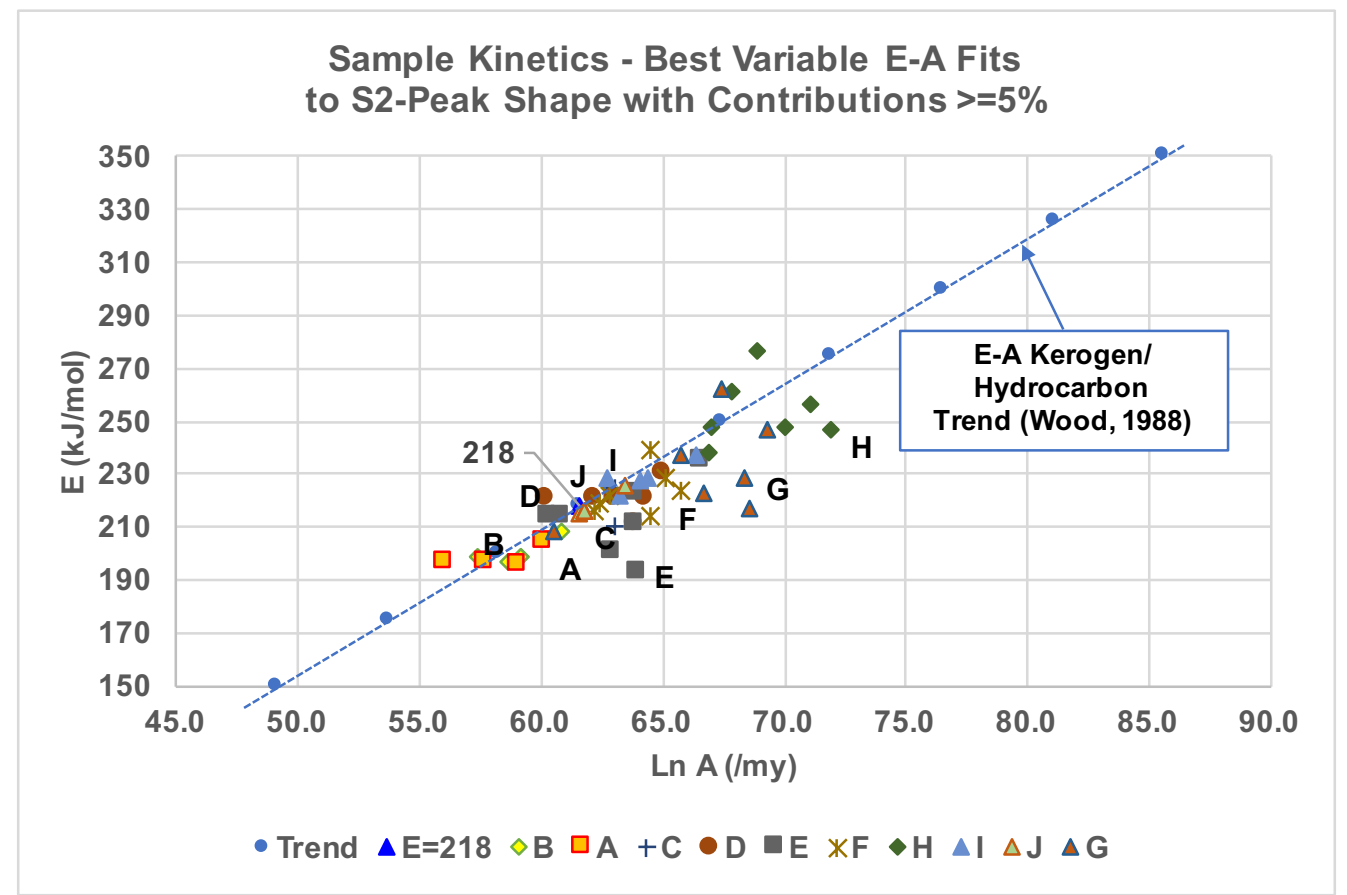

Fig. 9. Optimized best-fit key reaction kinetics (contributing $>=5 \%$ to solutions) using the variable $E-A$ approach (Opt 3 ) results for the ten kerogen/shale samples studied. Note these key-contributing reactions tend to be situated closer to the established $E$ - $A$ kerogen/hydrocarbon trend than those contributing smaller fractions to the solutions (compare with Fig. 8). Details of the key kinetic reactions plotted are listed in Table 6. 
Table 6. Optimizer Opt 3 best $E$ - $A$ reaction kinetic fits to full S2-peak shapes for ten kerogen/ shale samples using a distribution $E$ - $A$ values showing just those reactions in the solution that contribute $>=5 \%$ fraction to the solution. The $E$ - $A$ distributions of these significant reactions are illustrated in Fig. 9 . Note the fractional contributions of these major contributing reactions sum to $>0.9$ in all but one case.

\begin{tabular}{|c|c|c|c|c|c|c|c|c|c|c|c|c|c|}
\hline \multirow{3}{*}{ Sample } & \multirow{3}{*}{ Elements } & \multicolumn{12}{|c|}{$\begin{array}{l}\text { S2 peak shape fits applying a variable } A \text { (pre-exponential factor) value to each kinetic component (KC) } \\
\text { only kinetics contributing }>=5 \% \text { to the fit are included }\end{array}$} \\
\hline & & \multicolumn{11}{|c|}{ Key Kinetic Components Involved in Generating Accurate Shape Fit to Digitized S2 peak } & \multirow{2}{*}{$\begin{array}{l}\text { Contribution } \\
\% \text { of Fit }\end{array}$} \\
\hline & & KC\#1 & $\mathrm{KC \# 2}$ & $\mathrm{KC \# 3}$ & $\mathrm{KC \# 4}$ & KC\#5 & KC\#6 & KC\#7 & $\mathrm{KC \# 8}$ & KC\#9 & KC\#10 & KC\#11 & \\
\hline \multirow{3}{*}{ A } & $\mathrm{E}(\mathrm{kJ} / \mathrm{mol})$ & & & & 195.82 & & & 196.18 & 196.19 & & & 204.00 & \\
\hline & $\mathrm{LN}$ A (/my) & & & & 59.03 & & & 57.70 & 56.03 & & & 60.11 & \\
\hline & Fraction (f) & & & & 0.2379 & & & 0.2272 & 0.0575 & & & 0.4000 & $92.27 \%$ \\
\hline \multirow{3}{*}{ B } & $\mathrm{E}(\mathrm{kJ} / \mathrm{mol})$ & & & 197.00 & & 198.68 & 198.84 & 198.93 & & 208.57 & & & \\
\hline & LN A (/my) & & & 58.64 & & 57.44 & 59.15 & 59.18 & & 60.82 & & & \\
\hline & Fraction (f) & & & 0.4000 & & 0.1392 & 0.0513 & 0.1979 & & 0.1293 & & & $91.77 \%$ \\
\hline \multirow{3}{*}{$\mathrm{C}$} & $\mathrm{E}(\mathrm{kJ} / \mathrm{mol})$ & & & & 210.46 & & 223.77 & 225.00 & & & & & \\
\hline & LN A (/my) & & & & 63.07 & & 62.98 & 63.05 & & & & & \\
\hline & Fraction (f) & & & & 0.0934 & & 0.3494 & 0.4000 & & & & & $84.28 \%$ \\
\hline \multirow{3}{*}{$\mathrm{D}$} & $\mathrm{E}(\mathrm{kJ} / \mathrm{mol})$ & & & & 210.73 & & 220.88 & 220.93 & 220.96 & 220.97 & & 230.00 & \\
\hline & LN A (/my) & & & & 63.85 & & 60.21 & 62.23 & 64.31 & 63.02 & & 64.99 & \\
\hline & Fraction (f) & & & & 0.0798 & & 0.0527 & 0.2254 & 0.1258 & 0.0546 & & 0.4000 & $93.85 \%$ \\
\hline \multirow{3}{*}{ E } & $\mathrm{E}(\mathrm{kJ} / \mathrm{mol})$ & & & 192.39 & 200.92 & 211.50 & 213.88 & 214.09 & 223.00 & & 235.56 & & \\
\hline & LN A (/my) & & & 63.94 & 62.90 & 63.87 & 60.80 & 60.30 & 63.84 & & 66.65 & & \\
\hline & Fraction (f) & & & 0.0464 & 0.0804 & 0.0996 & 0.0669 & 0.1344 & 0.4000 & & 0.0897 & & $91.73 \%$ \\
\hline \multirow{3}{*}{$\mathrm{F}$} & $\mathrm{E}(\mathrm{kJ} / \mathrm{mol})$ & & & 213.87 & & 216.19 & 218.36 & & 221.49 & 223.35 & 228.00 & 238.81 & \\
\hline & LN A (/my) & & & 64.48 & & 62.24 & 62.47 & & 62.89 & 65.74 & 65.17 & 64.54 & \\
\hline & Fraction (f) & & & 0.0479 & & 0.1024 & 0.0917 & & 0.0765 & 0.0964 & 0.4000 & 0.1322 & $94.72 \%$ \\
\hline \multirow{3}{*}{ G } & $\mathrm{E}(\mathrm{kJ} / \mathrm{mol})$ & & 207.84 & 217.23 & 222.84 & 228.39 & 236.70 & & & 247.00 & & 261.67 & \\
\hline & LN A (/my) & & 60.56 & 68.59 & 66.69 & 68.41 & 65.81 & & & 69.29 & & 67.46 & \\
\hline & Fraction (f) & & 0.0539 & 0.0954 & 0.0585 & 0.1535 & 0.2043 & & & 0.2800 & & 0.0597 & $90.55 \%$ \\
\hline \multirow{3}{*}{$\mathrm{H}$} & $\mathrm{E}(\mathrm{kJ} / \mathrm{mol})$ & 238.00 & & 247.03 & 247.56 & 247.85 & & & & 256.27 & 261.12 & 276.70 & \\
\hline & LN A (/my) & 66.90 & & 71.90 & 67.06 & 70.08 & & & & 71.12 & 67.88 & 68.94 & \\
\hline & Fraction (f) & 0.4000 & & 0.0470 & 0.2220 & 0.0500 & & & & 0.1271 & 0.0597 & 0.0477 & $95.36 \%$ \\
\hline \multirow{3}{*}{ I } & $\mathrm{E}(\mathrm{kJ} / \mathrm{mol})$ & & 222.00 & 227.43 & 228.01 & 228.13 & & 237.28 & & & & & \\
\hline & LN A (/my) & & 63.24 & 64.11 & 64.44 & 62.74 & & 66.41 & & & & & \\
\hline & Fraction (f) & & 0.3500 & 0.1286 & 0.3542 & 0.0570 & & 0.0710 & & & & & $96.08 \%$ \\
\hline \multirow{3}{*}{$\mathrm{J}$} & $\mathrm{E}(\mathrm{kJ} / \mathrm{mol})$ & & & 215.00 & & 215.96 & 216.00 & 216.06 & & 225.79 & & & \\
\hline & LN A (/my) & & & 61.59 & & 61.82 & 61.83 & 61.83 & & 63.46 & & & \\
\hline & Fraction (f) & & & 0.3500 & & 0.1055 & 0.2074 & 0.1853 & & 0.0702 & & & $91.84 \%$ \\
\hline
\end{tabular}




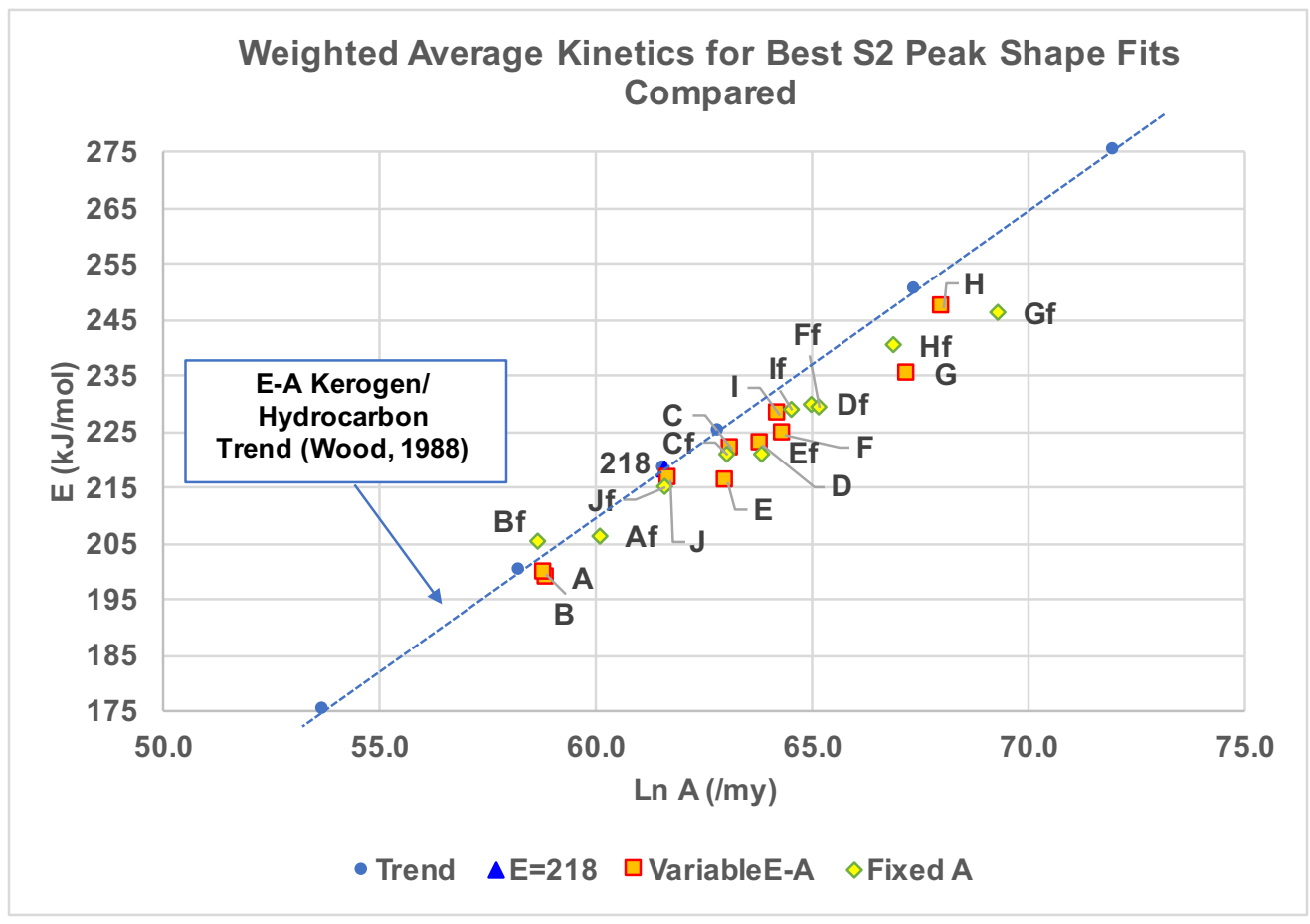

Fig. 10. Weighted average kinetics for the optimized best-fit reaction kinetics distributions for Opt 2 (labelled f for fixed- $A$ ) and Opt 3 for the ten kerogen/shale samples studied. Note, these kinetic weighted-average solutions all lie close to the established $E-A$ kerogen/hydrocarbon trend.

type. Some of the samples do show indications of bimodal distributions. This is perhaps most significant for sample $\mathrm{G}$ where two reactions with $E$ values separated by $\sim 10 \mathrm{~kJ} / \mathrm{mol}$ (Table 4 and Table 5) have significant fractional contributions in the optimum solutions. This potentially explains the broader S2 peak associated with that sample.

However, whether Opt 2 or Opt 3 best fits are applied, in order to match the S2 peak all reactions included in the distribution make a contribution. Hence, all reactions involved in the kinetic distribution (not the modal or weighted average values) should be used in applying the best fit results to a geological scale thermal history for a specific shale sample in order to accurately reflect the extent and timing of petroleum generation.

For Opt 3 the individual reactions that contribute $>=5 \%$ fractions to the optimum solutions are highlighted in Table 6 and Fig. 9. These reactions typically make up more than $90 \%$ of the reactions involved in the optimum best-fit solutions.

By comparing Figs. 8 and 9 it is clear that those reactions contributing most to the best-fit solutions generally lie close to the established $E-A$ trend than those reactions contributing small $(<5 \%)$ fractions to those solutions. In general, for both Opt 3 and Opt 2 approaches the reactions making small contributions tend to be making contributions to improve the fits to the more distal portions of the left and right flanks of the S2 peaks. Consequently, such reactions play a less significant role in the petroleum generation timing and peakgeneration temperatures of the kerogen mix than the other more significant reaction contributions.

Fig. 10 compares the weighted-averages of the kinetics distributions for the best-fit solutions for each sample applying approaches Opt 2 and Opt 3. Considering, these fits are based on exactly the same data set and are seeded with the same modal solutions (i.e., those from Table 3) the differences in these weighted averages are significant. Sample G stands out in this regard, with the bimodal kinetic distribution in Opt 3 solution undoubtedly contributing to that distinction. All of the weighted average solutions, for both Opt 2 and Opt 3, lie close to or offset just to the right of the established $E$ - $A$ trend.

Figs. 11 to 13 illustrate the actual best-fit solutions (Opt 3 ) to the $/{ }^{\circ} \mathrm{C}$ reaction increments and reaction transformation curves for three samples (A, I and G, respectively) that plot towards each end and the center of the range of reaction kinetics displayed in Fig. 10. Other samples could be shown as the quality of the fits achieved are similar for each sample (a comparison of MSE values in Table 5 reveals the high degrees of fits achieved for all samples with Opt 3). Note the significantly broader peak involved for sample G (Fig. 13) which, as mentioned, is indicative of bimodal nature of the reaction kinetics required for the optimum solution.

\section{Discussion}

\subsection{Appropriate formulations of the Arrhenius equa- tion to fit $S 2$ pyrolysis peaks}

The results presented demonstrate that the formulation of the Arrhenius equation in terms of Eq. (6) to establish reaction increments and Eq. (11) to establish transformation fractions is a viable and effective way to establish $E$-A distributions (using Eq. (13)) that accurately match/fit the full shapes of multiheating-rate $\mathrm{S} 2$ pyrolysis data when that data is expressed on 


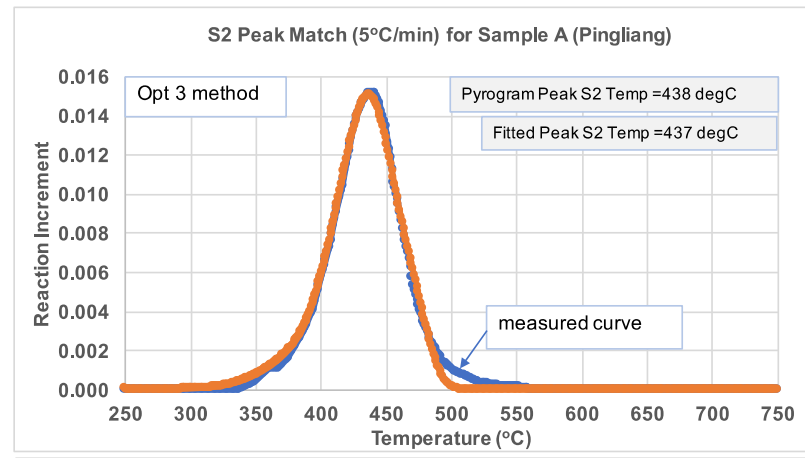

S2 Peak Match $\left(15^{\circ} \mathrm{C} / \mathrm{min}\right)$ for Sample A (Pingliang)

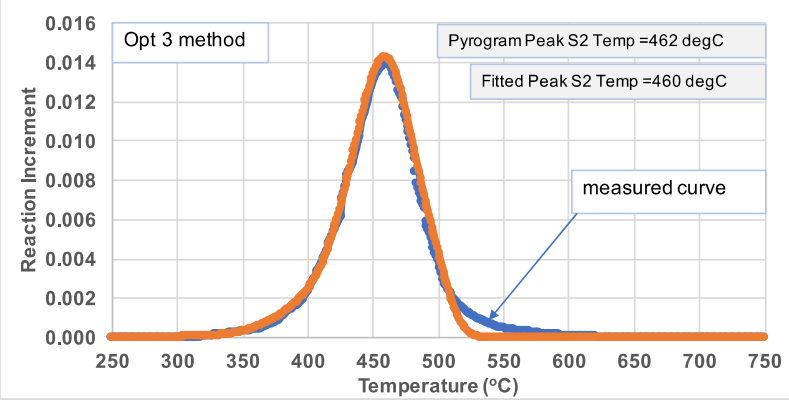

S2 Peak Match $\left(25^{\circ} \mathrm{C} / \mathrm{min}\right)$ for Sample A (Pingliang)

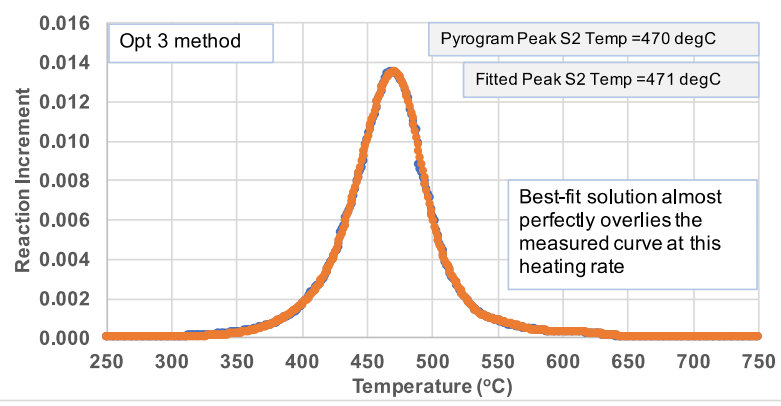

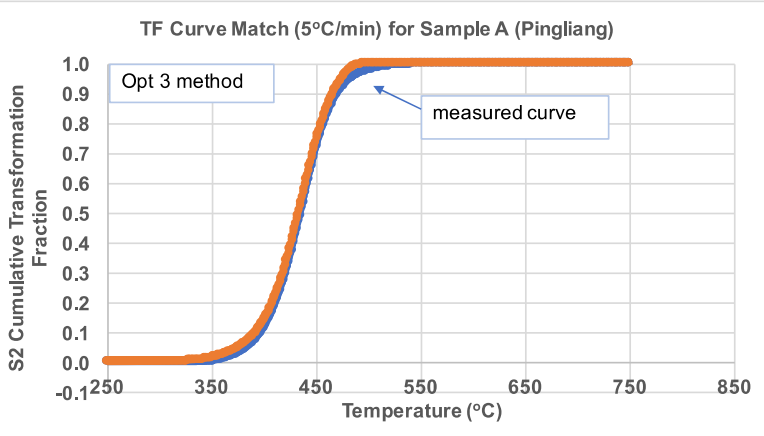
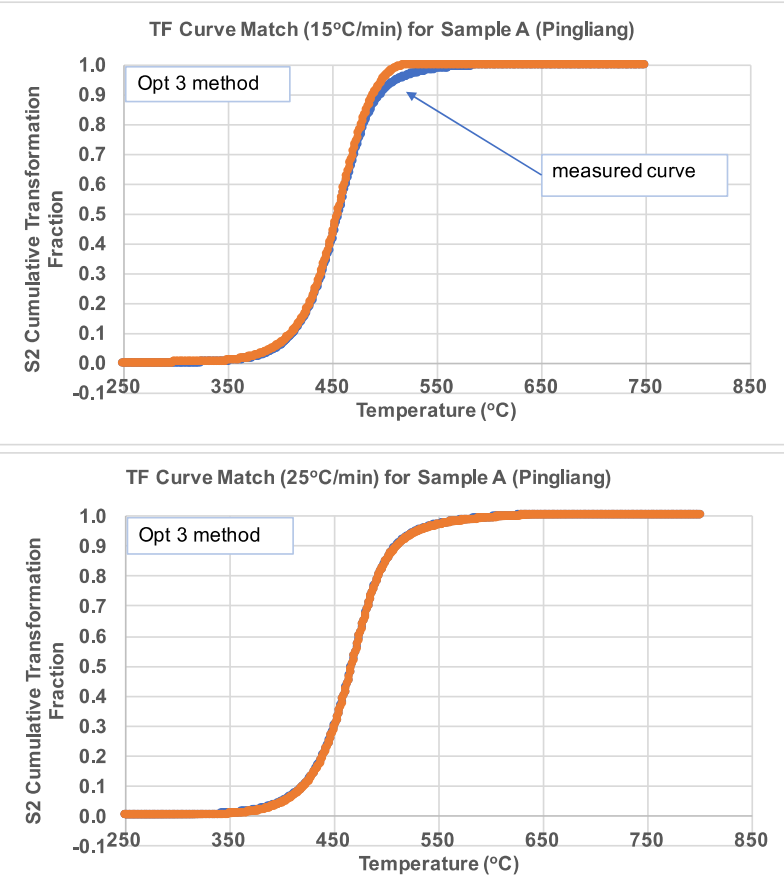

Fig. 11. Reaction increments (left) and transformation factors (right) for sample A at three different heating rates with the Opt 3 best-fit solutions almost perfectly overlying the digitized data for these curves. The weighted-average of the reaction kinetics distribution achieving this best fit $(\mathrm{MSE}=6.12 \mathrm{E}-01)$ is: $E=198.72 \mathrm{~kJ} / \mathrm{mol} \ln A=58.88 / \mathrm{my}$.

a normalized scale of 0 to 1 . This formulation is more versatile than the Arrhenius equation formulated as Eq. (14) which requires the reaction kinetic distributions to be expressed in terms of a constant/fixed a value and is restricted to a single heating rate over time.

Eqs. (6), (11) and (13) are able to provide meaningful fits to multi-heating-rate $\mathrm{S} 2$ pyrolysis data, with the aid of optimizers, using reaction kinetics distributions with fixed- $A$ or with variable $E-A$ values. This makes these equations more useful than those using Eq. (14), and raises the question of why do some petroleum geologists persist in applying that oversimplified formulation of the Arrhenius equation derivative?

\subsection{Appropriate methodology for fitting multi- heating-rate pyrolysis $S 2$ peaks}

Both the fixed- $A$ (Opt 2) and variable $E-A$ (Opt 3) methods applying the two-step methodology proposed with Eqs. (6), (11) and (13) can clearly provide accurate fits (i.e., low MSE between modelled and measured curves) to real multi-rate
S2 data sets, as demonstrated by the ten samples evaluated. However, which method (Opt 2 or Opt 3) provides the most credible results? A comparison of Fig. 7 with Figs. 8 and 9 reveals that the reaction kinetics involved in the Opt 3 best-fit solutions are distributed more realistically along the established $E-A$ kerogen/hydrocarbon trend. On the other hand, the Opt 2 best-fit solutions, although they straddle the established $E-A$ kerogen/hydrocarbon trend they involve some reactions that lie at significant distances either side of that trend.

The more distant reactions are from the established $E-A$ trend the more questionable they are in terms of relevance to kerogen/hydrocarbon reactions and geological time scales. Most shales involve mixtures of kerogen types I, II, III and IV with reaction kinetics known to lie in the vicinity of the established $E-A$ trend. Matching S2 peaks with reaction kinetic distributions that involve individual reaction $E-A$ values that lie close to and/or extend over ranges that are parallel to that trend are the most credible fits to the data. Consequently, Opt 2 (variable $E$ - $A$ distributions) are considered to be much more 

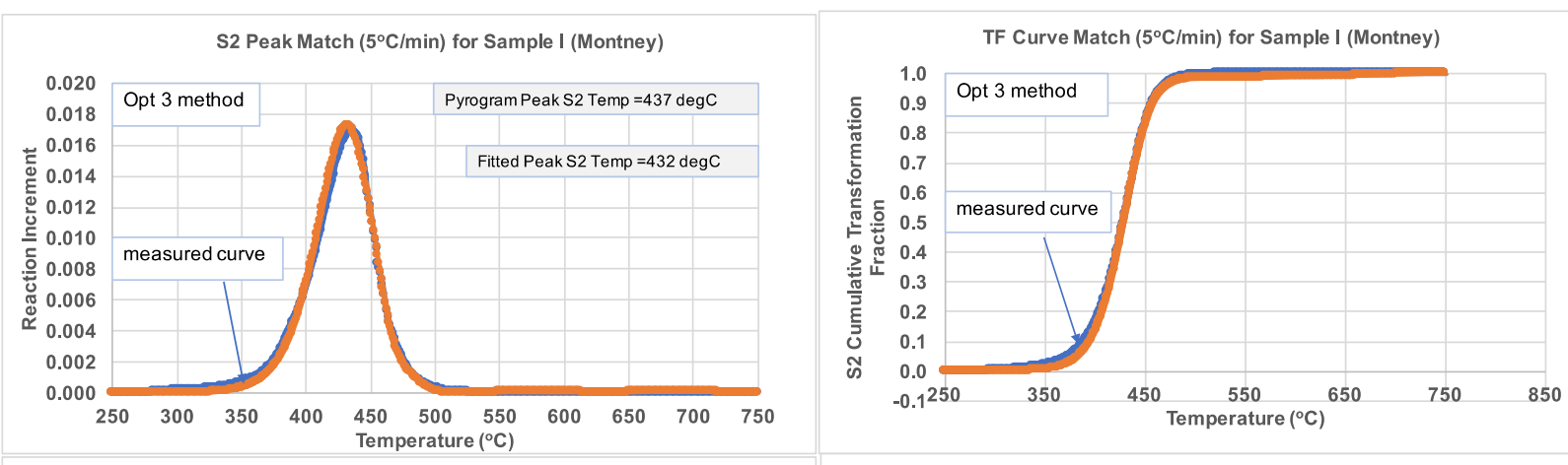

S2 Peak Match $\left(15^{\circ} \mathrm{C} / \mathrm{min}\right)$ for Sample I (Montney)
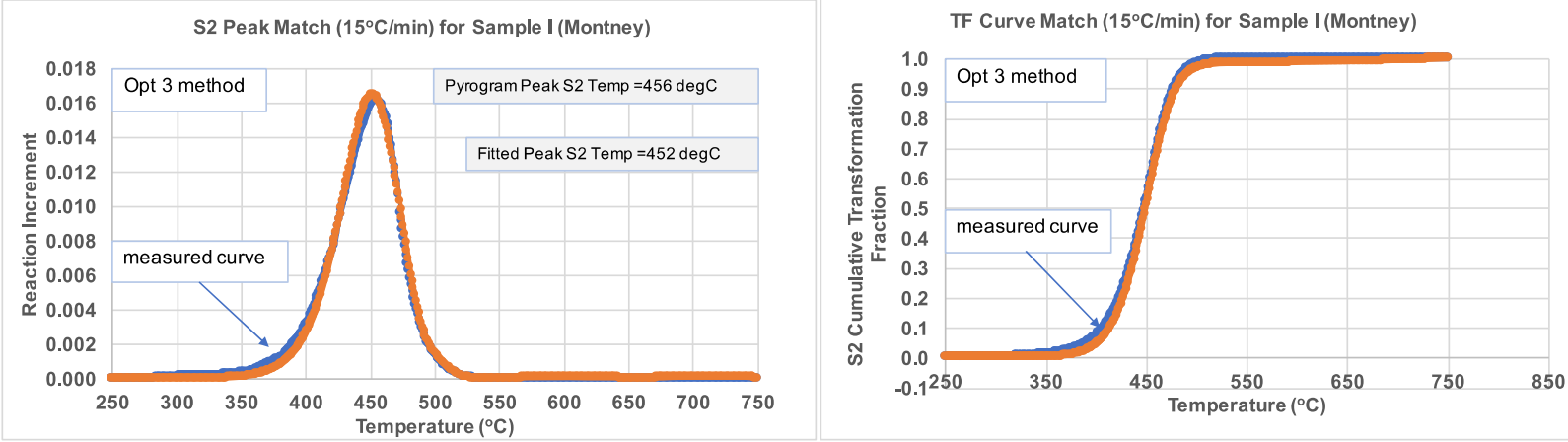

S2 Peak Match $\left(25^{\circ} \mathrm{C} / \mathrm{min}\right)$ for Sample I (Montney)
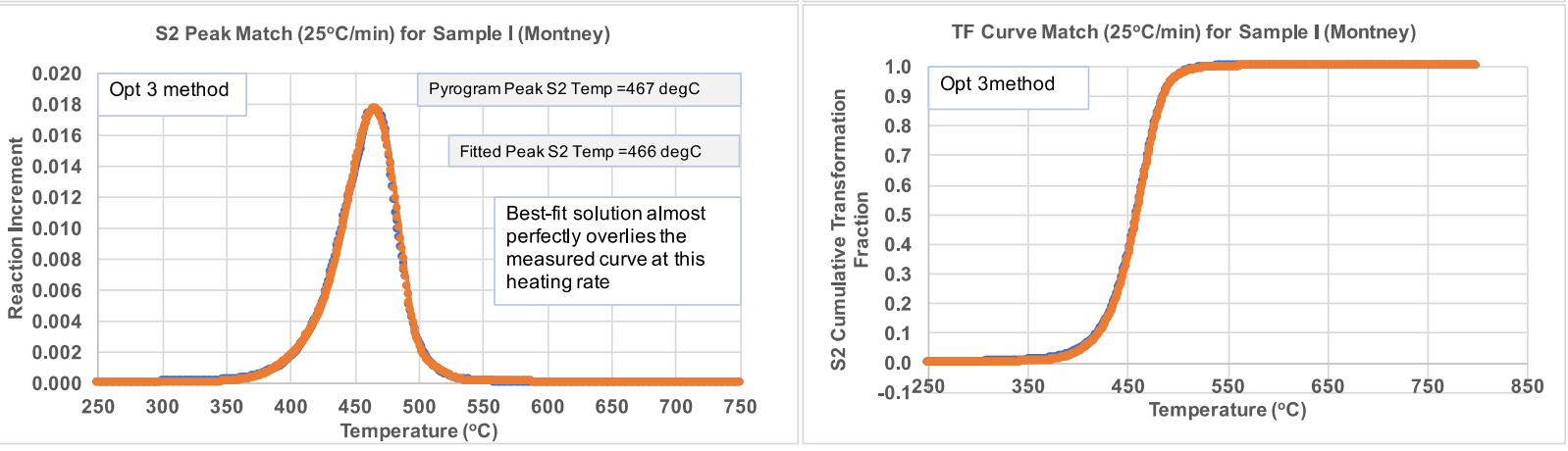

Fig. 12. Reaction increments (left) and transformation factors (right) for sample I at three different heating rates with the Opt 3 best-fit solutions almost perfectly overlying the digitized data for these curves. The weighted-average of the reaction kinetics distribution achieving this best fit $(\mathrm{MSE}=6.39 \mathrm{E}-01)$ is: $E=227.76 \mathrm{~kJ} / \mathrm{mol} \ln A=64.23 / \mathrm{my}$.

credible than fixed- $A$ distributions. This has significant implications for modelling petroleum generation using appropriate distributions of kerogen reaction kinetics. Clearly, more than one viable reaction-kinetic distribution "best-fit" solution exist for most shales, even using multi-heating-rate pyrolysis data modelled on a high-resolution (i.e., each $1^{\circ} \mathrm{C}$ ) basis. The challenge is to select the most credible one. Geologically, fixed- $A$ reaction kinetics distributions offer little to support their credibility other than that Eq. (14) is slightly easier to manipulate and compute than Eqs. (6), (11) and (13).

\subsection{Refining the established kerogen/hydrocarbon $E$ - A trend}

The established activation energy versus pre-exponential factor $(E-A)$ trend for kerogen/hydrocarbon reactions dates back to the 1980s (Wood, 1988) and is based on the limited set of data available at that time from various source published in the 1970s and 1980s. In the original publication that trend was illustrated as a dashed line with a question mark at its lower end, and the individual data points extracted from pyrolysis experiments on kerogens and hydrocarbonrelated reactions identified a significant spread of data around that trend. Ungerer (1990) subsequently published a similar trend based on pyrolysis data performed on selected kerogen samples in the 1980s which also showed a significant spread of data about the trend line proposed (see Fig. 1 here and Fig. 8, Ungerer, 1990). Although a significant amount of subsequently published kinetic data on kerogens and shales reveal $E-A$ distributions that plot close to or straddle the Wood (1988) and Ungerer (1990) trends (e.g., Peters et al., 2015; samples evaluated in this study), there is, undoubtedly, scope to refine and establish a kerogen/shale $E-A$ trend with better-defined range limits on that refined trend using a larger data set.

To define a more representative $E-A$ trend for the more common global kerogen/shale types, a large data set of multiheating rate pyrolysis data for various thermally-immature kerogens/shales needs to be collected/compiled from around the world. It is likely that it would be possible to use a betterdefined $E-A$ trend to constrain pyrolysis S2 peak modelling 

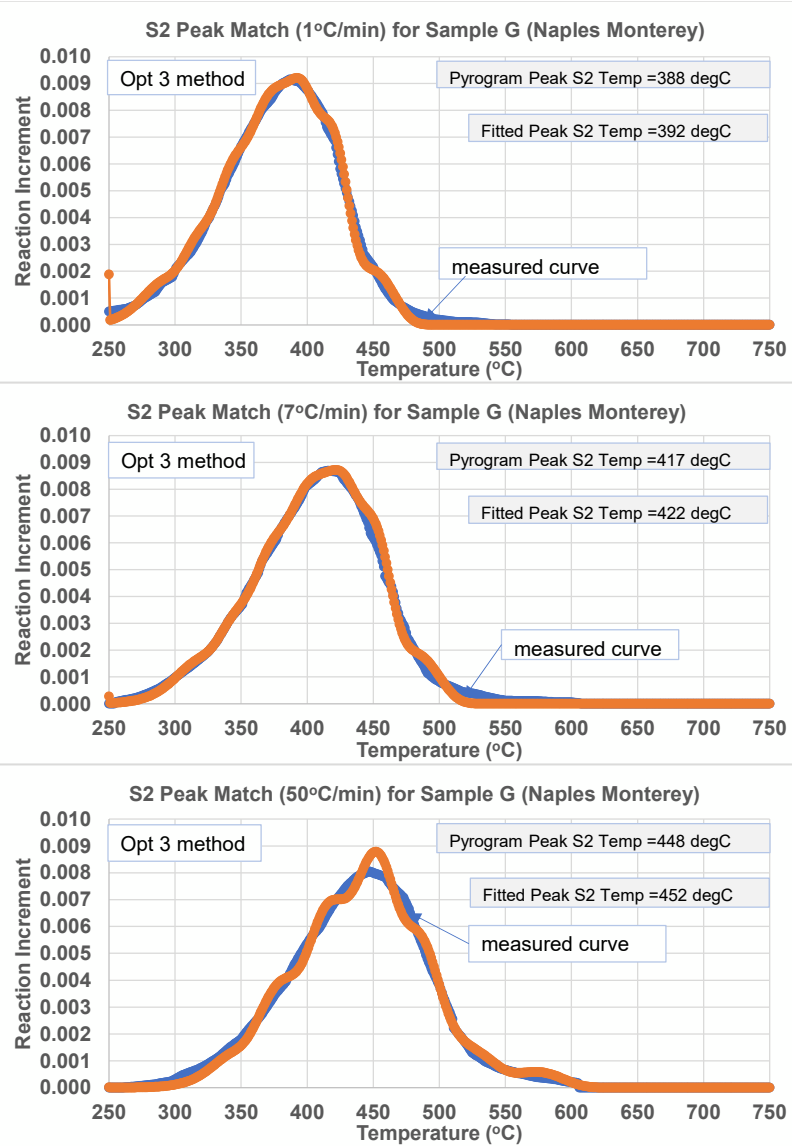

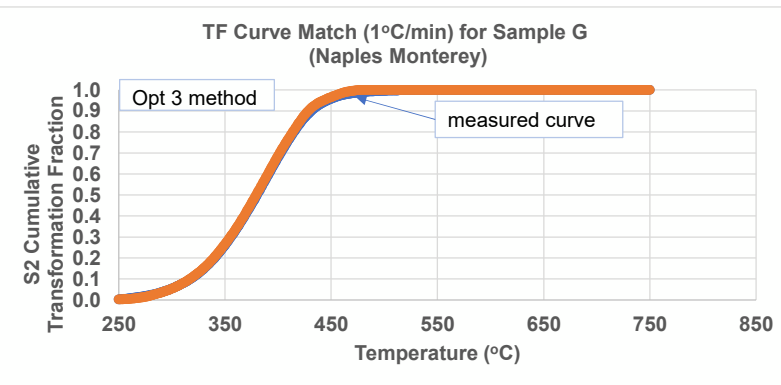

TF Curve Match $\left(7^{\circ} \mathrm{C} / \mathrm{min}\right)$ for Sample G (Naples Monterey)



TF Curve Match $\left(50^{\circ} \mathrm{C} / \mathrm{min}\right)$ for Sample G (Naples Monterey)

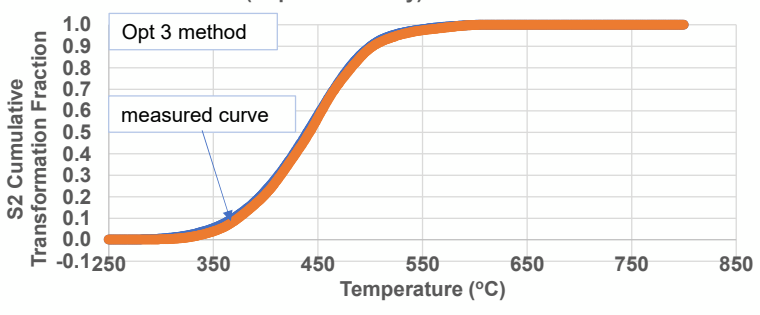

Fig. 13. Reaction increments (left) and transformation factors (right) for sample $\mathrm{G}$ at three different heating rates with the Opt 3 best-fit solutions almost perfectly overlying the digitized data for these curves. The weighted-average of the reaction kinetics distribution achieving this best fit $(\mathrm{MSE}=5.17 \mathrm{E}-01)$ is: $E=235.23 \mathrm{~kJ} / \mathrm{mol} \ln A=67.23 / \mathrm{my}$.

further, i.e., to review the credibility of peak fits using Opt 3 and, perhaps, to derive more reliable indicative kerogen reaction kinetics from the Opt 1 method described for singleheating rate pyrolysis data.

\subsection{Extracting meaningful reaction kinetics data from single-heating-rate pyrolysis $S 2$ peaks}

There has been some debate in recent years (Peters, 2014; Peters et al., 2015; Waples, 2016) regarding the value of singleversus multi- heating rate pyrolysis data in deriving meaningful reaction kinetics for modelling petroleum generation from kerogen/shales. The results of this study support the case that multi-heating rate data (using three significantly distinct heating ramps) provides more reliable reaction kinetic data. To some extent though that discussion has been focused on the wrong issue. It should have identified that the practice of using a fixed $A$-value to model reaction kinetic distributions applies flawed logic and imposes unrealistic assumptions.

The reason why single-heating ramp $\mathrm{S} 2$ peak data provide unreliable reaction kinetic results is that there are multiple $E$ $A$ distributions that can provide excellent shape fits to a single S2 peak shape. This is illustrated by Fig. 14 which shows two "best-fit" results applying the optimizer (step 2 only) to just the slowest heating ramp $\left(1^{\circ} \mathrm{C} / \mathrm{min}\right)$ data for sample E. The graph on the left (Fig. 14) shows the "best-fit" solution (MSE $=1.75 \mathrm{E}-01)$ when seeded initially with the 11 reactions set at reaction kinetics of E218 kJ/mol $\ln A 61.56 / \mathrm{my}$. The weighted average of the reaction kinetics for that fit is E165.60 kJ/mol $\ln A 61.44$. The graph on the right (Fig. 14) shows the "bestfit" solution (MSE = 1.24E-01) seeded initially with the 11 reactions spread with equal fractions along the established $E$ $A$ trend. The weighted average of the reaction kinetics for that fit is $\mathrm{E} 247.51 \mathrm{~kJ} / \mathrm{mol} \ln A 62.96$. Neither of these fits lies close to the best fit established collectively for the three heating rates, which is $(E=215.85 \mathrm{~kJ} / \mathrm{mol} \ln A=63.03$, Table 5).

The two fits shown in Fig. 14 are two of many that could be established to fit this single heating-rate peak, depending upon the $E-A$ values with which the eleven kinetic reactions considered by optimizer are seeded. Clearly the reaction kinetics derived in this way are unreliable. Table 7 reinforces this point by listing the "best-fit" results for the other samples (A to J) apply similar attempts to fit reaction kinetics distributions to the single peak derived from the lowest-heating-rate S2peak pyrolysis data. The high MSE $(>1.0 \mathrm{E}+00)$ for almost all the three-peak cases associated with single-peak fit attempts indicate that allow the optimizer fits the single peak well the kinetics distributions it uses to do so do not fit the other two 
Table 7. "Best-fit" weighted averages of reaction kinetics distributions for attempts to match single S2 peak shapes compared with multi-heating rate three-peak fits. Highlighted MSE values are for the objective function optimized in each case. MSE values of less than about 3.0E-01 indicate good fits for single-peak objectives. MSE values of less than about 9.0E-01 indicate good fits for three-peak objectives.

\begin{tabular}{|c|c|c|c|c|c|c|c|}
\hline \multicolumn{8}{|c|}{ Reaction kinectics distribution comparisons for single S2 peak fits with optimum (Opt 3) three-peak fits } \\
\hline \multirow[t]{2}{*}{$\begin{array}{l}\text { Sample } \\
\text { name }\end{array}$} & \multirow[t]{2}{*}{ Optimization objective } & \multicolumn{2}{|c|}{$\begin{array}{l}\text { Weighted average of } \\
\text { reaction kinetics } \\
\text { distribution providing } \\
\text { best fit }\end{array}$} & \multirow{2}{*}{$\begin{array}{l}\begin{array}{l}\text { Fastest } \\
\text { heating rate }\end{array} \\
\text { MSE Pk1 }\end{array}$} & \multirow{2}{*}{$\begin{array}{l}\text { Middle } \\
\text { heating rate }\end{array}$} & \multirow{2}{*}{$\begin{array}{l}\begin{array}{l}\text { Slowest } \\
\text { feating rate }\end{array} \\
\text { MSE Pk3 }\end{array}$} & \multirow{2}{*}{$\begin{array}{l}\begin{array}{l}\text { Measured } \\
\text { for all three } \\
\text { peaks }\end{array} \\
\text { MSE All } 3\end{array}$} \\
\hline & & $E(\mathrm{~kJ} / \mathrm{mol})$ & $\ln A(/ \mathrm{my})$ & & & & \\
\hline \multirow{3}{*}{ A } & 3 peak-fit optimized & 198.72 & 58.88 & 7.077E-02 & $2.925 \mathrm{E}-01$ & $2.485 \mathrm{E}-01$ & 6.118E-01 \\
\hline & E218 seed Pk3 only optimized & 196.18 & 60.57 & $3.074 \mathrm{E}+00$ & 2.303E-01 & $6.759 \mathrm{E}-02$ & $3.372 \mathrm{E}+00$ \\
\hline & E-A trend Seed Pk 3 optimized & 194.35 & 61.38 & $4.960 \mathrm{E}+00$ & $2.491 \mathrm{E}-01$ & $7.275 \mathrm{E}-02$ & $5.282 \mathrm{E}+00$ \\
\hline \multirow{3}{*}{ B } & 3 peak-fit optimized & 199.51 & 58.83 & $9.158 \mathrm{E}-02$ & $1.476 \mathrm{E}-01$ & $1.188 \mathrm{E}-01$ & 3.579E-01 \\
\hline & E218 seed Pk3 only optimized & 204.26 & 61.56 & $3.788 \mathrm{E}+00$ & $2.412 \mathrm{E}-01$ & $1.553 \mathrm{E}-01$ & $4.185 \mathrm{E}+00$ \\
\hline & E-A trend Seed Pk 3 optimized & 208.65 & 60.03 & $1.575 \mathrm{E}+00$ & 2.343E-01 & $1.675 \mathrm{E}-01$ & $1.977 \mathrm{E}+00$ \\
\hline \multirow{3}{*}{$\mathrm{C}$} & 3 peak-fit optimized & 221.61 & 63.11 & $1.257 \mathrm{E}-01$ & $1.491 \mathrm{E}-01$ & $1.507 \mathrm{E}-01$ & 4.255E-01 \\
\hline & E218 seed Pk3 only optimized & 214.81 & 61.56 & $7.985 \mathrm{E}-01$ & $1.393 \mathrm{E}-01$ & $1.168 \mathrm{E}-01$ & $1.055 \mathrm{E}+00$ \\
\hline & E-A trend Seed Pk 3 optimized & 204.62 & 59.19 & $8.361 \mathrm{E}-01$ & $3.988 \mathrm{E}-01$ & $2.336 \mathrm{E}-01$ & $1.469 \mathrm{E}+00$ \\
\hline \multirow{3}{*}{$\mathrm{D}$} & 3 peak-fit optimized & 222.44 & 63.85 & $8.035 \mathrm{E}-02$ & 3.293E-01 & $2.676 \mathrm{E}-01$ & $6.773 \mathrm{E}-01$ \\
\hline & E218 seed Pk3 only optimized & 177.98 & 61.27 & $5.037 \mathrm{E}+00$ & 8.804E-01 & 8.217E-02 & $5.999 \mathrm{E}+00$ \\
\hline & E-A trend Seed Pk 3 optimized & 173.01 & 56.65 & $1.717 \mathrm{E}+00$ & $1.119 \mathrm{E}+00$ & $1.632 \mathrm{E}-01$ & $2.999 \mathrm{E}+00$ \\
\hline \multirow{3}{*}{ E } & 3 peak-fit optimized & 215.85 & 63.03 & $2.307 \mathrm{E}-01$ & $2.490 \mathrm{E}-01$ & $2.747 \mathrm{E}-01$ & $7.545 \mathrm{E}-01$ \\
\hline & E218 seed Pk3 only optimized & 165.61 & 61.44 & $6.013 \mathrm{E}+00$ & $9.079 \mathrm{E}-01$ & $1.748 \mathrm{E}-01$ & $7.095 \mathrm{E}+00$ \\
\hline & E-A trend Seed Pk 3 optimized & 247.51 & 62.96 & $3.597 \mathrm{E}+00$ & $1.662 \mathrm{E}-01$ & $1.238 \mathrm{E}-01$ & $3.887 \mathrm{E}+00$ \\
\hline \multirow{3}{*}{$\mathrm{F}$} & 3 peak-fit optimized & 224.63 & 64.35 & $1.591 \mathrm{E}-01$ & $2.299 \mathrm{E}-01$ & $1.720 \mathrm{E}-01$ & $5.610 \mathrm{E}-01$ \\
\hline & E218 seed Pk3 only optimized & 211.44 & 61.63 & $5.697 \mathrm{E}-01$ & $2.253 \mathrm{E}-01$ & 7.999E-02 & $8.749 \mathrm{E}-01$ \\
\hline & E-A trend Seed Pk 3 optimized & 182.07 & 57.87 & $1.760 \mathrm{E}+00$ & $6.032 \mathrm{E}-01$ & 8.061E-02 & $2.444 \mathrm{E}+00$ \\
\hline \multirow{3}{*}{ G } & 3 peak-fit optimized & 235.23 & 67.23 & $2.040 \mathrm{E}-01$ & $1.575 \mathrm{E}-01$ & $1.551 \mathrm{E}-01$ & $5.166 \mathrm{E}-01$ \\
\hline & E218 seed Pk3 only optimized & 176.70 & 61.00 & $3.251 \mathrm{E}+00$ & $5.707 \mathrm{E}-01$ & $1.052 \mathrm{E}-01$ & $3.927 \mathrm{E}+00$ \\
\hline & E-A trend Seed Pk 3 optimized & 180.11 & 60.01 & $2.352 \mathrm{E}+00$ & $5.504 \mathrm{E}-01$ & $9.703 \mathrm{E}-02$ & $3.000 \mathrm{E}+00$ \\
\hline \multirow{3}{*}{$\mathrm{H}$} & 3 peak-fit optimized & 247.07 & 68.05 & $1.056 \mathrm{E}-01$ & $3.513 \mathrm{E}-01$ & $3.702 \mathrm{E}-01$ & $8.271 E-01$ \\
\hline & E218 seed Pk3 only optimized & 183.81 & 61.20 & $4.921 \mathrm{E}+00$ & $8.667 \mathrm{E}-01$ & $9.200 \mathrm{E}-02$ & $5.880 \mathrm{E}+00$ \\
\hline & E-A trend Seed Pk 3 optimized & 186.99 & 58.33 & $1.450 \mathrm{E}+00$ & $8.516 \mathrm{E}-01$ & $1.002 E-01$ & $2.402 \mathrm{E}+00$ \\
\hline \multirow{3}{*}{ I } & 3 peak-fit optimized & 227.76 & 64.23 & $1.169 \mathrm{E}-01$ & $2.457 \mathrm{E}-01$ & $2.765 \mathrm{E}-01$ & $6.391 E-01$ \\
\hline & E218 seed Pk3 only optimized & 193.43 & 61.13 & $4.881 \mathrm{E}+00$ & $5.706 \mathrm{E}-01$ & 1.304E-01 & $5.582 \mathrm{E}+00$ \\
\hline & E-A trend Seed Pk 3 optimized & 210.75 & 60.39 & $1.171 \mathrm{E}+00$ & $3.542 \mathrm{E}-01$ & $8.516 \mathrm{E}-02$ & $1.610 \mathrm{E}+00$ \\
\hline \multirow{3}{*}{$\mathrm{J}$} & 3 peak-fit optimized & 216.44 & 61.73 & $2.570 \mathrm{E}-01$ & $2.642 \mathrm{E}-01$ & $1.647 \mathrm{E}-01$ & $6.858 \mathrm{E}-01$ \\
\hline & E218 seed Pk3 only optimized & 201.36 & 61.46 & $4.986 \mathrm{E}+00$ & $4.430 \mathrm{E}-01$ & $2.563 \mathrm{E}-01$ & $5.685 \mathrm{E}+00$ \\
\hline & E-A trend Seed Pk 3 optimized & 228.02 & 56.09 & $5.123 \mathrm{E}+00$ & $2.871 \mathrm{E}-01$ & $8.857 \mathrm{E}-02$ & $5.498 \mathrm{E}+00$ \\
\hline
\end{tabular}



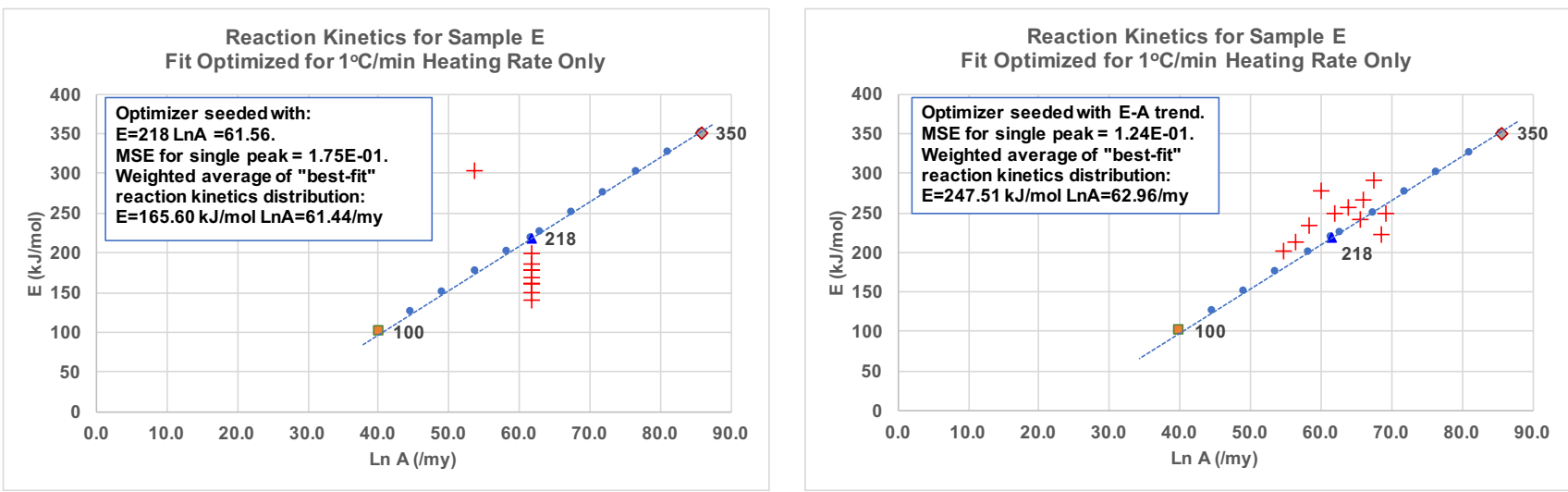

Fig. 14. Two "best-fit" reaction kinetics distributions derived by optimization for single-heating rate $\left(1{ }^{\circ} \mathrm{C} / \mathrm{min}\right) \mathrm{S} 2$-peak pyrolysis data of Sample $\mathrm{E}$ using different seed values. These are two of many possible excellent $E-A$ fits to that single peak. Neither fit shown is close to the best fit established for the three-heating rate $\mathrm{S} 2$ peaks for that sample $(E=215.85 \mathrm{~kJ} / \mathrm{mol} \ln A=63.03$, Table 5).

peaks. Also, the weighted averages of the kinetic distributions for the single-peak fits differ significantly from the three-peak kinetics.

\subsection{Peak fitting issues relating to thermally mature or post mature samples}

The reaction-kinetic modelling presented here focuses upon immature/early mature shale pyrolysis data. S2 pyrolysis peaks of shale samples at peak or post-peak thermal maturity tend to be broader and more complex than those for immature shales, which in most cases are relatively narrow and symmetrical across a liner temperature scale. Thermally mature shales often produce asymmetrical S2 peaks exhibiting multi-peak, fronting and back-tailing shapes (terms adopted from Jurisch et al., 2012). It is clear that a more complex set of processes are involved combining first-order reactions (e.g., progression of kerogen maturation), second order reactions (e.g., breakdown of bitumen, natural gas liquids etc. to smaller hydrocarbon molecules) and potentially non-kinetic processes (release of gases from more extensive nano-porosity in mature kerogens). Further work is required to quantify the combination of these processes. Work in progress is focused on modelling to produce accurate fits and explain the more complex, broader S2 peaks associated with kerogens/shales at peak or post thermally mature conditions. This is considered important as being able to model and predict these complex S2 peak shapes should help in locating thermally mature sweet-spots in shales that are more likely to be associated with higher petroleum yields.

\section{Conclusions}

Modelling S2 pyrolysis data normalized to a scale of 0 to 1 , using reaction kinetics based on the Arrhenius time temperature index $T T I_{A R R}$ method to calculate reaction increments (Eq. (6)) and transformation fractions (Eq. (11)) on a detailed temperature scale $\left(1{ }^{\circ} \mathrm{C}\right.$ interval from 250 to 700 ${ }^{\circ} \mathrm{C}$ ), and to combine those for multiple reactions using Eq. (13), provides excellent fits to published data for shales and kerogens extracted from shales in thermally immature or early mature conditions.

A two-step optimization approach is required to derive reaction kinetics distributions in terms of activation energies $(E)$ and pre-exponential factors $(A)$ that can fit the full S2 peak shapes with minimum errors. This requires multi-rate pyrolysis data generated at three different heating rates. Step 1 applies an optimizer to Eqs. (6), (11) and (13) (on a $1{ }^{\circ} \mathrm{C}$ scale) to identify the $E-A$ pair that best matches the $\mathrm{S} 2$ peak generation temperatures for the three heating rates. Step 2 then takes that $E-A$ pair as the modal point from which ten other reactions defined as $E$ - $A$ pairs are optimized (on a $1{ }^{\circ} \mathrm{C}$ intervals) to match the full shapes of the S2 peaks for the three different heating rates.

Two distinct approaches can be taken for step 2 that both provide excellent fits to the $\mathrm{S} 2$ curve data. The first approach (Opt 2) fixes the $A$ value at the modal value derived by step 1 and locates its optimum best-fit solution by finding the fractions of $11 E$ values (including the modal value) that best fit the data of the three S2 peaks. This is similar to the approach adopted by many kerogen kinetic studies over the past 25 years (applying Eq. (14) rather than Eqs. (6), (11) and (13)). The second approach (Opt 3 ) takes as its mode the $E$ $A$ pair derived from step 1 and locates its optimum best-fit solution by finding the fractions of $11 E-A$ values (including the modal value) that best fit the data of the three S2 peaks. This cannot be done with Eq. (14), but requires Eqs. (6), (11) and (13).

A comparison of the best-fit solutions with the established $E-A$ trend of kerogen/hydrocarbon reactions suggests that the Opt 3 approach provides more credible best-fit solutions than the Opt 2 approach. The reactions contributing to the Opt 3 best-fit solutions are distributed along the established $E$ $A$ trend, which is logical for shales that contain a mixture of kerogen types. On the other hand, the solutions generated by Opt 2 include contributions from reactions that are located far from the established $E-A$ kerogen/hydrocarbon reaction line. Also, there is clearly no theoretical justification to expect all the reactions involved in kerogen/shale thermal maturation to be aligned along a single $A$ value. That over-simplified 
assumption has been made by chemists/analysts purely for the convenience of being able to achieve easy fits to the data using equations such as Eq. (14). It is unfortunate that many geoscientists seem to have accepted that approach without questioning the implications and validity of that assumption.

There is a limited number, but more than one set, of kinetic reactions that can fit with reasonable accuracy even three pyrolysis S2 peaks generated by multi-rate analysis. However, the number of realistic fits is limited. This is not the case when fitting one S2 peak from a single heating rate pyrolysis analysis, where multiple potential fits with quite distinct reaction kinetics can be generated if $E-A$ are allowed to vary in an unconstrained way. Consequently, it is not possible to obtain reliably accurate reaction kinetics distributions from single-heating-rate pyrolysis data. Indicative reaction kinetics can be achieved by constraining the solutions to involve only those reactions lying close to the established $E-A$ trend, but these need to be refined by multi-rate pyrolysis data to verify the validity of the reaction kinetic distribution.

This work focuses upon immature/early mature shale pyrolysis data. Further work is required to model, fit and explain the more complex, broader S2 peaks associated with kerogens/shales at peak or post thermally mature conditions.

The established $E-A$ trend for kerogen/hydrocarbon reactions dates back to the 1980s and is based on the limited set of data available at that time. Although a significant amount of subsequently published kinetic data on kerogens and shales provide $E-A$ distributions lying close to or straddling that trend, there is clearly a requirement to refine that trend. To better define the spread of reaction kinetics around that trend a large dataset of kerogen/shale multi-heating rate pyrolysis data needs to be collected and compiled from shales around the world.

Open Access This article is distributed under the terms and conditions of the Creative Commons Attribution (CC BY-NC-ND) license, which permits unrestricted use, distribution, and reproduction in any medium, provided the original work is properly cited.

\section{References}

Abbassi, S., Edwards, D.S., George, S.C., et al. Petroleum potential and kinetic models for hydrocarbon generation from the Upper Cretaceous to Paleogene Latrobe Group coals and shales in the Gippsland Basin, Australia. Org. Geochem. 2016, 91(1): 54-67.

Abbassi, S., George, S.C., Edwards, D.S., et al. Generation characteristics of Mesozoic syn- and post-rift source rocks, Bonaparte Basin, Australia: New insights from compositional kinetic modelling. Mar. Pet. Geol. 2014, 50(40): 148-165.

Arrhenius, S. Über die Reaktionsgeschwindigkeit bei der Inversion von Rohrzucker durch Säuren. Z. Phys. Chem. 2017, 4(1): 226-248.

Braun, R.L., Burnham, A.K. Mathematical model of oil generation, degradation, and expulsion. Energy Fuels 1990, 4(2): 132-146.

Braun, R.L., Burnham, A.K., Reynolds, J.G., et al. Pyrolysis kinetics for lacustrine and marine source rocks by programmed micropyrolysis. Energy Fuels 2002, 5(1): 192-204.

Burnham, A.K., Braun, R.L., Gregg, H.R., et al. Comparison of methods for measuring kerogen pyrolysis rates and fitting kinetic parameters. Org. Geochem. 1988, 13(4): 839-845.

Chalmers, G.R., Bustin, R.M., Powers, I. A pore by any other name would be as small: The importance of meso- and microporosity in shale gas capacity. Paper Presented at the AAPG Annual Convention and Exhibition, Denver, Colorado, 2009.

Chalmers, G.R., Bustin, R.M., Power, I.M. Characterization of gas shale pore systems by porosimetry, pycnometry, surface area, and field emission scanning electron microscopy/transmission electron microscopy image analyses: Examples from the Barnett, Woodford, Haynesville, Marcellus, and Doig units. AAPG Bull. 2012, 96: 1099-1119.

Chen, Z., Liu, X., Guo, Q., et al. Inversion of source rock hydrocarbon generation kinetics from Rock-Eval data. Fuel 2017, 194: 91-101.

Clarkson, C.R., Solano, N., Bustin, R.M., et al. Pore structure characterization of North American shale gas reservoirs; using USANS/SANS, gas adsorption, and mercury intrusion. Fuel 2013, 103(1): 606-616.

Coats, A.W., Redfern, J.P. Kinetic parameters from Thermogravimetric data. Nature 1964, 201(4914): 68-69.

Dieckmann, V. Modelling petroleum formation from heterogeneous source rocks: The influence of frequency factors on activation energy distribution and geological prediction. Mar. Pet. Geol. 2005, 22(3): 375-390.

Espitalié, J., Madec, M., Tissot, B. Role of the mineral matrix in kerogen pyrolysis: Influence on petroleum generation and migration. AAPG Bull. 1980, 64: 59-66.

Flynn, J.H. The Temperature Integral-Its use and abuse. Thermochim. Acta 1997, 300(1-2): 83-92.

Friedman, H.L. Kinetics of thermal degradation of charforming plastics from thermogravimetry. Application to a phenolic plastic. J. Polym. Sci. 1963, 6: 183-195.

Friedman, H.L. Kinetics of thermal degradation of charforming plastics from thermogravimetry. Application to a phenolic plastic. J. Polym. Sci. Part C Polym. Symp. 1964, 6(1): 183-195.

Gorbachev, V.M. A solution of the exponential integral in the non-isothermal kinetics for linear heating. J. Therm. Anal. 1975, 8(2): 349-350.

Han, S., Horsfield, B., Zhang, J., et al. Hydrocarbon generation kinetics of lacustrine Yanchang shale in Southeast Ordos Basin, North China. Energy Fuels 2014, 28(9): 56325639.

Hood, A. Organic metamorphism and the generation of petroleum. AAPG Bull. 1975, 59(6): 986-996.

Huang, W.L. Experimental study of vitrinite maturation: Effects of temperature, time, pressure, water, and hydrogen index. Org. Geochem. 1996, 24(2): 233-241.

İnan, S., Schenk, H.J. Evaluation of petroleum generation and expulsion from a source rock by open and restricted system pyrolysis experiments. Part I. Extrapolation of 
experimentally-derived kinetic parameters to natural systems. J. Anal. Appl. Pyrolysis 2001, 58(2): 213-228.

Jurisch, S.A., Heim, S., Krooss, B.M., et al. Systematics of pyrolytic gas $\left(\mathrm{N}_{2}, \mathrm{CH}_{4}\right)$ liberation from sedimentary rocks: Contribution of organic and inorganic rock constituents. Int. J. Coal. Geol. 2012, 89(1): 95-107.

Larsen, E.C., Walton, J.H. Activated carbon as a catalyst in certain Oxidation-Reduction Reactions. J. Phys. Chem. 2002, 44(1): 70-85.

Larter, S. Chemical modelling of vitrinite reflectance evolution. Geol. Rundsch. 1989, 78: 349-359.

Lerche, I., Yarzab, R.E., Kendall, G.G.S.T.G. Determination of paleoheat flux from vitrinite reflectance data. Am. Assoc. Pet. Geol. Bull. 1984, 68: 1704-1717.

Lewan, M.D. Evalution of petroleum generation by Hydrous Pyrolysis experimentation. Phi. Trans. R. Soc. Lond. Ser. A 1985, 315: 123-134.

Lewan, M.D. Experiments on the role of water in petroleum formation. Geochim. Cosmochim. Ac. 1997, 61(17): 3691-3723.

Lewan, M.D., Ruble, T.E. Comparison of petroleum generation kinetics by isothermal hydrous and nonisothermal opensystem pyrolysis. Org. Geochem. 2002, 33(12): 14571475.

Liao, L., Wang, Y., Chen, C., et al. Kinetic study of marine and lacustrine shale grains using Rock-Eval pyrolysis: Implications to hydrocarbon generation, retention and expulsion. Mar. Pet. Geol. 2018, 89: 164-173.

Miura, K. A new and simple method to estimate $\mathrm{f}(\mathrm{E})$ and $\mathrm{k} 0$ (E) in the distributed activation energy model from three sets of experimental data. Energy Fuels 1995, 9: 302-307.

Nielsen, S.B., Barth, T. Vitrinite reflectance: Comments on "A chemical kinetic model of vitrinite maturation and reflectance" by Alan K. Burnham and Jerry J. Sweeney. Geochim. Cosmochim. Ac. 1991, 55(2): 639-641.

Passey, Q.R., Bohacs, K., Esch, W.L., et al. From oil-prone source rock to gas-producing shale reservoir-geologic and petrophysical characterization of unconventional shale gas reservoirs. Paper SPE 131350 Presented at the International Oil and Gas Conference and Exhibition in China, Beijing, 8-10 June, 2010.

Pepper, A.S., Corvi, P.J. Simple kinetic models of petroleum formation. Part I: Oil and gas generation from kerogen. Mar. Pet. Geol. 1995, 12(3): 291-319.

Peters, K.E. Petroleum generation kinetics: Single versus multiple-heating ramp open-system pyrolysis. Paper 41493 Presented at the AAPG International Conference and Exhibition, Istanbul, Turkey, 14-17 September, 2014.

Peters, K.E., Burnham, A.K., Walters, C.C. Petroleum generation kinetics: Single versus multiple heating-ramp open-system pyrolysis. AAPG Bull. 2015, 99(4): 591616.

Peters, K.E., Cassa, M.R. Applied source rock geochemistry: Chapter 5: Part II. Essential elements. AAPG Special Volumes 1994, 1994: 93-120.

Reynolds, J.G., Burnham, A.K. Comparison of kinetic analysis of source rocks and kerogen concentrates. Org. Geochem. 1995, 23(1): 11-19.
Reynolds, J.G., Burnham, A.K., Mitchell, T.O. Kinetic analysis of California petroleum source rocks by programmed temperature micropyrolysis. Org. Geochem. 1995, 23(2): 109-120.

Romero-Sarmiento, M.F., Euzen, T., Rohais, S., et al. Artificial thermal maturation of source rocks at different thermal maturity levels: Application to the Triassic Montney and Doig formations in the Western Canada Sedimentary Basin. Org. Geochem. 2016, 97: 148-162.

Schaefer, R.G., Schenk, H.J., Hardelauf, H., et al. Determination of gross kinetic parameters for petroleum formation from Jurassic source rocks of different maturity levels by means of laboratory experiments. Org. Geochem. 1990, 16(1-3): 115-120.

Schenk, H.J., Dieckmann, V. Prediction of petroleum formation: The influence of laboratory heating rates on kinetic parameters and geological extrapolations. Mar. Pet. Geol. 2004, 21(1): 79-95.

Stainforth, J.G. Practical kinetic modeling of petroleum generation and expulsion. Mar. Pet. Geol. 2009, 26(4): $552-572$.

Sundararaman, P., Merz, P.H., Mann, R.G. Determination of kerogen activation energy distribution. Energy Fuels 1992, 6(6): 793-803.

Sweeney, J.J. Evaluation of a simple model of vitrinite reflectance based on chemical kinetics. AAPG Bull. 1990, 10(10): 1559-1570.

Tissot, B.P., Espitalié, J. L'evolution thermique de la matiere organique des sediments: Applcatuib d'une simulation mathematique. Revue De 1'Iinstitut Francais Du Petrole 1975, 30: 743-777.

Tissot, B.P., Welte, D.H. Petroleum formation and occurrence. New York, USA, Springer-Verlag, 1984.

Ungerer, P. State of the art of research in kinetic modelling of oil formation and expulsion. Org. Geochem. 1990, 16(1-3): 1-25.

Ungerer, P., Pelet, R. Extrapolation of the kinetics of oil and gas formation from laboratory experiments to sedimentary basins. Nature 1987, 327: 42-54.

Wang, M., Lu, S., Xue, H. Kinetic simulation of hydrocarbon generation from lacustrine type I kerogen from the Songliao Basin: Model comparison and geological application. Mar. Pet. Geol. 2011, 28(9): 1714-1726.

Waples, D.W. Petroleum generation kinetics: Single versus multiple heating-ramp open-system pyrolysis. AAPG Bull. 2016, 100: 683-689.

Wood, D.A. Relationships between thermal maturity indices calculated using arrhenius equation and lopatin method: implications for petroleum exploration. AAPG Bull. 1988, 72(2): 115-135.

Wood, D.A. Re-establishing the merits of thermal maturity and petroleum generation multi-dimensional modelling with an arrhenius equation using a single activation energy. J. Earth Sci. 2017, 28(5): 804-834.

Wood, D.A. Kerogen conversion and thermal maturity modelling of petroleum generation: Integrated analysis applying relevant kerogen kinetics. Mar. Pet. Geol. 2018a, 89: 313-329. 
Wood, D.A. Thermal maturity and burial history modelling of shale is enhanced by use of Arrhenius time-temperature index and memetic optimizer. Petroleum 2018b, 4: 25-42.

Wood, D.A., Hazra, B. Characterization of organic-rich shales for petroleum exploration and exploitation: A reviewpart 2: Geochemistry, thermal maturity, isotopes and biomarkers. J. Earth Sci. 2017, 28(5): 758-778. 


\section{Appendix}

A supplementary file is available online that lists the $/{ }^{\circ} \mathrm{C}$ normalized reaction increments for $\mathrm{S} 2$ peak data relating to each of three multi-heating rate runs of the ten published samples (A to J) digitized for this study. 